\title{
VERIFICAÇÃO DO SINCRONISMO DO ACOPLAMENTO ELÉTRICO ENTRE CIRCUITOS SIMULANDO O COMPORTAMENTO DE UM SISTEMA MECÂNICO PARTÍCULA NUMA CAIXA
}

\section{Cristhiane Gonçalves}

Tese de Doutorado apresentada à Escola de Engenharia de São Carlos, Universidade de São Paulo, como parte dos requisitos para obtenção do título de Doutor em Ciências, Programa de Engenharia Elétrica

Área de concentração: Telecomunicações Orientador: Prof. Dr. Luiz Gonçalves Neto

São Carlos

Fevereiro de 2012 
AUTORIZO A REPRODUÇÃO E DIVULGAÇÃO TOTAL OU PARCIAL DESTE TRABALHO, POR QUALQUER MEIO CONVENCIONAL OU ELETRÔNICO, PARA FINS DE ESTUDO E PESQUISA, DESDE QUE CITADA A FONTE.

Ficha catalográfica preparada pela Seção de Tratamento da Informação do Serviço de Biblioteca - EESC/USP

\begin{tabular}{|c|c|}
\hline \multirow[t]{3}{*}{$\mathrm{G} 638 \mathrm{v}$} & $\begin{array}{l}\text { Gonçalves, Cristhiane. } \\
\text { Verificação do sincronismo do aclopamento elétrico } \\
\text { entre circuitos simulando o comportamento de um sistema } \\
\text { mecânico partícula numa caixa. / Cristhiane Gonçalves ; } \\
\text { orientador Luiz Gonçalves Neto. São Carlos, } 2011 \text {. }\end{array}$ \\
\hline & $\begin{array}{l}\text { Tese (Doutorado - Programa de Pós-Graduação em } \\
\text { Engenharia Elétrica e Área de Concentração em } \\
\text { Telecomunicações)-- Escola de Engenharia de São Carlos da } \\
\text { Universidade de São Paulo, } 2011 \text {. }\end{array}$ \\
\hline & $\begin{array}{l}\text { 1. Sistemas caóticos. 2. Circuito eletrônico partícula } \\
\text { numa caixa. 3. Sincronização de sistemas caóticos. } 4 . \\
\text { Tecnologia CDMA. I.Título. }\end{array}$ \\
\hline
\end{tabular}




\section{FOLHA DE JULGAMENTO}

\section{Candidata: Engenheira CRISTHIANE GONÇALVES}

Título da tese: "Verificação do sincronismo do acoplamento elétrico entre circuitos simulando o comportamento de um sistema mecânico partícula em caixa".

Data da defesa: 03/02/2012

\section{Comissão Julgadora:}

Prof. Associado Luiz Gonçalves Neto (Orientador)

(Escola de Engenharia de São Carlos/EESC)

Prof. Associado Ben-Hur Viana Borges

(Escola de Engenharia de São Carlos/EESC)

Prof. Dr. Frederico Dias Nunes

(Universidade Federal de Pernambuco/UFPE)

Prof. Dr. Robson Barcellos

(Centro Universitário Central Paulista/UNICEP)

Prof. Dr. Arlindo Neto Montagnoli

(Universidade Federal de São Carlos/UFSCar)

\section{Resultado:}
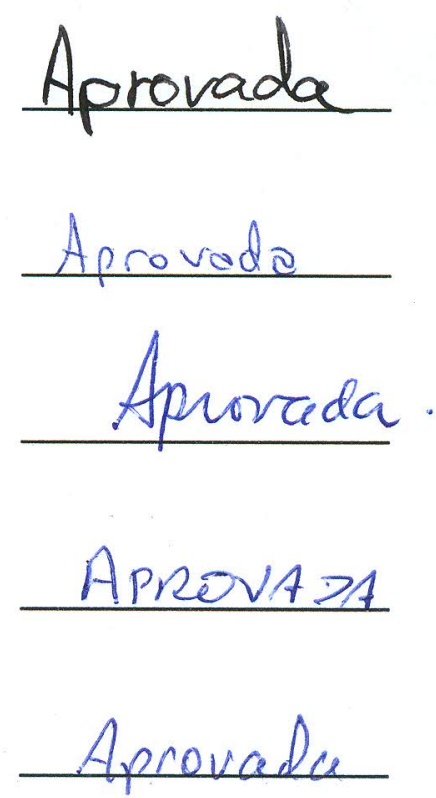

Coordenador do Programa de Pós-Graduação em Engenharia Elétrica:

Prof. Titular Denis Vinicius Coury

Presidente da Comissão de Pós-Graduação:

Prof. Associado Paulo Cesar Lima Segantine 
A Deus, meu Pai e meu Amigo, a quem eu devo a realização deste sonho. 


\section{AGRADECIMENTOS}

Ao Professor Dr. Luiz Gonçalves Neto, pela amizade, ensinamentos técnicos e de vida, e contribuições ao longo destes seis anos de trabalho.

Aos meus pais, José Carlos e Rosely, que tanto investiram na minha educação com carinho e altruísmo.

À minha irmã Carla, presença constante em minha vida.

Ao Professor Dr. José Carlos Pizolato Junior, pela amizade, colaboração, e discussões sobre o trabalho.

À minha amiga Eng. ${ }^{a}$ Larissa Lima, pela amizade e discussões técnicas.

A todos os meus vizinhos de laboratório, alunos do Laboratório de Telecomunicações da EESC-USP, pela amizade e companheirismo.

Aos funcionários do Departamento de Engenharia Elétrica da EESC-USP, em especial à Marisa, Jussara e Sr. José Carlos . 
"Nunca, jamais desanimeis, embora venham ventos contrários."

Santa Paulina 


\section{SUMÁRIO}

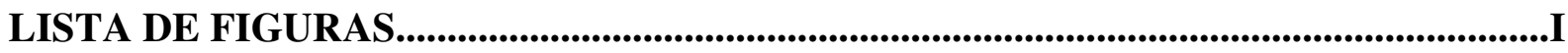

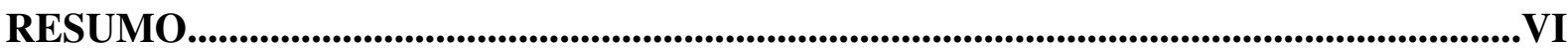

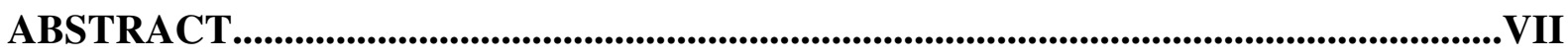

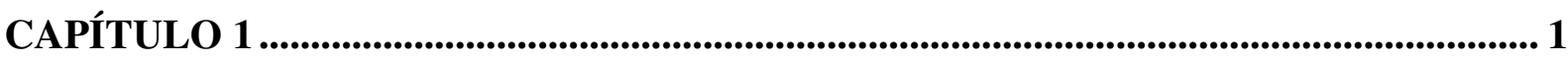

INTRODUÇÃO

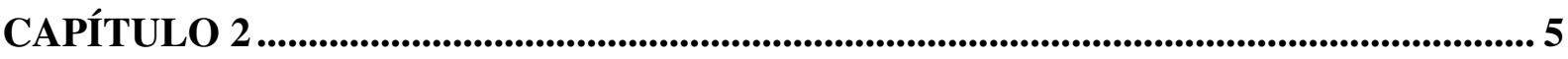

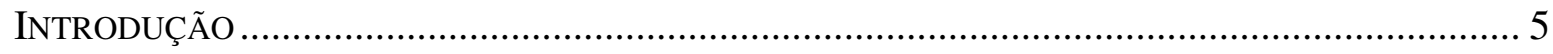

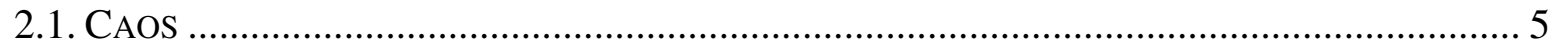

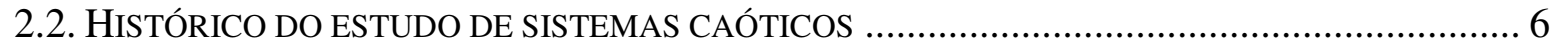

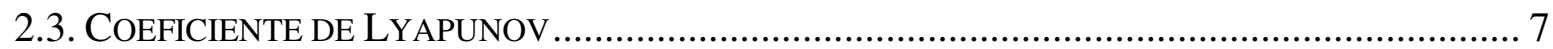

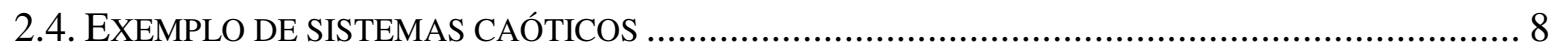

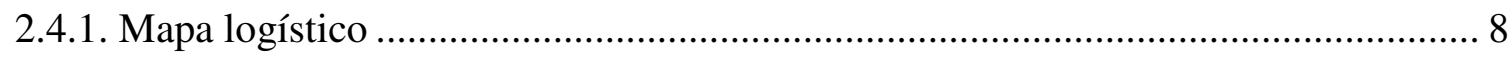

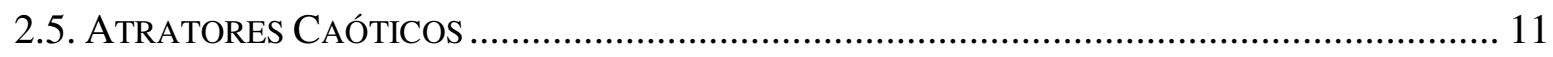

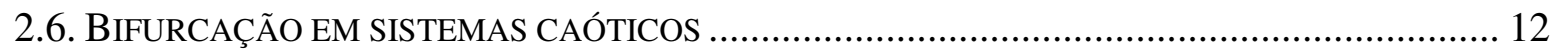

2.6.1. Transição de duplo período .................................................................................... 12

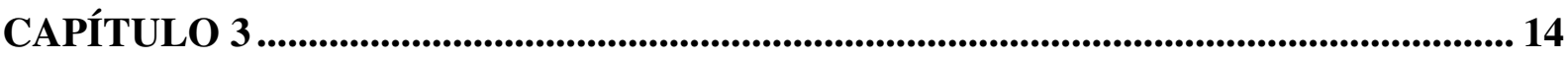

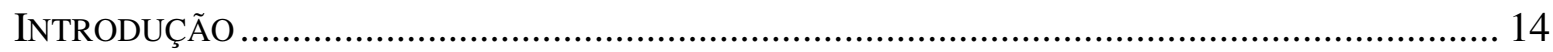

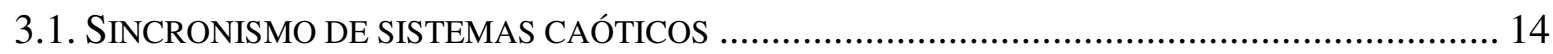

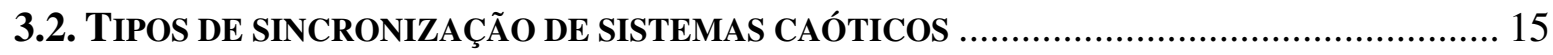

3.3. SINCRONIZAÇÃO DE OSCILADORES REGULARES POR FREQUÊNCIA.............................. 16

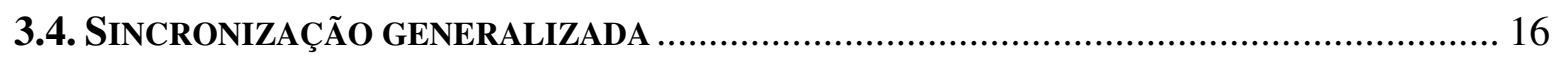

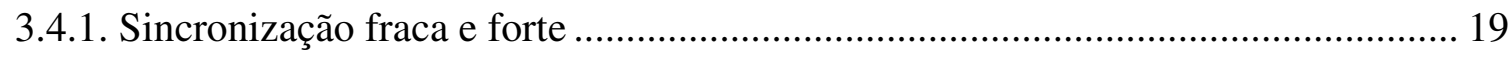

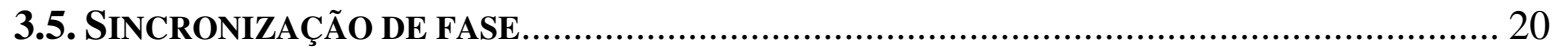

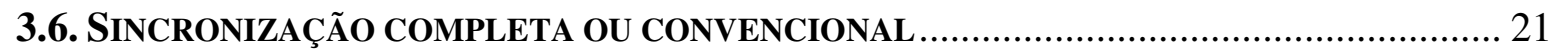

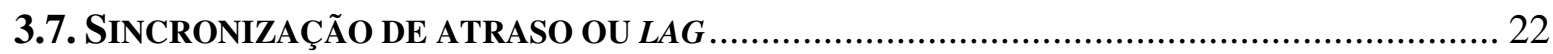

3.8. SINCRONIZAÇÃO POR REALIMENTAÇÃO DE ERRO ….............................................. 22

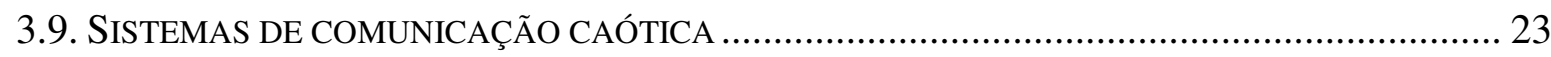




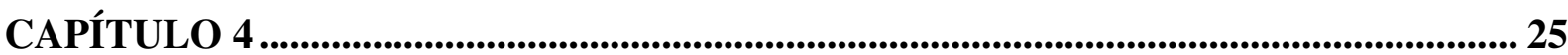

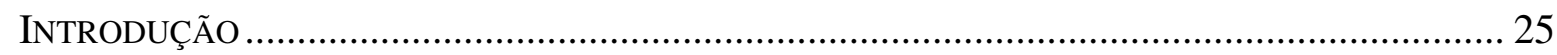

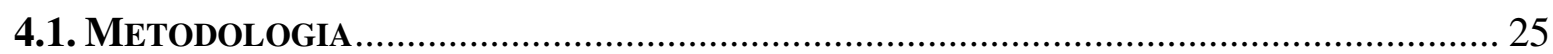

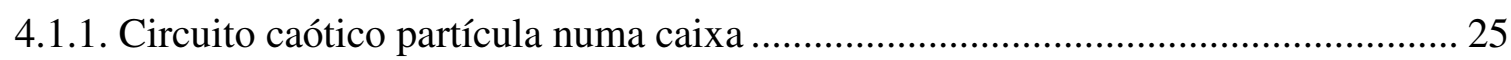

4.1.2. Implementação elétrica de sistemas de sincronização......................................... 30

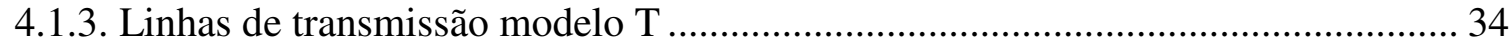

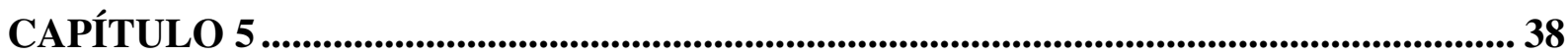

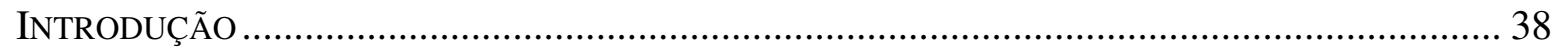

5. RESULTADOS EXPERIMENTAIS E SIMULAÇÕES NUMÉRICAS …....................................... 38

5.1. RESULTADOS PARA UM ÚNICO CIRCUITO PARTÍCULA NUMA CAIXA................................. 38

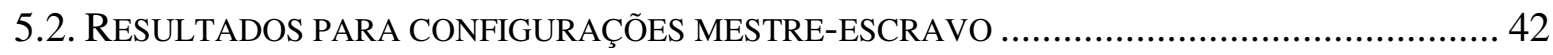

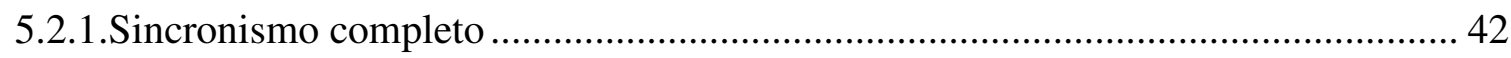

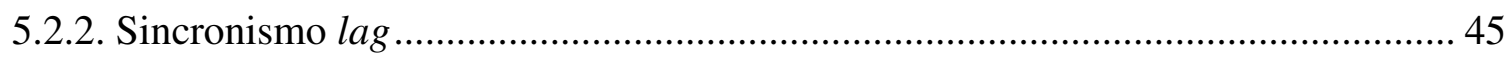

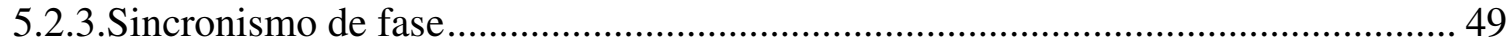

5.2.4. Resultados em diversas configurações mestre escravo com linhas de transmissão 52

5.2.5. Resultados para dois pares de circuitos partícula numa caixa em configurações mestre-escravo, casados dois a dois.

5.2.6. Resultados para três pares de circuitos partícula numa caixa em configurações

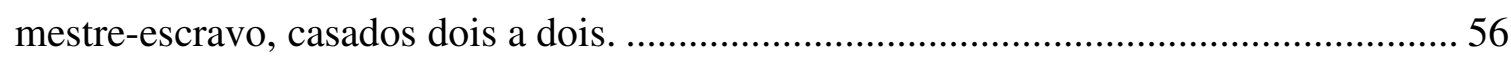

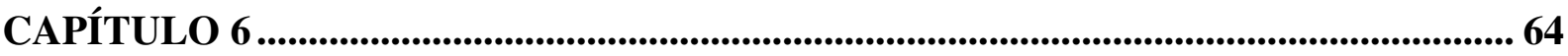

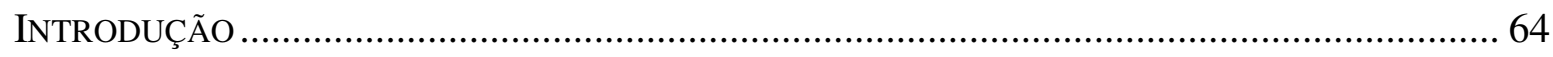

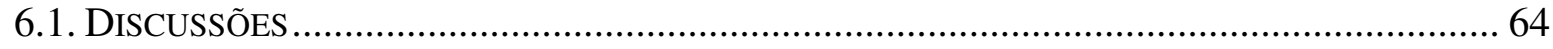

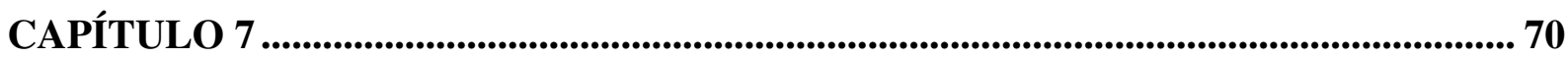

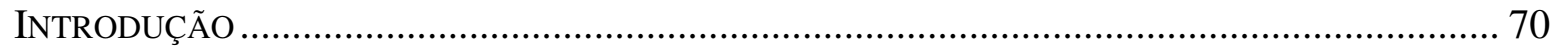

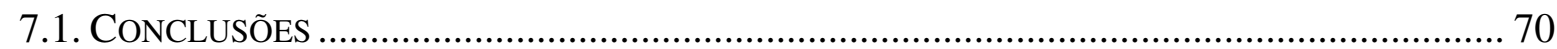

CAPÍTULO 8 (......................................................................................................................... 73

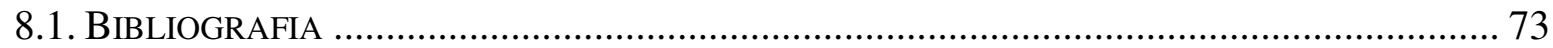

APÊNDICE A 
ARTIGO.

79

CONGRESSO

ANEXO A

MÉTODO TRAPEZOIDAL 


\section{LISTA DE FIGURAS}

Figura 1 - Simulação numérica de valores da função $x_{n+1}$ em função do parâmetro $r$, 11

Figura 2- Coeficientes de Lyapunov referentes ao mapa logístico [23]. Coeficientes de Lyapunov positivos indicam o comportamento caótico.

Figura 3 - Exemplo de atrator caótico do sistema partícula numa caixa, obtido para frequência $\mathrm{f}=1096 \mathrm{~Hz}$. 13

Figura 4- Diagrama relacionando o tipo de sincronismo com o acoplamento dos sistemas.... 20

Figura 5 - Diagrama de blocos do esquema de sincronização por realimentação de erro.

Figura 6 - (a) Partícula na caixa oscilando. (b) Força aplicada pelas molas. 26

Figura 7 - Simulação numérica da oscilação caótica da partícula numa caixa para o modelo mecânico proposto. 28

Figura 8 - Diagrama esquemático do circuito eletrônico partícula na caixa, descrito pela equação (33). Os valores dos componentes são: resistores $(k \Omega)$ : $R_{1}=47 ; R=R_{e}=R_{2}=10 ; R_{L}=0,51$; capacitores $(n F): C_{1}=C_{2}=12 ; \operatorname{diodos} D_{1}$ e $D_{2}$ : N4148; amplificadores operacionais 741 ou equivalentes. 29

Figura 9 - Resultado da simulação numérica para a equação do circuito partícula numa caixa.30

Figura 10 - Curva de tensão versus corrente em relação à tensão de saída do segundo amplificador operacional $\left(\mathrm{V}_{2}\right)$.

Figura 11 - Diagrama de blocos da montagem experimental de dois circuitos partícula numa caixa idênticos, apresentados em uma configuração mestre-escravo. 32

Figura 12 - Malha de realimentação do circuito eletrônico partícula na caixa.....

Figura 13 - Montagem experimental para aquisição de dados da implementação elétrica do sistema composto por dois circuitos idênticos partícula numa caixa. 
Figura 14 - Diagrama de blocos da montagem de dois circuitos partícula numa caixa idênticos.

Figura 15 - Linha de transmissão modelo T.

Figura 16 - Diagrama de blocos emulando a transmissão de informação através de um canal utilizando-se linhas de transmição modelo T.

Figura 17 - (a)Quebra de simetria do espaço de fase do circuito eletrônico partícula numa caixa para uma frequência $\mathrm{f}=950 \mathrm{~Hz}$; (b) início da bifurcação do atrator do circuito eletrônico partícula numa caixa, frequência $\mathrm{f}=958 \mathrm{~Hz}$.

Figura 18 - Diagramas de fase do circuito partícula numa caixa para uma amplitude fixa de 2V, e frequiência variável como parâmetro de bifurcação: (a) Período 1-f=958 Hz; (b) Período 2-f=963 Hz; (c) Período 4- f=965 Hz; e (d) Caos, f=1096 Hz. 40

Figura 19 - Resultado da simulação numérica do comportamento caótico do circuito partícula numa caixa sob as mesmas condições dos resultados experimentais mostrados na Figura 18(a), utilizando-se os parâmetros frequência $\mathrm{f}=1096 \mathrm{~Hz}$ e amplitude de $2 \mathrm{~V}_{\mathrm{pp}}$.

Figura 20 - (a) Formas de onda de saída dos circuitos mestre (CH1) e escravo (CH2). Pode-se observar que os circuitos exibem um rico comportamento caótico, ocorrendo o regime de sincronismo completo entre suas saídas. Em (b), são vistas as formas de onda dos circuitos sobrepostas, para resistência de realimentação $R_{R E}=100 \Omega$

Figura 21 - Diagrama de fase das saídas dos circuitos mestre e escravo. Pode-se notar que o mesmo exibe o padrão da função identidade, tal que $x_{e}(t)=x_{m}(t)$. Este comportamento é uma evidência do regime de sincronismo completo descrito na teoria da seção 3.6. ...... 44

Figura 22- Resultados da simulação numérica das saídas dos circuitos mestre $\left(\mathrm{V}_{2 \mathrm{~m}}\right)$ e escravo $\left(\mathrm{V}_{2 \mathrm{e}}\right)$, para resistência de realimentação $R_{R E}=100 \Omega$. As formas de onda das saídas dos circuitos mestre e escravo apresentam regime de sincronismo completo. 45

Figura 23 - Simulação numérica do diagrama de fase das saídas dos circuitos mestre (CH1) e escravo $(\mathrm{CH} 2)$ para esta configuração proposta 
Figura 24 - Formas de onda das saídas dos circuitos mestre $(\mathrm{CH} 1)$ e escravo $(\mathrm{CH} 2)$ para resistência de realimentação $R_{R E}=100 \mathrm{k} \Omega$. As saídas dos circuitos encontram-se em atraso uma em relação à outra, ocorrendo o sincronismo de atraso, tal que $x_{e}\left(t+\tau_{0}\right) \approx x_{m}(t)$

Figura 25 - Diagrama de fase dos circuitos mestre $(\mathrm{CH} 1)$ e escravo $(\mathrm{CH} 2)$ para resistência de realimentação $R_{R E}=100 \mathrm{k} \Omega$.

Figura 26 - Resultados da simulação numérica das formas de onda das saídas dos circuitos mestre $\left(\mathrm{V}_{2 \mathrm{~m}}\right)$ e escravo $\left(\mathrm{V}_{2 \mathrm{e}}\right)$, para resistência de realimentação $R_{R E}=100 \mathrm{k} \Omega$. 48

Figura 27 - Resultados da simulação numérica do espaço de fase dos circuitos mestre $\left(\mathrm{V}_{2 \mathrm{~m}}\right)$ e escravo $\left(\mathrm{V}_{2 \mathrm{e}}\right)$, para resistência de realimentação $R_{R E}=100 \mathrm{k} \Omega$. As saídas dos circuitos mestre e escravo apresentam regime de sincronismo de defasagem ou lag.

Figura 28 - Formas de onda das saídas dos circuitos mestre $(\mathrm{CH} 1)$ e escravo $(\mathrm{CH} 2)$ para resistência de realimentação $\mathrm{R}_{\mathrm{RE}}=500 \mathrm{k} \Omega$. 50

Figura 29 - Diagrama de fase para os circuitos mestre $(\mathrm{CH} 1)$ e escravo $(\mathrm{CH} 2)$ para resistência de realimentação $R_{R E}=500 \mathrm{k} \Omega$, num regime de sincronismo de fase. 51

Figura 30- Simulação numérica para as formas de onda de saída dos circuitos mestre (CH1) e escravo $(\mathrm{CH} 2)$ para resistência de realimentação $R_{R E}=500 \mathrm{k} \Omega$, num regime de sincronismo de fase. 52

Figura 31 - Simulação numérica do diagrama de fase para os circuitos mestre $(\mathrm{CH} 1)$ e escravo $(\mathrm{CH} 2)$ para resistência de realimentação $R_{R E}=500 \mathrm{k} \Omega$, num regime de sincronismo de fase. .53

Figura 32 - (a) Sinais de saída do circuito mestre $(\mathrm{CH} 1)$ e do circuito escravo $(\mathrm{CH} 2)$ passando pela linha de transmissão T equivalente a $100 \mathrm{~m}$. (b) Diagrama de fase dos circuitos mestre e escravo, utilizando a linha de transmissão equivalente a $100 \mathrm{~m}$. 
Figura 33 - (a) Sinais de saída do circuito mestre $(\mathrm{CH} 1)$ e do circuito escravo $(\mathrm{CH} 2)$ passando pela linha de transmissão T equivalente a $1 \mathrm{~km}$. (b) Diagrama de fase dos circuitos mestre e escravo, utilizando a linha de transmissão equivalente a $1 \mathrm{~km}$. 55

Figura 34 - (a)Sinais de saída do circuito mestre (CH1) e do circuito escravo $(\mathrm{CH} 2)$ passando pela linha de transmissão T equivalente a $10 \mathrm{~km}$. (b) Diagrama de fase dos circuitos mestre e escravo, utilizando a linha de transmissão equivalente a $10 \mathrm{~km}$. 55

Figura 35 - (a) Sinal de saída dos circuitos mestre $1(\mathrm{CH} 1)$ e escravo $1(\mathrm{CH} 2)\left(\mathrm{R}_{1}=44 \mathrm{k} \Omega\right)$, e (b) diagrama de fase referente às saídas dos mesmos.

Figura 36 - (a) Sinal de saída dos circuitos mestre $1(\mathrm{CH} 1)\left(\mathrm{R}_{1}=44 \mathrm{k} \Omega\right.$ ) e escravo $2(\mathrm{CH} 2)$ $\left(\mathrm{R}_{1}=47 \mathrm{k} \Omega\right)$, e (b) o respectivo diagrama de fase. Como se pode verificar, os circuitos mestre 1 e escravo 2 não se sincronizaram quando a soma dos sinais de saída dos circuitos escravos 1 e 2 são reaplicadas aos mesmos, através da malha de realimentação.57

Figura 37 - (a) Sinal de saída dos circuitos mestre $1(\mathrm{CH} 1)$ e escravo $1(\mathrm{CH} 2)\left(\mathrm{R}_{1}=44 \mathrm{k} \Omega\right)$, e (b) diagrama de fase referente às saídas dos mesmos.

Figura 38 - (a) Sinal de saída dos circuitos mestre $2(\mathrm{CH} 1)$ e escravo $2(\mathrm{CH} 2)\left(\mathrm{R}_{1}=47 \mathrm{k} \Omega\right)$, e (b) diagrama de fase referente às saídas dos mesmos.

Figura 39 - (a) Sinal de saída dos circuitos mestre $3(\mathrm{CH} 1)$ e escravo $3(\mathrm{CH} 2)\left(\mathrm{R}_{1}=50 \mathrm{k} \Omega\right)$, e (b) diagrama de fase referente às saídas dos mesmos. 60

Figura 40 - (a) Sinal de saída dos circuitos mestre $1(\mathrm{CH} 1)\left(\mathrm{R}_{1}=44 \mathrm{k} \Omega\right)$ e escravo $2(\mathrm{CH} 2)$ $\left(\mathrm{R}_{1}=47 \mathrm{k} \Omega\right)$, e (b) o respectivo diagrama de fase. Como se pode verificar, os circuitos mestre 1 e escravo 2 não sincronizaram-se quando a soma dos sinais de saída dos circuitos escravos 1 ,2 e 3 são reaplicadas aos mesmos, através da malha de realimentação.

Figura 41 - (a) Sinal de saída dos circuitos mestre $1(\mathrm{CH} 1)\left(\mathrm{R}_{1}=44 \mathrm{k} \Omega\right.$ ) e escravo $3(\mathrm{CH} 2)$ $\left(\mathrm{R}_{1}=50 \mathrm{k} \Omega\right)$, e (b) o respectivo diagrama de fase.

Figura 42 - Sinal de saída dos circuitos mestre $2(\mathrm{CH} 1)\left(\mathrm{R}_{1}=47 \mathrm{k} \Omega\right)$, e escravo $1(\mathrm{CH} 2)$ $\left(\mathrm{R}_{1}=44 \mathrm{k} \Omega\right)$, e (b) o respectivo diagrama de fase. Como se pode verificar, os circuitos mestre 2 e escravo 1 não sincronizaram-se quando a soma dos sinais de saída dos 
circuitos escravos 1, 2 e 3 são reaplicadas aos mesmos, através da malha de realimentação.

Figura 43 - Sinal de saída dos circuitos mestre $2(\mathrm{CH} 1)\left(\mathrm{R}_{1}=47 \mathrm{k} \Omega\right)$ e escravo $3(\mathrm{CH} 2)$ $\left(\mathrm{R}_{1}=50 \mathrm{k} \Omega\right)$, e (b) o respectivo diagrama de fase. Como se pode verificar, os circuitos mestre 2 e escravo 3 não sincronizaram-se quando a soma dos sinais de saída dos circuitos escravos 1, 2 e 3 são reaplicadas aos mesmos, através da malha de realimentação. 63

Figura 44 - Sinal de saída dos circuitos mestre $3(\mathrm{CH} 1)\left(\mathrm{R}_{1}=50 \mathrm{k} \Omega\right)$ e escravo $1(\mathrm{CH} 2)\left(\mathrm{R}_{1}=44\right.$ $\mathrm{k} \Omega$ ), e (b) o respectivo diagrama de fase. 63

Figura 45 - Sinal de saída dos circuitos mestre $3(\mathrm{CH} 1)\left(\mathrm{R}_{1}=50 \mathrm{k} \Omega\right.$ ) e escravo $2(\mathrm{CH} 2)$ $\left(\mathrm{R}_{1}=47 \mathrm{k} \Omega\right)$, e (b) o respectivo diagrama de fase. 64 


\section{RESUMO}

A dinâmica de sistemas caóticos é uma área de pesquisa relativamente recente, diretamente relacionada com os campos da engenharia, física e matemática aplicada. A sincronização entre sistemas dinâmicos tem sido um tópico de pesquisa muito freqüente, abrangendo campos desde a mecânica de corpos celestiais até a física dos lasers.

Entretanto, a maioria dos trabalhos da área concentra-se em simulações numéricas do comportamento de sistemas caóticos.

Com o objetivo de verificar aplicações em engenharia do sincronismo entre circuitos, foi proposto o circuito eletrônico partícula em caixa, que é relativamente simples, se comparado com outros trabalhos na literatura.

A originalidade deste trabalho consiste em verificar a robustez de alguns sistemas compostos de circuitos idênticos que simulam o comportamento de uma partícula em caixa em configurações mestre-escravo, em diversas topologias, explorando o sincronismo dos mesmos utilizando uma malha fechada de realimentação de erro. A robustez do acoplamento destes sistemas é estudada por meio de montagens experimentais e simulações numéricas.

A observação da sua dinâmica permite sugerir aplicações na área de telecomunicações em multiplexação de sinais, acesso multiusuário e tecnologia CDMA (Code Division Multiple Access).

Palavras-chave: circuito eletrônico partícula em caixa. sincronização de sistemas caóticos, tecnologia CDMA. 


\begin{abstract}
The dynamics of chaotic systems is a relatively new research area, directly related to the fields of engineering, physics and applied mathematics. Synchronization between dynamic systems has been a very frequent topic of research, covering fields ranging from mechanics of celestial bodies to the physics of lasers.

However, most of the work area focuses on numerical simulations of the behavior of chaotic systems.

In order to verify engineering applications of synchronism of circuits, it was proposed a particle in a box electronic circuit, which is relatively simple if compared to other studies.

The originality of this work is to verify the robustness of some systems composed of identical circuits that simulate the behavior of a particle in a box in master-slave configurations in several topologies, exploring their synchronism using a closed loop feedback error. The strength of the coupling of these systems is studied through numerical simulations and experimental setups.

The observation of this dynamics allows us to suggest applications in telecommunications in signal multiplexing, multiuser access and CDMA (Code Division Multiple Access).
\end{abstract}

Keywords: Particle-in-a-box electronic circuit, chaos synchronization, CDMA technologies. 


\section{Capítulo 1}

\section{Introdução}

O sincronismo de sistemas caóticos é um tópico de pesquisa muito recorrente, tendo importância tanto teoricamente, quanto em aplicações em engenharia, para transmissão de informação por meio do envio de sinais caóticos [1], [2]. Para que a transmissão da informação ocorra com sucesso, deve-se minimizar o erro de sincronismo, a fim de que não haja degradação do desempenho do sistema.

$\mathrm{Na}$ literatura, alguns autores sugerem multiplexação e esquemas de cifragem utilizando sincronização de sistemas caóticos [2],[3], onde múltiplos pares de osciladores caóticos podem ser sincronizados por meio de um único canal. Os subsistemas escravos sincronizam-se com suas contrapartes do sistema mestre. Esse tipo de sincronismo torna-se um esquema de comunicação de multiplexação, onde as formas de onda caóticas são portadoras de informação [4].

Os subsistemas caóticos se dividem basicamente em duas classes de sistemas: autônomos e não autônomos. Os circuitos autônomos são aqueles que possuem comportamento caótico inerente e obrigatoriamente apresentam um ou mais elementos não lineares. Já os circuitos não autônomos dependem de alimentação externa para exibir o comportamento caótico, como é o caso do sistema utilizado neste trabalho de doutorado.

Dentre a classe de circuitos autônomos, Lorenz [5] demonstrou que o comportamento caótico pode ocorrer em sistemas descritos por equações diferenciais ordinárias, com ao menos três variáveis e duas não linearidades quadráticas. O circuito caótico autônomo proposto por Chua [6]-[9], bem como suas variações, é muito difundido na literatura, e sua importância se deve ao fato de suas propriedades matemáticas serem observadas em experimentos físicos, utilizando um dispositivo simples.

O sincronismo entre circuitos caóticos que foi proposto por Pecora e Carroll [10],[11] possibilitou uma nova maneira de analisar dois sistemas caóticos remotos, um transmissor e outro receptor, sincronizados por meio de um sinal aplicado ao transmissor. Neste sentido, o comportamento de circuitos caóticos eletrônicos e suas possibilidades para aplicações em telecomunicações têm sido amplamente estudados na literatura. Zimmerman et. al. 
implementaram um circuito eletrônico que emula o comportamento mecânico de uma partícula em mesa vibratória [12], obtendo excelentes resultados experimentais em concordância com o modelo proposto, também analisado por meio de simulações numéricas. Pizolato et al. [13] propuseram o circuito eletrônico partícula numa caixa, estudando sua aplicação em modulação caótica como alternativa para sistemas de comunicações explorando sua não linearidade.

A proposta deste trabalho é, utilizando-se montagens experimentais e simulações numéricas, verificar a robustez de sistemas compostos de circuitos idênticos que simulam o comportamento de uma partícula numa caixa [13] em configurações mestre-escravo, em diversas topologias, explorando o sincronismo dos mesmos utilizando uma malha fechada de realimentação de erro [11].

A observação da dinâmica do circuito partícula numa caixa e dos sistemas propostos permite sugerir aplicações na área de telecomunicações em multiplexação de sinais, em analogia à tecnologia CDMA (Code Division Multiple Access) [14].

O trabalho está organizado da seguinte maneira: no capítulo 1 é apresentada a introdução ao trabalho. No capítulo 2, são introduzidos conceitos da teoria do caos. O capítulo 3 apresenta a teoria do sincronismo de sistemas caóticos. A metodologia utilizada no trabalho é descrita no capítulo 4. No capítulo 5 são apresentados os resultados experimentais e as simulações numéricas. No capítulo 6 são apresentadas as discussões do trabalho, no capítulo 7, são apresentadas as conclusões da pesquisa. E, finalmente, as referências bibliográficas são listadas no capítulo 8. 


\section{Capítulo 2}

\section{Introdução}

A teoria de sistemas dinâmicos é essencial para a compreensão de sistemas complexos.

Nesta seção serão discutidos alguns importantes conceitos, como comportamento não linear, coeficiente de Lyapunov, atratores caóticos, bifurcação, transição de duplo período, e a constante de Feigenbaum, e exemplos de sistemas caóticos.

\subsection{Caos}

Caos per se é um termo utilizado para descrever o comportamento aparentemente complexo de alguns sistemas. O elemento chave para entender este comportamento é a noção de não linearidade.

Pode-se ter uma ideia intuitiva de não linearidade de um sistema a partir da caracterização de seu comportamento frente a um estímulo e sua resposta.

Um sistema é dito linear se a propriedade de superposição atende a condição a seguir, quando a um estímulo $S(t)$ é aplicado às funções de entrada $u(t)$ e $v(t)$, sendo $a$ e $b$ constantes complexas [15]:

$$
S[a u(t)+b v(t)]=a S[u(t)]+b S[v(t)]
$$

Um sistema não linear, diferentemente, obedece à relação:

$$
S[a \cdot u(t)+b \cdot v(t)] \neq a \cdot S[u(t)]+b S[v(t)]
$$

As características típicas de um sistema caótico determinístico são:

- Não linearidade: se o sistema é linear, não pode ser caótico; 
- Sensitividade às condições iniciais: pequenas mudanças no estado inicial podem levar a um comportamento radicalmente diferente no estado final. O conceito do efeito borboleta ilustra este comportamento [16]. Uma pequena perturbação da atmosfera, gerada por uma borboleta batendo suas asas afetará as condições climáticas nos próximos dias.

- Irregularidade no comportamento do sistema;

- Predição do sistema: impossível devido à sensitividade às condições iniciais, as quais podem ser conhecidas somente com certo grau de precisão.

A investigação do caos e sistemas caóticos é uma área de pesquisa relativamente recente, diretamente relacionada com os campos da engenharia e da matemática aplicada. Dentro deste contexto, a dinâmica não linear pode ser descrita como o estudo dos sistemas cujas equações de movimento contêm uma dependência não linear de seus estados de variáveis. Enquanto o caos ocorre frequentemente em sistemas não lineares, jamais pode ocorrer em sistemas lineares.

\subsection{Histórico do estudo de sistemas caóticos}

Em 1963, Edward Lorenz estudou a irregularidade em um modelo de previsão do tempo, apresentando o primeiro atrator caótico ou atrator estranho, como era comumente conhecido[16]. O termo Teoria do Caos foi introduzido por Tien-Yen e James Yorke em 1975 [17].

Em 1976, Robert May introduziu uma aplicação da equação logística à ecologia, mostrando o comportamento caótico da população de indivíduos [18]. Posteriormente, o trabalho do pesquisador Mitchell Feigenbaum, publicado em 1978, teve grande repercussão por apresentar um número universal associado com a relação do comportamento caótico de sistemas não lineares. Esta constante, que mede a razão entre períodos de bifurcações sucessivas em sistemas caóticos, mais tarde foi denominada constante de Feigenbaum [19] em homenagem ao pesquisador.

. Em 1980, Benoit Mandelbrot publicou um trabalho de grande relevância no estudo de sistemas caóticos, aplicando a geometria fractal à computação gráfica e compressão de imagens[20]. 
Dentre aplicações em engenharia, o revolucionário trabalho de Pecora e Carrol [10], possibilitou o estudo da sincronização de sistemas caóticos. Os pesquisadores estudaram como sistemas caóticos idênticos ou quase idênticos podem ser sincronizados, por meio de uma técnica que consiste em tomar um sistema caótico e produzir um subsistema do original, duplicando uma parte do mesmo.

A complexidade inerente aos sistemas caóticos dá origem ao termo caos. Ao contrário do que se tem em mente, este termo não indica uma desordem completa, como é difundido seu uso no cotidiano. Caos é o comportamento aparentemente aleatório de um sistema, o qual é de fato determinístico. Isto significa que o sistema não possui aleatoriedade ou ruído, mas sim que seu comportamento irregular surge de sua não linearidade. Como discutido anteriormente, tais sistemas são altamente sensíveis às condições iniciais, de maneira que dois estados com uma separação inicial pequena podem ter estados finais muito diferentes, e assim as perturbações das condições iniciais crescem exponencialmente. O espaço de fase de um sistema caótico é topologicamente sobreposto, tal que qualquer subconjunto do espaço de fase irá eventualmente sobrepor outro subconjunto. $\mathrm{O}$ espaço de fase pode conter estruturas tais como regiões de estabilidade e pontos ou regiões de acumulação, que são conhecidos como atratores estranhos [5]. Por esta razão, as órbitas de um sistema caótico no espaço de fase são, por definição, aperiódicas.

\subsection{Coeficiente de Lyapunov}

A sensitividade às condições iniciais é uma das características mais conhecidas do caos, e se tornou popular pelo uso do termo: efeito borboleta [15]. A medida dessa manifestação de sensitividade dos sistemas lineares pode ser analisada através do coeficiente de Lyapunov [21]. Dada uma pequena perturbação em um estado inicial de um sistema composto de dois subsistemas, os dois estados resultantes divergem exponencialmente no tempo. Essa é a manifestação da dependência sensitiva dos sistemas caóticos de suas condições iniciais. Supondo que $x(t)$ é um ponto no espaço de fase, e $x(t)+\delta(t)$ é um ponto da vizinhança, os dois pontos são separados por um comprimento inicial $\delta(t)<<1$. Tem-se que: 


$$
\delta(t) \sim\left|\delta_{0}\right| \exp (\lambda t)
$$

Onde $\lambda$ é chamado coeficiente de Lyapunov [21].

Se o comportamento do sistema é periódico, ou seja, não caótico, $\lambda<0$. Se o sistema é aperiódico, $\lambda>0$. Em geral, um sistema $n$-dimensional terá $n$ expoentes, onde cada um denota o comprimento de um eixo principal de uma elipsoide no espaço de fase. O maior coeficiente de Lyapunov controla efetivamente o tamanho do elipsoide, e $\lambda$ é este valor em (3).

Para um sistema unidimensional, tal como o mapa logístico, o coeficiente de Lyapunov pode ser calculado como:

$$
\lambda=\lim _{n \rightarrow \infty} \frac{1}{n} \sum_{i=0}^{n-1}\left[f^{\prime}\left(x_{i^{\prime}}\right)\right]
$$

Onde $f^{\prime}$ denota a primeira derivada da função do mapa logístico. Tomando-se $\mathrm{n}$ suficientemente grande para assegurar convergência, pode-se calcular o coeficiente de Lyapunov como função do parâmetro caótico r (seção 2.4).

Na próxima seção, serão abordadas algumas características e aplicações de sistemas não lineares.

\subsection{Exemplo de sistemas caóticos}

\subsubsection{Mapa logístico}

Um sistema dinâmico determinístico consiste em um conjunto de estados possíveis, com uma regra que determina o estado presente em termos dos estados anteriores. Existem vários sistemas que exibem esta característica, uma regra na qual verifica-se que o estado atual do sistema possa ser determinado unicamente através dos estados anteriores [22].

Cumpre ressaltar que o determinismo pode ser analisado para sistemas dinâmicos discretos no tempo, onde pode ser tomado o estado atual como entrada, atualizando o sistema e produzindo um novo estado na saída. Outro tipo de sistema dinâmico é o contínuo no tempo, 
de modo que as atualizações do sistema ocorrem continuamente, e neste caso, a relação de recorrência se torna um conjunto de equações diferenciais [22].

Um exemplo de sistema caótico unidimensional é o mapa logístico. O sistema é descrito por uma variável de estado simples $x \in[0,1]$, cuja evolução é governada pela relação de recorrência discreta no tempo:

$$
x_{n+1}=r x_{n}\left(1-x_{n}\right)
$$

Onde $\mathrm{r}$ é chamado parâmetro caótico e $0 \leq r \leq 4$. Para valores de $\mathrm{r}$ nesta escala, o sistema exibe um comportamento drasticamente diferente. Para visualizar a evolução do sistema, pode-se traçar um mapa de Poincaré, ou mapa de retorno [23]. Um mapa de retorno mostra o estado das variáveis em um instante de tempo posterior em relação ao estado das mesmas em um instante anterior. No caso do mapa logístico, pode-se plotar a variável $x_{n+1}$ em função da variável $x_{n}$, para diferentes valores do parâmetro caótico, como visto na Figura 1.

No caso de $\mathrm{r}<1$, então $\mathrm{x} \rightarrow 0$, na medida que $\mathrm{n} \rightarrow \infty$, independente da posição inicial $x_{0}$, onde $\mathrm{x}=0$ é chamado atrator do sistema. Ao aumentar o parâmetro caótico tal que $\mathrm{r}>1$, observa-se que o sistema em geral converge para um ponto fixo $x_{f} \in[0,1]$. O ponto $x_{f}$ é determinado por $\mathrm{r}$, e é independente do ponto inicial $x_{0}$. Para quaisquer valores maiores do parâmetro caótico, um novo comportamento emerge. Ao invés de convergir para um ponto singular, o sistema oscila entre dois ou mais pontos estáveis até o limite $n \rightarrow \infty$. O comportamento de um ciclo estável entre dois pontos que passa então a um atrator de quatro pontos, assim sucessivamente, é conhecido como bifurcação de duplo período. Aumentando lentamente o parâmetro caótico, pode-se notar que as bifurcações continuam ocorrendo, sempre de forma recorrente, até $\mathrm{r} \sim 3,56$, ponto em que o sistema se torna caótico, como visto na simulação numérica mostrada na Figura 1.

Na Figura 2 é apresentado graficamente o cálculo dos coeficientes de Lyapunov correspondentes ao mapa logístico. Observa-se que no ponto $r \sim 3,83$, o sistema apresenta uma janela de instabilidade, de período 3, e consequentemente o coeficiente de Lyapunov passa a ser negativo. O leitor pode se aprofundar no tema consultando a referência [23]. 


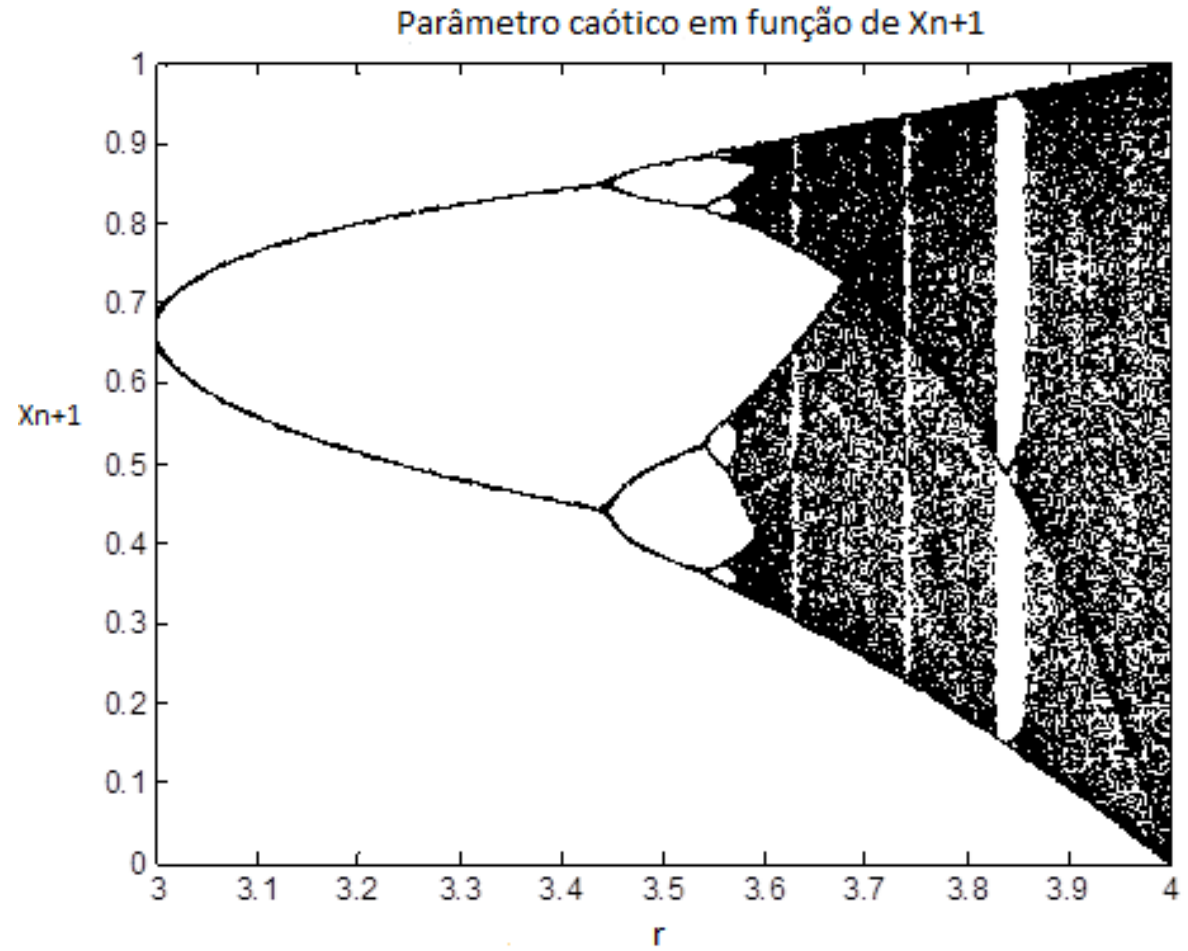

Figura 1 - Simulação numérica de valores da função $\mathrm{x}_{\mathrm{n}+1}$ em função do parâmetro $\mathrm{r}$, onde $3<\mathrm{r}<4$.

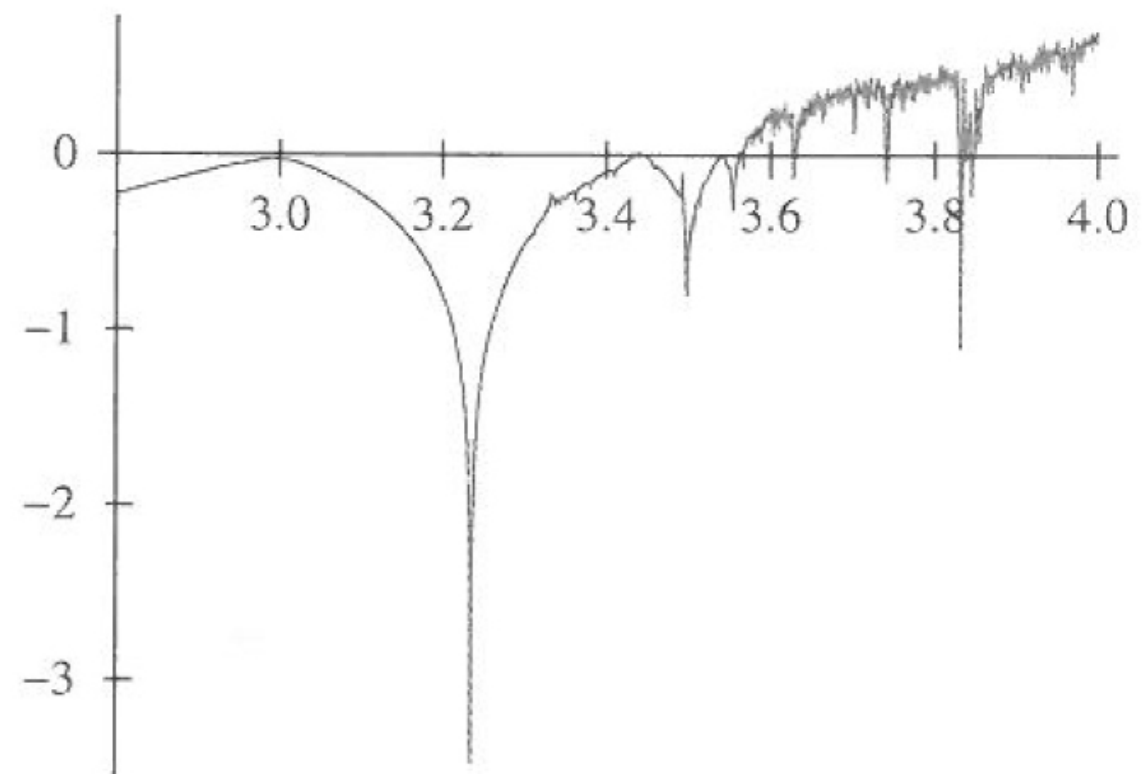

Figura 2- Coeficientes de Lyapunov referentes ao mapa logístico [23]. Coeficientes de Lyapunov positivos indicam o comportamento caótico. 
Analisando os gráficos apresentados na Figura 1 e Figura 2, percebe-se que a escolha de parâmetros ideal, no caso, o parâmetro de bifurcação $r$, permite que toda a dinâmica do sistema, desde o comportamento periódico ao caótico seja observada. Ao invés de oscilar entre um número finito de pontos, o mapa de retorno exibe um comportamento aperiódico, nunca retornando ao mesmo ponto. Este comportamento caótico continua com o aumento de r, exceto em alguns valores para os quais janelas de estabilidade aparecem. O diagrama da Figura 1 confirma que ocorrem sucessivas bifurcações, e que a razão do período entre bifurcações sucessivas é igual à constante de Feigenbaum, $\delta=4,669$ como descrito na Seção anterior [19].

\subsection{Atratores Caóticos}

A descrição dos atratores caóticos é um aspecto importante na explicação dos fenômenos dinâmicos [22].

Quando o movimento caótico é observado em um sistema físico, no conjunto no qual o mesmo está ocorrendo, ele atrai uma porção significativa de suas condições iniciais[16],[22]. Quando o conjunto limite de várias trajetórias for o mesmo, esse conjunto limite designa-se atrator. $\mathrm{O}$ atrator deve ter a propriedade de um ponto qualquer escolhido ao acaso ter probabilidade não nula de convergir para este conjunto.

As trajetórias caóticas costumam aparecer na proximidade de um conjunto de pontos de equilíbrio (ou ciclo) atrativos e repulsivos, designados como atrator estranho. A conjugação de atração e repulsão dá origem ao comportamento caótico. Na Figura 3 é apresentado um exemplo de atrator caótico. 


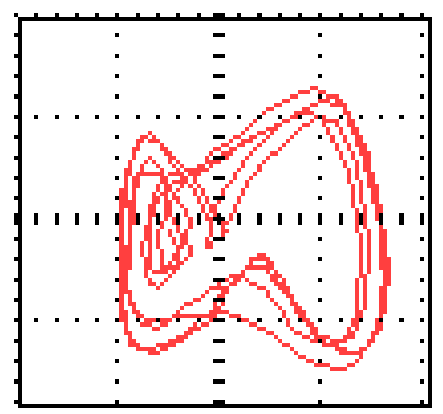

Figura 3 - Exemplo de atrator caótico do sistema partícula numa caixa, obtido para frequência $\mathrm{f}=1096 \mathrm{~Hz}$.

\subsection{Bifurcação em sistemas caóticos}

Uma mudança qualitativa na dinâmica de um sistema que ocorre quando um parâmetro do sistema varia é chamada bifurcação [24]. Uma bifurcação é dita genérica se suas características básicas não podem ser alteradas por pequenas perturbações.

Tomando-se por base o mapa logístico, sistema caótico determinístico apresentado na Seção 2.4.1, nota-se que, quando o parâmetro caótico $\mathrm{r}$ atinge o valor $\mathrm{r}=3$, o ponto fixo se divide em dois, como pode-se notar, uma típica bifurcação.

Um dos tipos mais comuns do fenômeno de bifurcação, a bifurcação de Hopf, está associada ao surgimento ou desaparecimento de uma órbita periódica do espaço de fase de um sistema [26].

Uma maneira de visualizar a série de bifurcações que um sistema tridimensional apresenta é através da seção de Poincaré [22],[26].

\subsubsection{Transição de duplo período}

Na seção 2.4.1.foi apresentado o mapa logístico:

$$
x_{n+1}=r x_{n}\left(1-x_{n}\right)
$$


Seguindo uma rota que vai de um sistema ordenado ao caos, a transição de duplo período, caracterizada por uma série de parâmetros de controle $r_{1}, r_{2}, \ldots . ., r_{n}, \ldots$. tais que, quando $r_{n}<r<r_{n+1}$, o período do sistema é $2^{n}$. O valor limite é $r_{\infty}=\lim _{n \rightarrow \infty} r_{n}=3,569945$, além do qual a dinâmica do sistema passa de periódica a caótica. Este esquema de bifurcação ocorre em diversos sistemas, como o pêndulo, em sistemas conservativos, entre outros. $\mathrm{O}$ dobramento do período é importante, pois confere um grau de universalidade aos sistemas, como analisado por Feigenbaum [19],[26].

Para cada $r_{n}$, o número de bifurcações dobra, e a distância entre bifurcações consecutivas $\frac{r_{n}-r_{n-1}}{r_{n+1}-r_{n}} \approx \delta=4,6692$. 


\section{Capítulo 3}

\section{Introdução}

Sincronização (do grego syn $=$ o mesmo, comum, e chronos $=$ tempo), é um fenômeno comum em sistemas lineares e não lineares, descoberto por Huygens enquanto observava experimentos com dois pêndulos [25],[26].

A dinâmica de sistemas complexos pode ocorrer de tal forma que a lei de evolução de subsistemas em estados diferentes ocorra de maneira independente, ou em algum ponto, os estados de cada um dos sistemas comece a mudar no mesmo ritmo. Essa noção de sincronismo é apresentada neste capítulo.

Atualmente, o fato de diferentes partes de um sistema ou dois sistemas acoplados (não necessariamente osciladores) poderem se acoplar, é estudado em diversas aplicações em engenharia mecânica e elétrica [10],[11].

O sincronismo de sistemas desempenha um papel muito importante em diversas outras áreas de pesquisa, como no estudo da sincronização dos lasers, no campo das ciências biológicas como, por exemplo, no estudo do ritmo cardíaco, redes neurais, modelos de crescimento de população, dentre outros.

\subsection{Sincronismo de sistemas caóticos}

O desenvolvimento da teoria de sistemas dinâmicos demonstrou que sistemas caóticos podem exibir diversos tipos de sincronismo[27].

Dois sistemas caóticos idênticos iniciados nas mesmas condições tornam-se rapidamente não relacionados. Lou Pecora e Tom Caroll, no Naval Research Lab, estudaram como sistemas caóticos idênticos ou quase idênticos podem ser sincronizados [10]. A técnica consiste em tomar um sistema caótico e produzir um subsistema do original, duplicando uma parte do mesmo. O sistema original trabalha independente do outro, porém o subsistema é conduzido por um sinal do original. Sob algumas condições, este subsistema se comporta 
caoticamente, mas em completa sincronização com sua contraparte no sistema original. $\mathrm{O}$ comportamento como um todo é caótico, mas o acoplamento do subsistema é estável. Sua estabilidade garante que qualquer ruído ou perturbação seja amortecido e continue mantendo o ajuste do sinal de entrada, apesar de sua complexidade. Até então, não havia se pensado que um sistema não linear seria estável quando aplicado um sinal caótico. O problema consiste em encontrar subsistemas estáveis de um sistema caótico geral. O primeiro circuito caótico sincronizado foi desenvolvido por Carroll, colaborador de Pecora [10], em 1989. Ele utilizou um circuito que já exibia comportamento caótico e construiu um subcircuito do mesmo, o qual era estável em relação ao sinal que vinha do primeiro. O circuito final apresentava duas partes, nas quais tensões e correntes flutuavam de maneira caótica, mas cujas tensões e correntes estavam sincronizadas umas com as outras. Carroll e Pecora conseguiram então construir circuitos caóticos simples que claramente demonstravam o sincronismo do comportamento caótico.

\subsection{Tipos de sincronização de sistemas caóticos}

Um fato surpreendente sobre sistemas caóticos é sua susceptibilidade à sincronização. Neste trabalho de doutorado, foram aplicadas técnicas de sincronismo para o sistema proposto, as quais serão introduzidas a partir desta seção.

A classificação do tipo de sincronização é baseada na característica do mecanismo de acoplamento, seja ele unidimensional ou bidimensional. A sincronização estável com acoplamento externo tem sido chamada sincronização por uma força externa (por frequência de sincronização), ou sincronização mestre-escravo, como proposto por Pecora e Carroll [10]. Os tipos de sincronização mais difundidos na literatura são: sincronização de frequências, sincronização de fase, sincronização completa ou idêntica, sincronização de defasagem ou lag (do inglês, perna, ou seja, os sistema escravo está possui atraso de fase em relação ao mestre) e sincronização generalizada [27]-[30], os quais serão definidos a seguir. 


\subsection{Sincronização de osciladores regulares por frequência}

Neste tipo de sincronismo, observa-se a frequência dos circuitos. Se a trajetória é, na maioria das vezes, uma rotação em torno de um eixo quando as frequências medidas estão localizadas nos picos do espectro de potência associados com a rotação média do sinal, temse:

$$
\begin{aligned}
& \omega_{x}=g(x) \\
& \omega_{y}=g(y)
\end{aligned}
$$

Onde $\omega_{x}$ e $\omega_{y}$ são as frequências típicas de dois sistemas x e y, respectivamente.

A função observada é tipicamente:

$$
h[g(x), g(y)]=n_{x} \omega_{x}-n_{y} \omega_{y}
$$

Onde $n_{x}$ e $n_{y}$ são inteiros. Quando existe sincronismo, tem-se que

$$
n_{x} \omega_{x}-n_{y} \omega_{y}=0
$$

\subsection{Sincronização generalizada}

O regime de sincronização generalizada, introduzido para sistemas do tipo mestreescravo, é definido como a presença de alguma relação funcional entre os circuitos mestreescravo [1], [27],[28] como:

$$
x_{e}(t)=F\left[x_{m}(t)\right]
$$

Onde $x_{e}(t)$ é o estado do sistema mestre, e $x_{m}(t)$ é o estado do sistema escravo.

De acordo com as propriedades desta relação, a sincronização generalizada pode ser dividida em sincronização forte e fraca [30]. O sincronismo forte ocorre quando existe uma situação de grande interação entre as fases e amplitudes de osciladores, enquanto que a sincronização fraca ocorre quando essa interação começa a existir. A sincronização completa é um caso particular da sincronização forte.

Sejam dois osciladores caóticos acoplados unidirecionalmente: 


$$
\begin{aligned}
& \dot{x}_{m}=H\left(x_{m}, g_{m}\right) \\
& \dot{x}_{e}=G\left(x_{e}, g_{e}\right)+\varepsilon P\left(x_{m}, x_{e}\right)
\end{aligned}
$$

Onde $x_{m, e}$ são os vetores de estado dos circuitos mestre e escravo, respectivamente, e $\mathrm{H}$ e G definem os campos vetoriais destes sistemas, e $g_{m}$ e $g_{e}$ são vetores dos parâmetros de controle, neste caso específico, frequência e amplitude, $\mathrm{P}$ denota o termo de acoplamento, e $\varepsilon$ é o parâmetro escalar de acoplamento.

Sejam as dimensões dos sistemas mestre e escravo $N_{m}$ e $N_{e}$, o comportamento dos osciladores acoplados é caracterizado pelo espectro dos coeficientes de Lyapunov, tal que $\lambda_{1} \geq \lambda_{2} \geq \ldots . \geq \lambda_{N_{d}+N_{r}}$. Devido à independência do sistema mestre em relação ao escravo, tal espectro pode ser dividido em duas partes, o espectro do sistema mestre e o espectro do escravo. A condição para que ocorra a sincronização generalizada é que o coeficiente de Lyapunov do sistema escravo $\lambda_{1}^{e}<0$, como visto em [30].

A manifestação da sincronização generalizada é, na maioria das vezes, considerada para dois sistemas idênticos, com parâmetros iguais ou ligeiramente diferentes. No caso de sistemas idênticos, as dimensões dos sistemas mestre e escravo são iguais, tais que $N_{m}=N_{e}=N$, e a equação (13) pode ser reescrita como:

$$
\begin{aligned}
& \dot{x}_{m}=H\left(x_{m}, g_{m}\right) \\
& \dot{x}_{e}=H\left(x_{e}, g_{e}\right)+\varepsilon A\left(x_{m}-x_{e}\right)
\end{aligned}
$$

Onde $A=\left\{\delta_{i, j}\right\}$ é a matriz de acoplamento, e $\delta_{i i}=0$ ou 1 , e $\delta_{i j}=0$, se $i \neq j$. A dinâmica do sistema escravo pode ser considerada como a dinâmica do sistema não autônomo modificado, $\dot{x}_{\text {mod }}$, tal que: 


$$
\dot{x}_{\text {mod }}=H^{\prime}\left(x_{\text {mod }}, g_{e}, \mathcal{E}\right)
$$

Sob uma força externa $\varepsilon A x_{d}$;

$$
\dot{x}_{\text {mod }}=H^{\prime}\left(x_{\text {mod }}, g_{e}, \varepsilon\right)+\varepsilon A x_{m}
$$

Onde $H^{\prime}(x, g)=H(x, g)-\varepsilon A x_{m}$. O termo $-\varepsilon A x_{m}$ é a dissipação do sistema.

A sincronização generalizada aumenta, conforme a equação (13), enquanto o aumento do parâmetro $\mathcal{E}$ pode ser considerado o resultado de dois processos dissipativos ocorrendo simultaneamente, o aumento da dissipação do sistema e da amplitude do sinal externo.

Para o sistema modificado, a variável $\varepsilon$ é o parâmetro de acoplamento. Quando $\varepsilon$ é igual a zero, a dinâmica do sistema modificado coincide com o sistema escravo, $x_{e}(t)$ sem acoplamento. Com o aumento do parâmetro de acoplamento $\mathcal{E}$, a dinâmica do sistema modificado se torna mais simples, de forma que o sistema $x_{\text {mod }}(t)$ deve passar por uma transição de oscilações caóticas a periódicas, e talvez ao estágio estacionário, se a dissipação for grande o suficiente. Neste caso, um dos coeficientes de Lyapunov, $\lambda_{0}^{m}$ do sistema modificado é igual a zero, ou negativo, se o estado do sistema for estacionário, e todos os outros coeficientes de Lyapunov são negativos. O sinal externo na equação (13) tende a impor a dinâmica do oscilador caótico mestre, ao sistema modificado, tornando-a um pouco mais complexa. Então, a sincronização generalizada vai ocorrer somente se o estado $x_{\text {mod }}(t)$ for determinado completamente pelo sinal externo, tal que $x_{\text {mod }}(t)=F\left[x_{m}(t)\right]$, e a relação funcional entre os sistemas mestre e escravo $x_{e}(t)=F\left[x_{m}(t)\right]$ terá início, e então será observada a sincronização generalizada. O parâmetro de acoplamento $\varepsilon$ está relacionado com o tipo de sincronismo de acordo com o diagrama apresentado na Figura 4. 


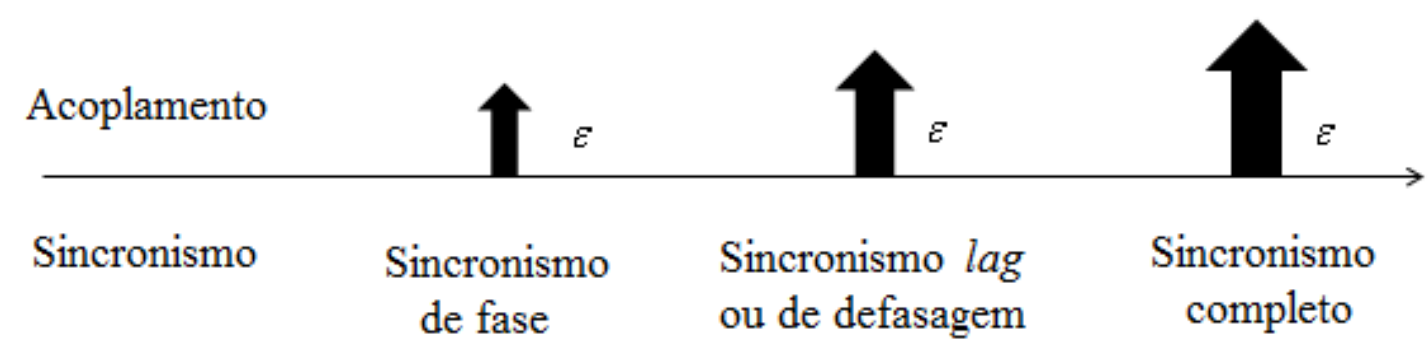

Figura 4- Diagrama relacionando o tipo de sincronismo com o acoplamento dos sistemas.

Conforme o parâmetro do acoplamento aumenta, o sincronismo exibido pelo sistema caótico passa pelos regimes do sincronismo de fase, lag, e completo, os quais serão explicados a seguir.

\subsubsection{Sincronização fraca e forte}

A condição para que haja sincronização entre um estado $\dot{x}_{e}(t)$ e $\dot{x}_{m}(t)$ é dada pela equação do sistema escravo:

$$
\frac{d x_{e}}{d t}=\delta x_{e} \frac{\partial}{\partial x_{e}}\left\{G\left(x_{e}, g_{e}\right)+\varepsilon A\left(x_{m}, x_{e}\right)\right\}
$$

Para $\mathrm{n}$ coeficientes de Lyapunov condicionais $\lambda_{j}^{n}$, com $j=1,2, \ldots, n$. Seja um sistema discreto no tempo, que apresenta dois mapas idênticos acoplados, tal que :

$$
\begin{gathered}
x(i+1)=f\left(x_{i}\right) \\
y(i+1)=f(y(i))+\varepsilon\{f(x(i))-f(y(i))\}
\end{gathered}
$$

Com o mapa de auxiliar de resposta:

$$
y^{\prime}(i+1)=f\left(y^{\prime}(i)\right)+\varepsilon\left\{f\left(x^{\prime}(i)\right)-f\left(y^{\prime}(i)\right)\right\}
$$


Para cada parâmetro de acoplamento $\varepsilon$, as equações (19) e (20) tem parâmetros invariantes $y=x$, desde que se admita a sincronização convencional ou completa, onde ocorre a coincidência entre os estados dos circuitos idênticos, caracterizado por um hiperplano no espaço de fase do mesmo. A sincronização fraca é observada sempre em sistemas idênticos, e precede a sincronização forte [30]. O limiar entre a sincronização fraca e forte é determinado pelos coeficientes de Lyapunov condicionais, tal que:

$$
\lambda_{n}=\ln (1-\varepsilon)+\lim _{n \rightarrow \infty} \frac{1}{n} \sum_{i=1}^{n}\left|\ln \left(f^{\prime}(y(i))\right)\right|
$$

Definindo o coeficiente de Lyapunov da distribuição invariante $x=y$, tem-se que:

$$
\lambda_{0}=\ln (1-\varepsilon)+\lim _{n \rightarrow \infty} \frac{1}{n} \sum_{i=1}^{n}\left|\ln \left(f^{\prime}(x(i))\right)\right|
$$

A dependência destes coeficientes em relação a $\varepsilon$ ocorre de forma que $\lambda_{n}$ se torna nulo para valores de parâmetro de acoplamento $\varepsilon_{\omega}$ e $\varepsilon_{s}$, referentes aos níveis de acoplamento fraco e forte, respectivamente. Para valores de $\varepsilon>\varepsilon_{s}$, os coeficientes coincidem, tal que $\lambda_{0}(n)=\lambda_{n}(\varepsilon)$.

\subsection{Sincronização de fase}

A interação entre dois osciladores caóticos autônomos não idênticos pode levar a uma interação entre suas dinâmicas, onde suas amplitudes permanecem caóticas e não correlacionadas [1]. É necessário determinar, neste caso, a fase e a amplitude de um sinal arbitrário $s(t)$. Segundo Rosenblum et al. [29], seja um sinal analítico:

$$
\Psi(t)=s(t)+j \widetilde{s}(t)=A(t) e^{i \phi(t)}
$$


Onde a função $\tilde{s}(t)$ é dada por :

$$
\tilde{s}(t)=\frac{1}{\pi} P \cdot V \int_{\infty}^{\infty} \frac{s(\tau)}{t-\tau} d \tau
$$

Onde P.V. é a integral do teorema de valor principal de Cauchy, e $\tau$ é o tempo característico.

A amplitude instantânea $A(t)$ e a fase instantânea $\phi(t)$ do sinal $s(t)$ são determinadas a partir da equação (24). Da equação (25), a transformada $\tilde{s}(t)$ de $s(t)$ pode ser considerada a convolução das funções $s(t)$ e $\frac{1}{\pi t}$. Para as frequências mais relevantes, tem-se que $\omega>0$, e $\tilde{S}(j \omega)=-j S(j \omega)$. Pode-se obter $\tilde{S}(t)$ a partir de $s(t)$ utilizando um filtro cuja amplitude de resposta é unitária, e cuja resposta de fase é defasada de $\frac{\pi}{2}$. Para osciladores caóticos pode-se calcular a fase tomando $s(t)$ como um observável qualquer.

\subsection{Sincronização completa ou convencional}

A sincronização completa implica na coincidência de estados de sistemas idênticos que interagem entre si [28], tal que:

$$
x_{m}(t)=x_{e}(t)
$$

Este tipo de sincronização aparece apenas em sistemas que apresentam parâmetros idênticos, e é um caso particular do sincronismo generalizado [1]. Em alguns casos, quando os parâmetros diferem ligeiramente, os estados são próximos, mas permanecem diferentes [1], tal que:

$$
\left|x_{m}(t)-x_{e}(t)\right| \approx 0
$$




\subsection{Sincronização de atraso ou lag}

Para osciladores não idênticos acoplados, conforme aumenta o parâmetro de acoplamento $\mathcal{E}$, ocorre primeiramente a transição de um estado assíncrono para um sincronismo de fase [27], [29]. Para acoplamentos maiores, ocorre a transição para um sincronismo de atraso de fase ou lag, onde os estados dos sistemas mestre e escravo coincidem, porém deslocados no tempo, obedecendo à relação [27]:

$$
x_{e}\left(t+\tau_{0}\right) \approx x_{m}(t)
$$

Este tipo de sincronismo é também um caso particular do sincronismo generalizado [1].

\subsection{Sincronização por realimentação de erro}

O objetivo desta técnica é estimar um sinal escalar de saída $g(t)$ dada uma observação de um sinal ruidoso $r(t)$. Este tipo de sincronização de erro utiliza a diferença instantânea entre a estimação de $g(t)$, dada por $\hat{g}(t)$ e o sinal recebido $r(t)$, produzindo um sinal de erro $e(t)$, o qual modifica o estado do receptor a fim de minimizar o erro [10], [11], [13].

O sistema sincronizável por realimentação de erro tem estrutura como mostra o diagrama de blocos da Figura 5.

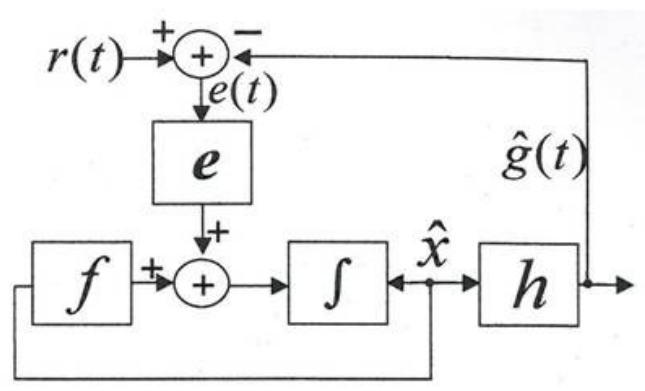

Figura 5 - Diagrama de blocos do esquema de sincronização por realimentação de erro. 


\subsection{Sistemas de comunicação caótica}

Neste trabalho, foi utilizado um circuito caótico que emula o comportamento de uma partícula numa caixa, o qual é descrito no capítulo 3. O comportamento caótico do circuito foi analisado por meio de um esquema mestre-escravo, em diferentes configurações.

A observação de Pecora e Carroll de que dois sistemas caóticos podem ser sincronizados gerou um enorme interesse na transmissão de informação usando sinais caóticos [10],[11]. A maioria das aplicações comerciais de comunicações, como telefonia celular, rádio e outras, estão suscetíveis a efeitos de propagação multicaminho que surgem da interação de sinais no receptor que viajam ao longo de diferentes caminhos de propagação. A modulação caótica oferece soluções potencialmente simples para sistemas de comunicação banda larga [31].

Pesquisadores em laboratórios militares têm explorado o controle do caos utilizando pequenas perturbações para fazer circuitos caóticos seguirem sequências de sinais prescritos [4],[32]. Por meio da exploração de osciladores elétricos não lineares, o sistema pode produzir uma sequência aleatória de picos positivos e negativos. Assumindo que um pico positivo represente o valor 1 e um pico negativo represente o valor 0 , o sinal leva a uma sequência binária. Hayes [32] utiliza uma sequência de método de controle do caos para que um sinal siga uma órbita cuja sequência binária representa a informação que se deseja codificar. Por exemplo, uma letra do alfabeto seria representada por uma sequência binária. O sinal transmitido é então detectado e decodificado.

\subsection{Codificação}

É possível utilizar o caos para a comunicação de mensagens codificadas. A técnica consiste em tomar uma tensão caótica de um sinal original, adicionar o sinal referente à informação a ser transmitida e enviá-la para um receptor sincronizado ao primeiro circuito. $\mathrm{O}$ receptor pode subtrair o sinal caótico e recuperar a informação. Felizmente, qualquer indivíduo que interceptar o sinal, verá somente um ruído, um sinal caótico. Este tipo de comunicação foi desenvolvido por Neff e Carroll [33]. Apesar de a comunicação segura 
utilizando o caos ser mais sofisticada do que adicionar o sinal a ser transmitido a um sinal caótico, este é o princípio básico deste tipo de comunicação.

Chua et al. construíram circuitos analógicos sincronizados de captura de fase ou PLL (Phase-Locked Loop)[31], sistemas onde o sinal de realimentação é usado para sincronizar a frequência instantânea do sinal de saída com a frequência instantânea do sinal de entrada.

Pecora continuou a explorar circuitos caóticos utilizando a ideia de que um componente de malha de captura de fase em um circuito permite que o receptor siga a mudança de frequência de um sinal de entrada. Este componente é o que permite o funcionamento de um rádio FM por exemplo. A frequência é somente um parâmetro em um sistema dinâmico, neste caso um sistema cíclico. Pecora trabalhou utilizando uma cascata de circuitos sincronizados para construir sistemas caóticos que seguem a mudança de parâmetro de um transmissor análogo ao circuito malha de captura de fase [10]. O processo se inicia com um sistema caótico composto de no mínimo dois circuitos estáveis. Os dois circuitos operam em cascata, de maneira que o primeiro alimenta o segundo, que é uma réplica de uma parte do sistema original onde o sinal sincronizado é produzido. Ambos os sistemas sincronizar-se-ão, então o segundo subsistema irá duplicar o sinal de entrada, assumindo que todos os parâmetros do sistema sejam os mesmos. Os parâmetros são variáveis dinâmicas do sistema que usualmente não mudam com o tempo. Entretanto, ao mudar um parâmetro do sistema original, os circuitos podem ligeiramente sair de sincronização com o sinal original. A detecção deste efeito permite ajustar os parâmetros no receptor correspondentes aos do sistema original, então eles tomam a saída do segundo subsistema como a entrada do sistema principal. Esta característica pode assegurar uma maneira de enviar sinais codificados para permitir a transição de informação, em termos das variações de parâmetros de sinais banda larga, os quais são mais resistentes a ruídos e interferências. Desde que permita um receptor identificar um parâmetro oculto em um sistema remoto de envio, esta característica pode ser útil em identificar sinais. Dentro deste contexto, a comunicação caótica tem sido objeto de estudo de vários grupos de pesquisa [34]. 


\section{Capítulo 4}

\section{Introdução}

Neste capítulo serão introduzidos alguns conceitos necessários para a compreensão e desenvolvimento do trabalho.

\subsection{Metodologia}

A implementação elétrica de circuitos caóticos tem sido objeto de estudo deste grupo de pesquisa [12],[13] sendo encontrados outros trabalhos recentes na literatura [6],[7],[36]. Entretanto, a maioria dos trabalhos da área concentra-se em simulações numéricas do comportamento de sistemas caóticos. Foi realizada neste trabalho a implementação elétrica do circuito caótico partícula numa caixa, um circuito relativamente simples, se comparado com outros trabalhos na literatura [6], [7],[36]. O circuito é descrito nesta seção.

\subsubsection{Circuito caótico partícula numa caixa}

O circuito eletrônico partícula numa caixa é assim descrito, por apresentar um comportamento análogo ao sistema mecânico, conforme pode ser visto na Figura 6.

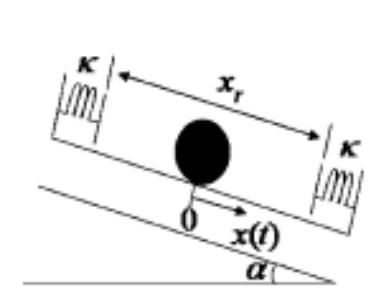

(a)

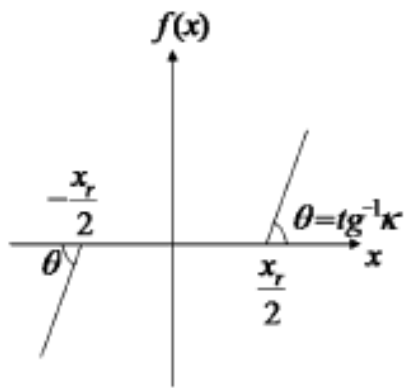

(b)

Figura 6 - (a) Partícula na caixa oscilando. (b) Força aplicada pelas molas. 
No sistema, a partícula com massa $m$ pode colidir com a com as paredes da caixa, na direção $x$. As paredes são apoiadas pelas molas lineares de coeficiente $\kappa$, e as colisões entre a partícula e a caixa são totalmente inelásticas. As paredes e as molas não possuem massa nem dimensão. O termo $x_{r}$ é a distância entre as paredes. É possível fazer a caixa oscilar variando o ângulo $\alpha$. O ângulo $\theta$ representa $t^{-1}(\kappa)$.

Neste modelo, são desprezados o comprimento e a massa das paredes e das molas, e a força viscosa que atua contra o movimento da partícula, resultando na equação diferencial (29).

$$
m \frac{d^{2} x}{d t^{2}}+\mu \frac{d x}{d t}+f(x)=m g \operatorname{sen} \alpha(t)
$$

Nesta equação, $\mu$ representa o coeficiente viscoso, e o termo $f(x)$ representa a força aplicada pelas molas. A Figura 6 (b) mostra as características desta força. O ângulo $\theta$ representa o termo $\operatorname{tg}^{-1} \kappa$, e o termo $m g \operatorname{sen} \alpha$ descreve a força externa atuando na partícula devido à aceleração gravitacional $g$. É possível fazer a caixa oscilar variando o ângulo $\alpha$. Dependendo dos parâmetros dados pela equação (29), a partícula dentro da caixa exibe oscilação periódica com período T, passando pelo período $2 \mathrm{~T}$ e 4T, uma oscilação caótica não periódica. Para analisar o modelo proposto, na Figura 7 é apresentado um diagrama da simulação numérica do modelo partícula na caixa. 


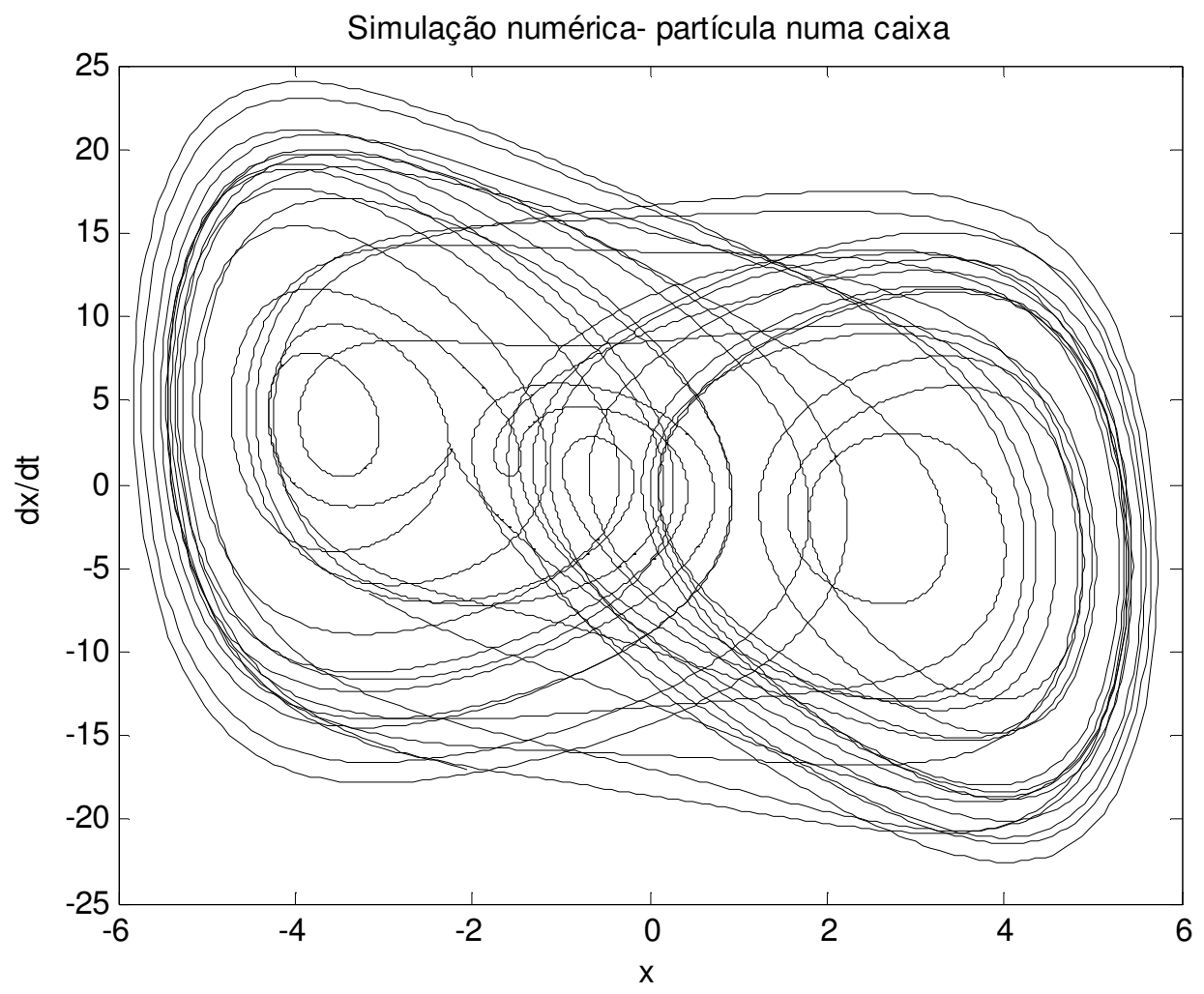

Figura 7 - Simulação numérica da oscilação caótica da partícula numa caixa para o modelo mecânico proposto.

Baseado neste modelo mecânico, foi proposto primeiramente por Neto [37] um sistema eletrônico que emula o comportamento do choque da partícula com as paredes da caixa, quando a mesma oscila de um ângulo $\alpha(t)$. O diagrama esquemático do circuito eletrônico partícula na caixa é mostrado na Figura 8 a seguir. 


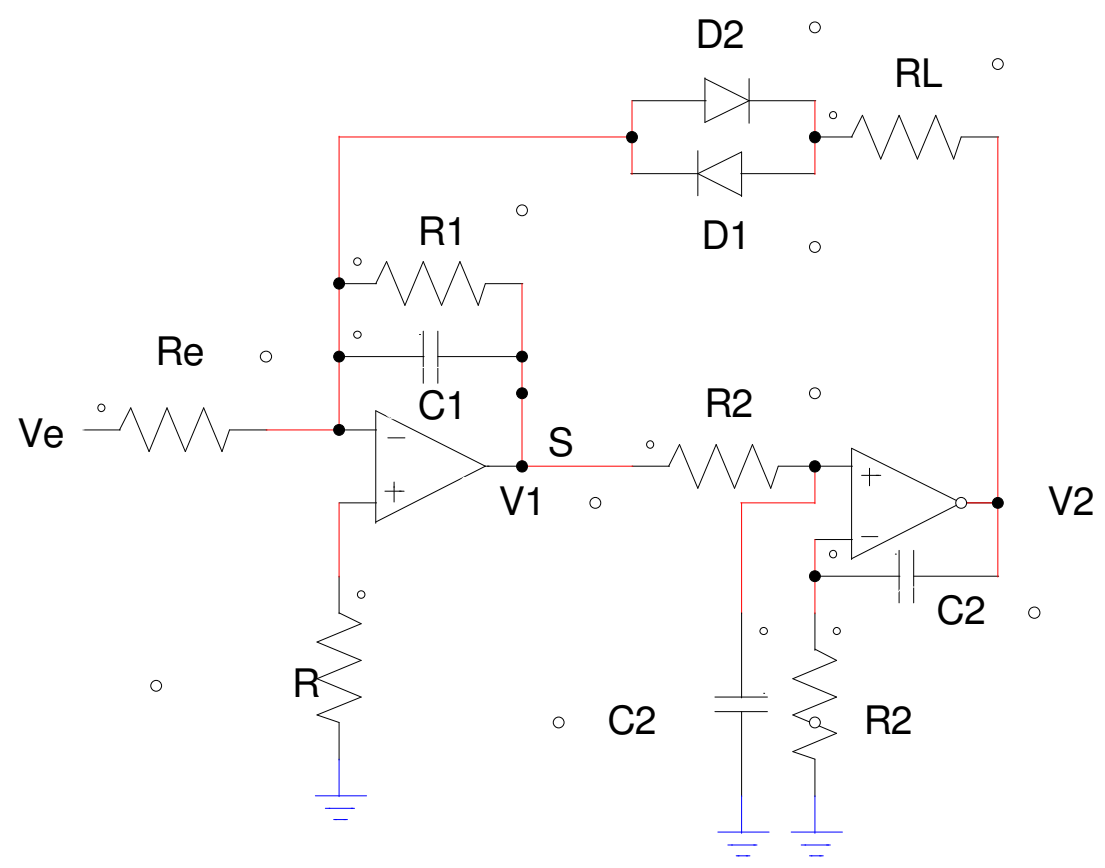

Figura 8 - Diagrama esquemático do circuito eletrônico partícula na caixa, descrito pela equação (33). Os valores dos componentes são: resistores $(k \Omega)$ : $R_{1}=47 ; R=R_{e}=R_{2}=10 ; R_{L}=0,51 ;$ capacitores $(n F): C_{1}=C_{2}=12 ; \operatorname{diodos} D_{1}$ e $D_{2}$ : N4148; amplificadores operacionais 741 ou equivalentes.

O circuito eletrônico partícula numa caixa tem um sinal de entrada senoidal $V_{e}=V_{\max } \operatorname{sen}(\omega t)$, e a contribuição de corrente no ponto $\mathrm{S}$, pela Lei dos nós e Lei das Malhas resulta na equação diferencial (30).

$$
R_{2} C_{1} C_{2} \frac{d^{2} V_{2}}{d t^{2}}+\frac{R_{2} C_{2}}{R_{1}} \frac{d V_{2}}{d t}+I_{D}\left(V_{2}\right)=-\frac{V_{e}}{R_{e}}
$$

Na equação (30), o sinal $V_{2}$ corresponde à posição x descrita na Figura 6, e o sinal $\frac{d V_{2}}{d t}$ corresponde à velocidade $\frac{d x}{d t}$. Os valores dos componentes são: resistores $(k \Omega)$ : $R_{1}=47 ; R=R_{e}=R_{2}=10 ; R_{L}=0,51$; capacitores $(n F): C_{1}=C_{2}=12 ; \operatorname{diodos} D_{1}$ e $D_{2}$ : N4148; amplificadores operacionais 741 ou equivalentes. Todos os componentes utilizados apresentam um erro de $\pm 10 \%$ em seus valores nominais. 
Na Figura 9 é apresentada a simulação numérica do circuito partícula numa caixa proposto.

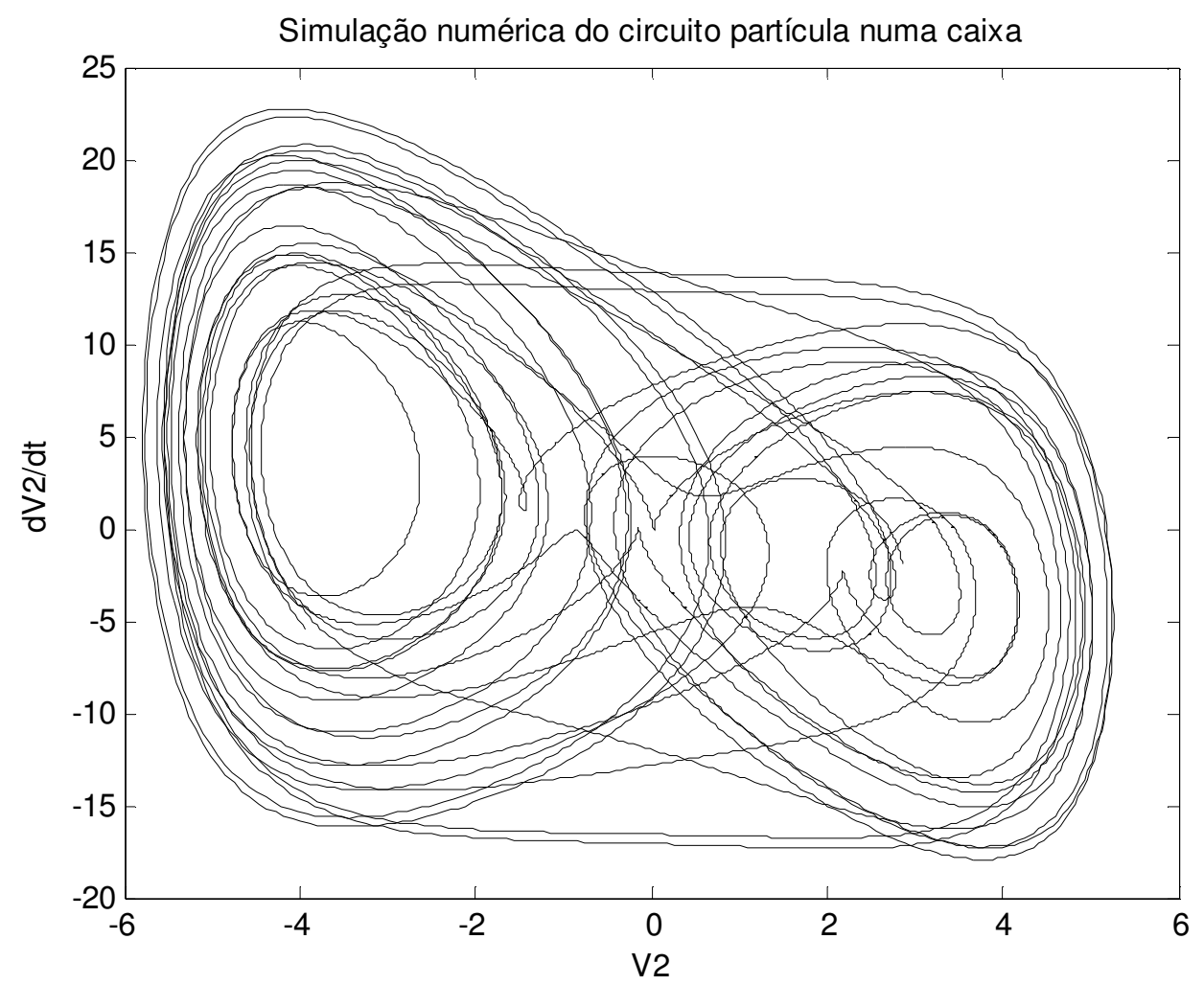

Figura 9 - Resultado da simulação numérica para a equação do circuito partícula numa caixa.

Nota-se a semelhança na dinâmica dos resultados das simulações numéricas do modelo mecânico partícula numa caixa e de seu análogo elétrico, o circuito eletrônico partícula numa caixa. O sinal $V_{2}$ corresponde à posição x descrita na Figura 6 , e o sinal $\frac{d V_{2}}{d t}$ corresponde à velocidade $\frac{d x}{d t}$

O circuito eletrônico simula o comportamento mecânico do sistema da Figura 6(a). Este circuito permite uma simulação eletrônica robusta e simples do comportamento mecânico das colisões da partícula dentro da caixa, exibindo um comportamento caótico. Os dispositivos chave deste circuito são os diodos antiparalelos $D_{1}$ e $D_{2}$ em associação com o resistor $R_{L}$. Eles simulam as colisões com a parede e a não linearidade deste circuito. A associação destes 
dispositivos simula a colisão da partícula nas paredes na direção $\mathrm{x}$, resultando no termo não linear $I_{D}\left(V_{2}\right)$. Na Figura 10 é apresentada a curva ajustada da corrente do diodo N4148 antiparalelo associado com uma resistência $\mathrm{R}_{\mathrm{L}}$ em série, em função da tensão de saída do segundo amplificador operacional $\left(\mathrm{V}_{2}\right)$.

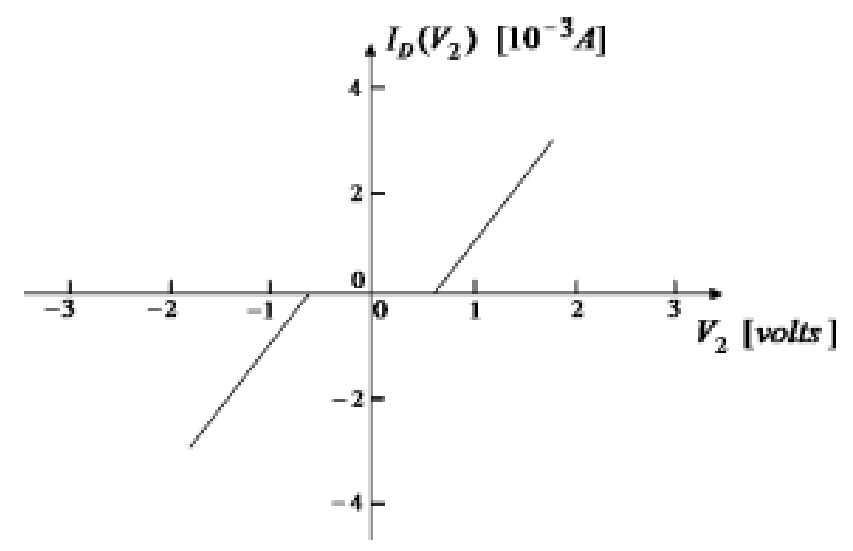

Figura 10 - Curva de tensão versus corrente em relação à tensão de saída do segundo amplificador operacional $\left(\mathrm{V}_{2}\right)$.

\subsubsection{Implementação elétrica de sistemas de sincronização}

Tendo em vista o estudo do comportamento de sistemas caóticos do ponto de vista experimental, foi implementado um sistema eletrônico, idêntico ao apresentado na Figura 8.

Posteriormente foi feita a montagem de um sistema composto de dois circuitos idênticos partícula numa caixa, conectados através de uma malha de realimentação, utilizando uma resistência de realimentação $R_{R E}=100 \mathrm{k} \Omega$, com a finalidade de reduzir a sensibilidade do sistema devido à perturbações externas. O diagrama de blocos desta montagem experimental é apresentado na Figura 11. 


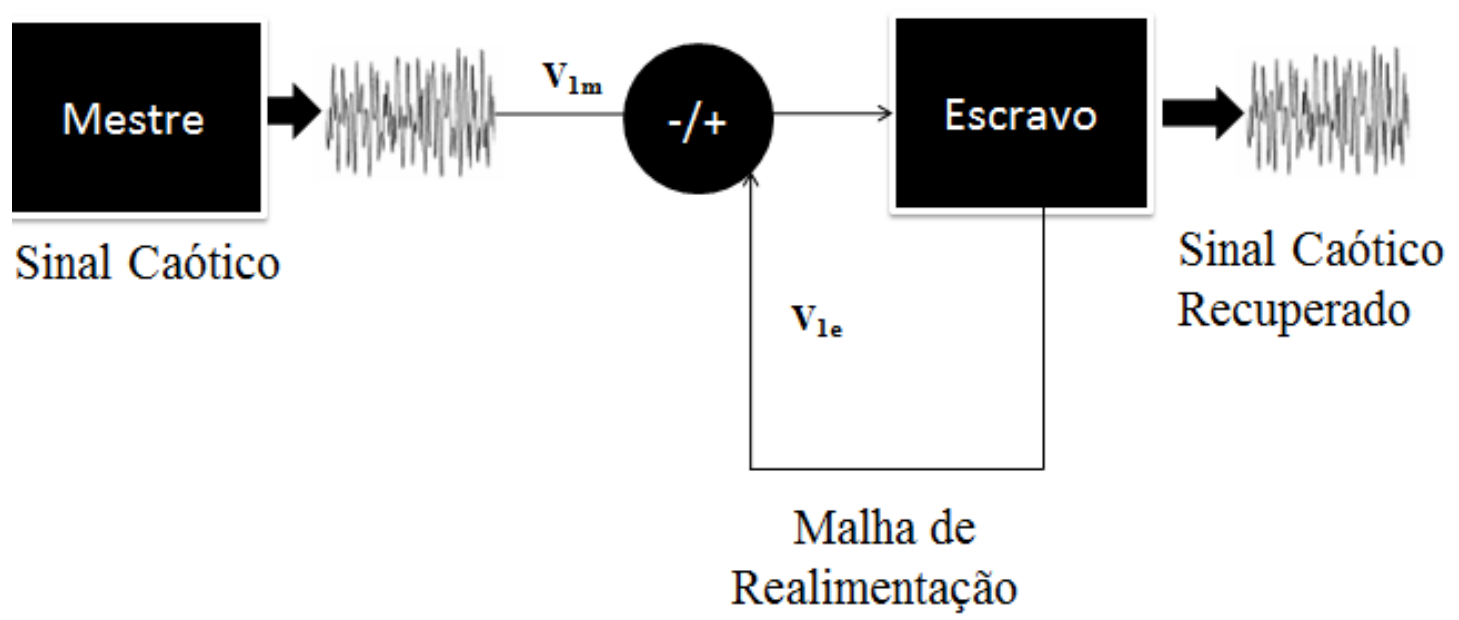

Figura 11 - Diagrama de blocos da montagem experimental de dois circuitos partícula numa caixa idênticos, apresentados em uma configuração mestre-escravo.

O diagrama esquemático com os componentes da montagem experimental é apresentado na Figura 12.

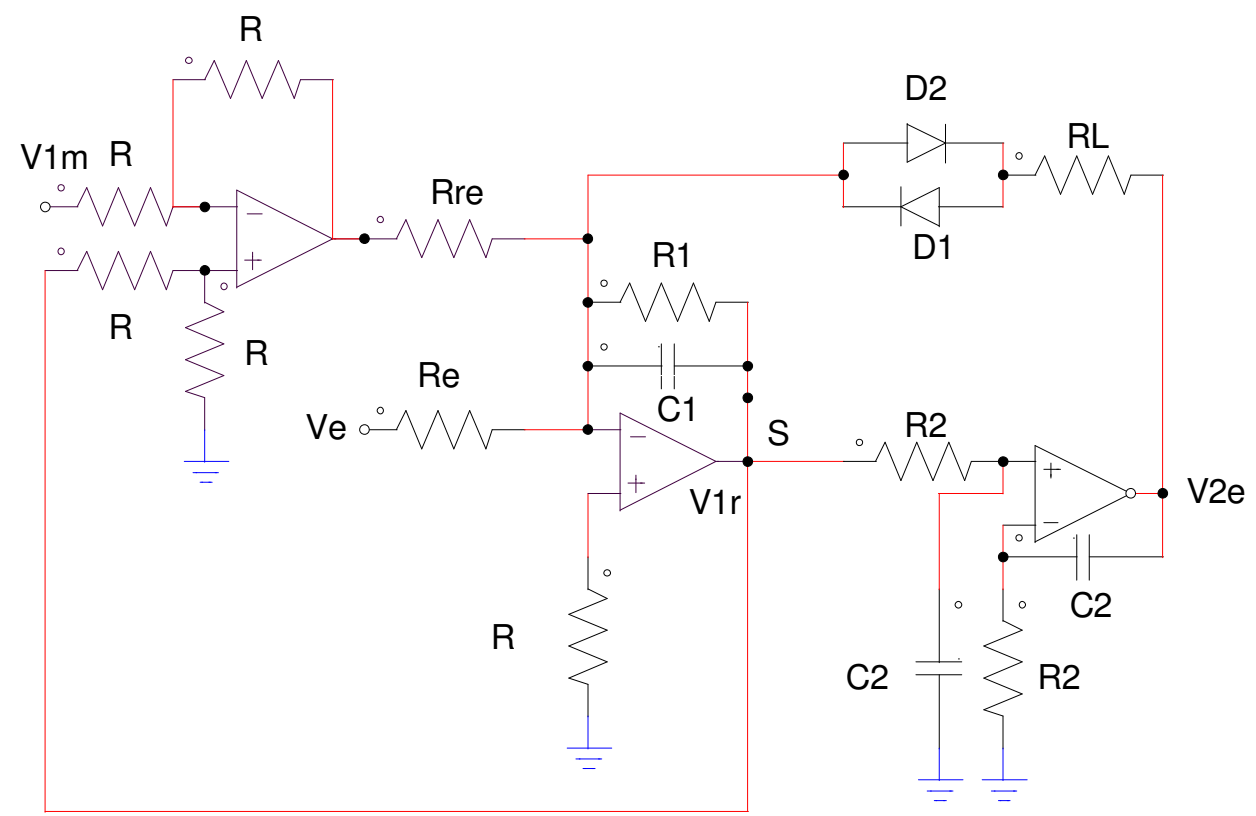

Figura 12 - Malha de realimentação do circuito eletrônico partícula na caixa 
Nesta configuração mestre-escravo, $V_{1 m}$ corresponde à tensão de saída do primeiro amplificador do sistema mestre e $V_{2 e}$ corresponde à tensão de saída do segundo amplificador do circuito escravo.

A técnica de Pecora Carrol aplicada à equação (30) resulta na decomposição em dois circuitos. As equações para o circuito mestre são:

$$
\begin{gathered}
\frac{d V_{1 m}}{d t}=-\frac{V_{1 m}}{R_{1} C_{1}}-I_{d} \frac{V_{2 m}}{C_{1}}-\frac{V_{e m}}{C_{1} R_{e}} \\
\frac{d V_{2 m}}{d t}=\frac{V_{1 m}}{R_{2} C_{2}}
\end{gathered}
$$

Onde $V_{1 m}$ é a tensão de saída do primeiro amplificador do circuito mestre, $V_{2 m}$ é a tensão de saída do segundo amplificador do circuito mestre e $V_{e m}$ é a tensão de entrada senoidal do circuito mestre.

Da mesma forma, as equações para o circuito escravo são:

$$
\begin{gathered}
\frac{d V_{1 e}}{d t}=-\frac{V_{1 e}}{R_{1} C_{1}}-I_{d} \frac{V_{2 e}}{C_{1}}-\frac{V_{e e}}{C_{1} R_{e}}+\varepsilon\left(V_{1 d}-V_{1 R}\right) \\
\frac{d V_{2 e}}{d t}=\frac{V_{1 e}}{R_{2} C_{2}}
\end{gathered}
$$

Onde $V_{1 e}$ é a tensão de saída do primeiro amplificador do circuito escravo, $V_{2 e}$ é a tensão de saída do segundo amplificador do circuito escravo e $V_{e e}$ é a tensão de entrada senoidal do circuito escravo. 
A montagem do sistema composto de dois circuitos partícula numa caixa, em uma configuração mestre escravo, os quais se comunicam através de um esquema malha fechada de realimentação apresentado na Figura 12, é semelhante ao descrito por Pecora [10].

O sistema foi testado utilizando-se uma configuração proposta conforme fotografia mostrada na Figura 13, composta de dois osciloscópios, um analógico, e outro digital da marca Minipa ${ }^{\circledR}(a)$ e (f), dois geradores de função da marca Minipa ${ }^{\circledR} 2 \mathrm{MHz}$ (b) e (e), duas fontes digitais marca Minipa ${ }^{\circledR}$,(c) e (d) modelo MPL 3303, para garantir que os sinais de entrada senoidal dos circuitos mestre e escravo não estivessem necessariamente em fase. Posteriormente, os dados foram transferidos para um computador, via cabo USB. Então as informações foram armazenadas. A Figura 13 mostra uma fotografia da montagem experimental para aquisição de dados do sistema.

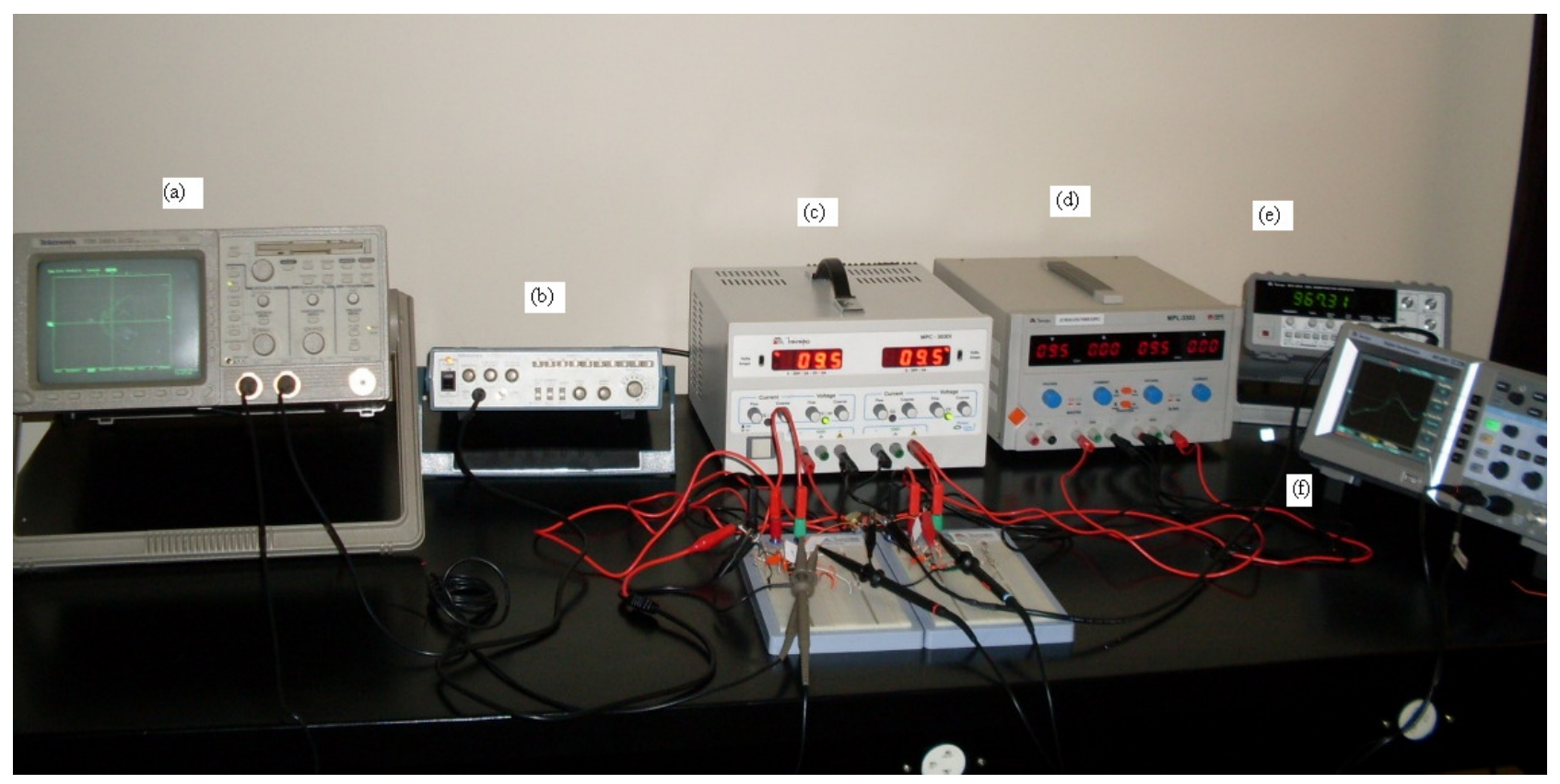

Figura 13 - Montagem experimental para aquisição de dados da implementação elétrica do sistema composto por dois circuitos idênticos partícula numa caixa.

Para aumentar a topologia do sistema composto de circuitos partícula numa caixa idênticos, foi proposta uma configuração composta de dois pares de circuitos mestre e escravo casados dois a dois, sendo que os pares diferiam apenas pelo valor da resistência $\mathrm{R}_{1}$.

A Figura 14 apresenta o diagrama de blocos desta configuração. 


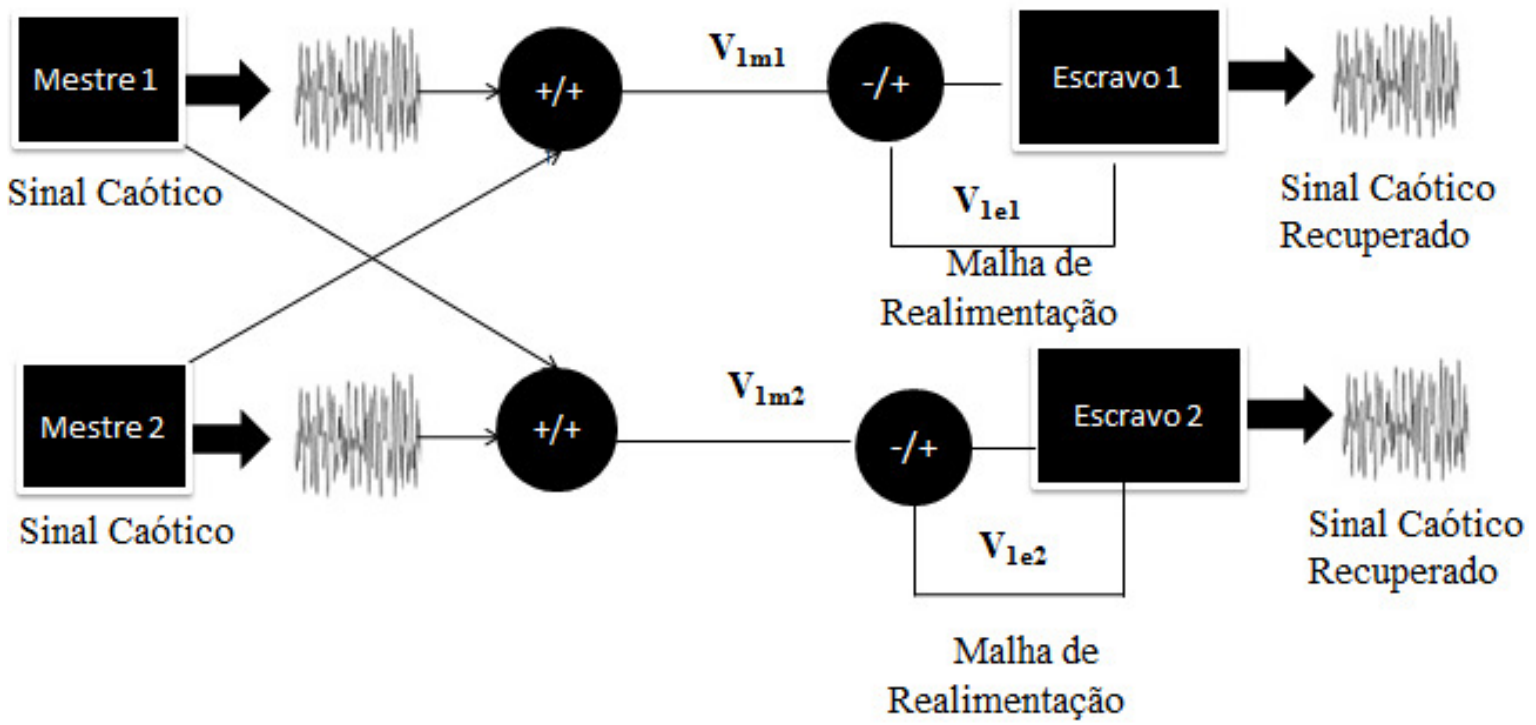

Figura 14 - Diagrama de blocos da montagem de dois circuitos partícula numa caixa idênticos.

Posteriormente, em analogia com um sistema multiusuário, foram montados três pares de circuito mestre/escravo casados dois a dois, cujos valores da resistência $\mathrm{R}_{1}$ diferiam entre si.

\subsubsection{Linhas de transmissão modelo $T$}

Uma maneira de transmitir informação ou potência é utilizar estruturas de guiamento, que orientam a propagação de energia de uma fonte a uma carga, tais como guias de onda ou linhas de transmissão [35]. As linhas de transmissão são utilizadas na área de telecomunicações em altas frequências. Existem vários modelos de linhas de transmissão, dentre elas o modelo $\mathrm{T}$. 
Na Figura 15 é visto um diagrama da configuração de uma linha de transmissão modelo T.

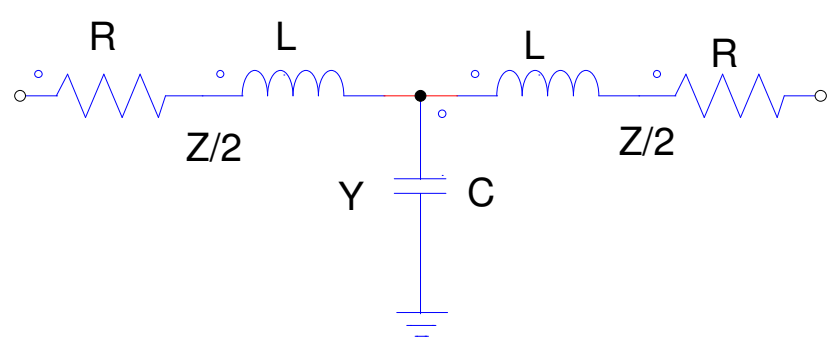

Figura 15 - Linha de transmissão modelo T.

As equações da linha de transmissão modelo T proposta são:

$$
\begin{aligned}
& \frac{\dot{Z}}{2}=\frac{R}{2}+\frac{j \omega L}{2} \\
& \dot{Y}=-j \omega C
\end{aligned}
$$

Onde $\dot{Z}$ é a derivada da impedância da linha de transmissão, e $\dot{Y}$ é a derivada de sua admitância, R é a resistência, L é a indutância, C é a capacitância e $\omega$ é a frequência da linha de transmissão.

Para testar a robustez do acoplamento do circuito elétrico partícula na caixa, foram estudadas configurações do sistema transmissor receptor, acoplado a uma linha de transmissão modelo T, a fim de verificar a transmissão de informação através de um canal, para distâncias equivalentes a $100 \mathrm{~m}, 1 \mathrm{~km}, 10 \mathrm{~km}$.

Foram utilizados valores dos elementos resistor, capacitor e indutor, de tal forma a emular o comportamento de linhas de transmissão T equivalentes a $100 \mathrm{~m}, 1 \mathrm{~km}$ e $10 \mathrm{~km}$. Como o valor da resistência é em média $\frac{R}{2}=\frac{6,5 \Omega}{1.000 m}$, a indutância cerca de $L=0,2 \frac{\mu H}{m}$, e a capacitância $C=79,4 \frac{p F}{m}$. Os valores nominais de resistência, indutância e capacitância 
calculados para as linhas de transmissão equivalentes a 100m, 1km e 10 km são apresentados na Tabela 1.

Tabela 1. Valores calculados para os elementos das linhas de transmissão modelo T para as distâncias de $100 \mathrm{~m}, 1 \mathrm{~km}$, e $10 \mathrm{~km}$.

\begin{tabular}{|c|c|c|c|}
\hline Distância & Resistência (R/2) & Indutância(L) & Capacitância(C) \\
\hline $100 \mathrm{~m}$ & $0,325 \Omega$ & $10 \mu \mathrm{H}$ & $7,94 \mathrm{nF}$ \\
\hline $1 \mathrm{~km}$ & $3,25 \Omega$ & $100 \mu \mathrm{H}$ & $79,4 \mathrm{nF}$ \\
\hline $10 \mathrm{~km}$ & $32,5 \Omega$ & $1000 \mu \mathrm{H}$ & $794 \mathrm{nF}$ \\
\hline
\end{tabular}

Os valores calculados para os componentes foram substituídos na montagem experimental foram substituídos por elementos de valores mais próximos possíveis, de acordo com os elementos disponíveis comercialmente, conforme apresentado na Tabela 2.

Tabela 2. Valores utilizados para os elementos das linhas de transmissão modelo T para as distâncias de $100 \mathrm{~m}, 1 \mathrm{~km}$, e $10 \mathrm{~km}$.

\begin{tabular}{|c|c|c|c|}
\hline Distância & Resistência (R/2) & Indutância(L) & Capacitância(C) \\
\hline $100 \mathrm{~m}$ & $0,33 \Omega$ & $10 \mu \mathrm{H}$ & $6,85 \mathrm{nF}$ \\
\hline $1 \mathrm{~km}$ & $3,33 \Omega$ & $100 \mu \mathrm{H}$ & $68,5 \mathrm{nF}$ \\
\hline $10 \mathrm{~km}$ & $33,3 \Omega$ & $1000 \mu \mathrm{H}$ & $685 \mathrm{nF}$ \\
\hline
\end{tabular}

A fim de verificar a robustez do acoplamento do circuito elétrico partícula na caixa, foram estudadas configurações do sistema transmissor receptor, acoplado a uma linha de transmissão modelo $\mathrm{T}$, analisando a transmissão de informação através de um canal, para distâncias equivalentes a 100m, $1 \mathrm{~km}, 10 \mathrm{~km}$, conforme o diagrama de blocos apresentado na Figura 16. 


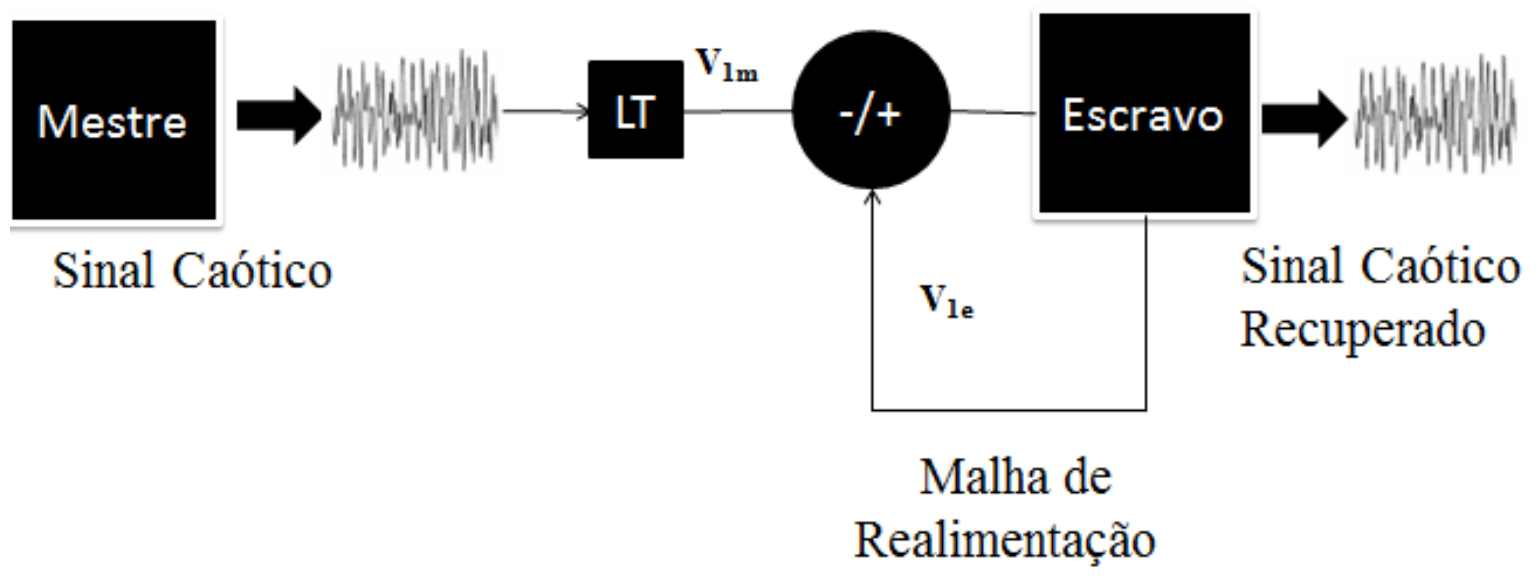

Figura 16 - Diagrama de blocos emulando a transmissão de informação através de um canal utilizando-se linhas de transmição modelo T. 


\section{Capítulo 5}

\section{Introdução}

Neste capítulo são apresentados os resultados experimentais e das simulações numéricas do sistema proposto, realizadas com auxilio do software Matlab®, empregando-se o método trapezoidal (vide Apêndice A).

\section{Resultados experimentais e simulações numéricas}

\subsection{Resultados para um único circuito partícula numa caixa}

Os resultados experimentais das medidas de um único circuito partícula numa caixa são apresentados primeiramente nesta seção, e posteriormente os resultados referentes às outras configurações. O comportamento caótico periódico do sistema pode ser obtido pela variação do parâmetro de bifurcação, que controla o circuito.

A quebra de simetria do sistema começa a ocorrer com a variação de frequência do sinal de entrada senoidal $V_{e}=V_{\max } \sin (\omega t)$, quando sua dinâmica passa por um ponto de estabilidade. Este comportamento foi observado para o circuito eletrônico partícula numa caixa, conforme resultados apresentados na Figura 17.

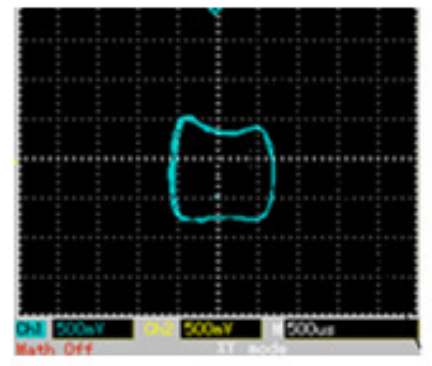

(a)

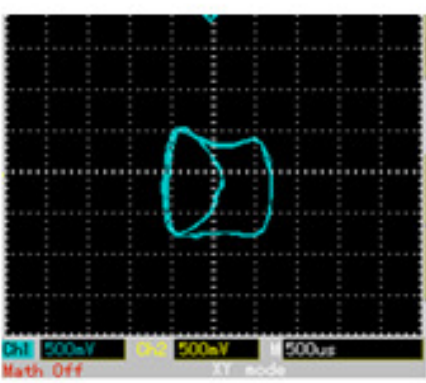

(b)

Figura 17 - (a)Quebra de simetria do espaço de fase do circuito eletrônico partícula numa caixa para uma frequência $\mathrm{f}=950 \mathrm{~Hz}$; (b) início da bifurcação do atrator do circuito eletrônico partícula numa caixa, frequência f $=958 \mathrm{~Hz}$. 
A variação do parâmetro frequência do sinal de entrada senoidal $V_{e}=V_{\max } \sin (\omega t)$ foi utilizada como parâmetro de bifurcação. Conforme foi aumentada a frequência do sinal de entrada, foram observadas sucessivas bifurcações de Hopf, de período $1(\mathrm{f}=958 \mathrm{~Hz}$ ); período 2 (f=963 Hz); período $4(\mathrm{f}=965 \mathrm{~Hz})$, até o comportamento1096 Hz do sistema passar por uma transição para o regime caótico. Estes resultados são apresentados nos diagramas de fase da Figura 18.

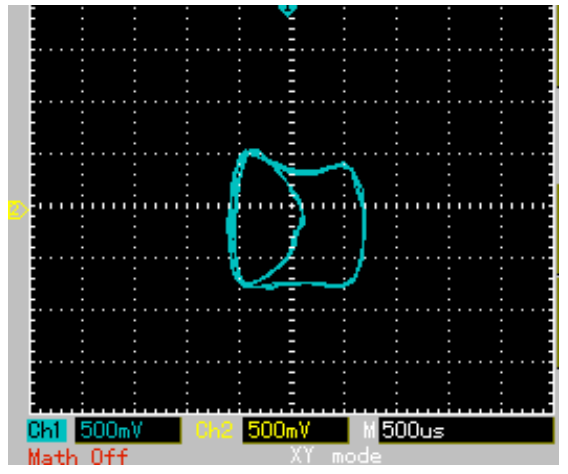

(a)

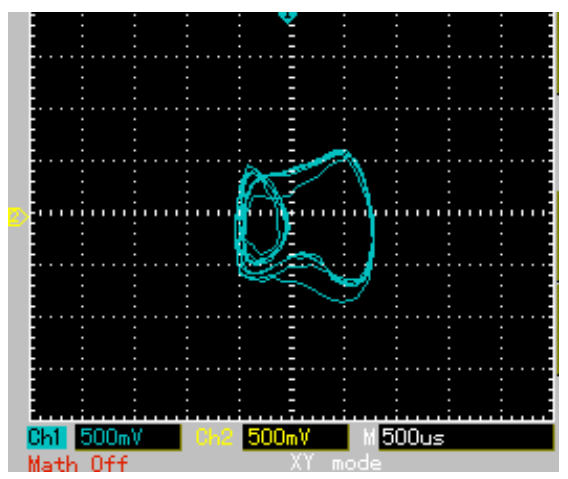

(c)

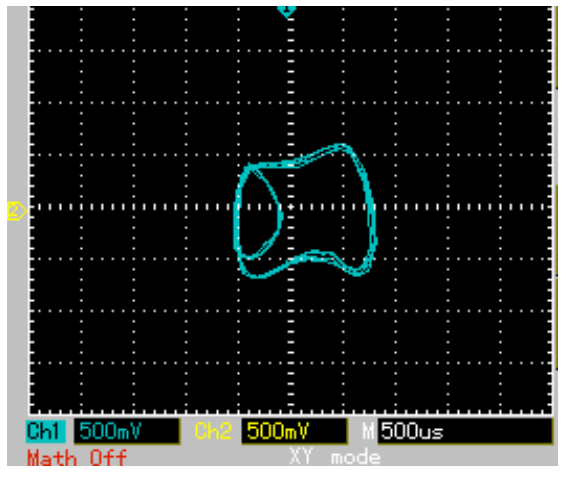

(b)

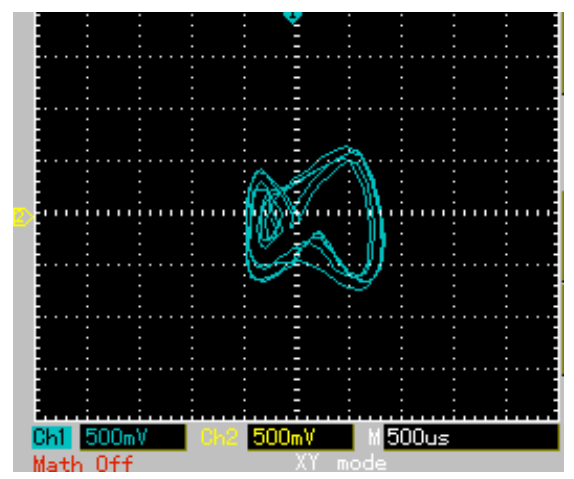

(d)

Figura 18 - Diagramas de fase do circuito partícula numa caixa para uma amplitude fixa de $2 \mathrm{~V}$, e freqüência variável como parâmetro de bifurcação: (a) Período 1-f=958 Hz; (b) Período 2-f=963 Hz; (c) Período 4- f=965 Hz; e (d) Caos, f=1096 Hz. 
As simulações numéricas a partir da equação (30) do circuito partícula na caixa foram normalizadas [37], a fim de comparar os parâmetros necessários para observar a dinâmica do sistema. Partindo da equação (34), fazendo a substituição $t=k . \tau$, tem-se:

$$
\frac{R_{2} C_{1} C_{2}}{k^{2}} \frac{d^{2} V_{2}}{d \tau^{2}}+\frac{R_{2} C_{2}}{R_{1} k} \frac{d V_{2}}{d \tau}+f\left(V_{2}\right)=-\frac{A}{R_{E}} \sin (\omega k \tau)
$$

Onde $f\left(V_{2}\right)$ é a função que descreve a curva corrente-tensão do diodo N4148 em antiparalelo com a resistência $\mathrm{R}_{\mathrm{L}}$.

Fazendo $\frac{R_{2} C_{1} C_{2}}{k^{2}}=\frac{R_{2} C_{2}}{R_{1} k}$, tem-se que $k=R_{1} C_{1}$, logo a equação (34) normalizada resulta em :

$$
\frac{d^{2} V_{2}}{d \tau^{2}}+\frac{d V_{2}}{d \tau}+f\left(V_{2}\right) \frac{C_{1} R_{1}^{2}}{R_{2} C_{2}}=-\frac{C_{1} R_{1}^{2}}{R_{2} C_{2}} \frac{V_{E}}{R_{E}}
$$

Foi realizada uma simulação numérica do comportamento caótico do circuito partícula numa caixa sob as mesmas condições que os resultados experimentais mostrados na Figura 18(a), utilizando-se os parâmetros frequência $\mathrm{f}=1096 \mathrm{~Hz}$ e amplitude de $2 \mathrm{~V}$ pico a pico. $\mathrm{O}$ resultado dessa simulação numérica é apresentado na Figura 19. 


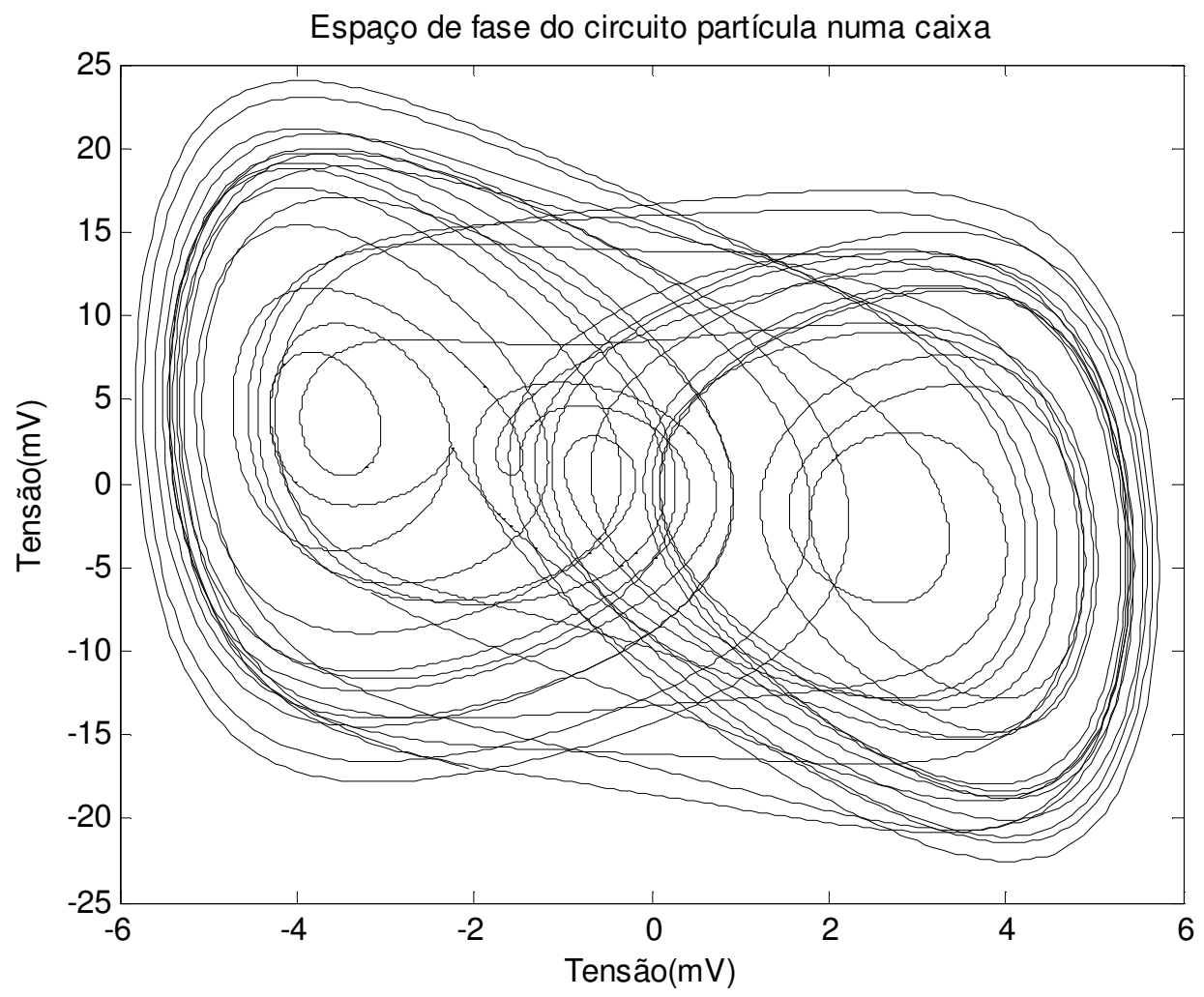

Figura 19 - Resultado da simulação numérica do comportamento caótico do circuito partícula numa caixa sob as mesmas condições dos resultados experimentais mostrados na Figura 18(a), utilizando-se os parâmetros frequência $\mathrm{f}=1096 \mathrm{~Hz}$ e amplitude de $2 \mathrm{~V}_{\mathrm{pp}}$.

Pode-se verificar que os resultados experimentais e numéricos obtidos na Figura 18 e Figura 19 apresentam concordância, tendo ambos exibindo comportamento caótico semelhante, o que sugere a adequação do modelo proposto ao circuito eletrônico partícula numa caixa implementado. 


\subsection{Resultados para configurações mestre-escravo}

\subsubsection{Sincronismo completo}

Nesta seção são apresentados os resultados experimentais e simulações numéricas para circuitos partícula numa caixa idênticos, numa configuração mestre-escravo, no regime de sincronismo completo.

Tendo em vista uma configuração mestre-escravo, constituída de circuitos partícula numa caixa idênticos, conforme diagrama de blocos apresentado na Figura 11, foram analisados os sinais de saída dos circuitos mestre (CH1) e escravo (CH2), conforme apresentado na Figura 20(a). A fim de verificar a possibilidade de ocorrência do regime de sincronismo completo, os sinais de saída dos circuitos foram sobrepostos, conforme Figura 20(b). O regime de sincronismo completo foi obtido utilizando-se uma resistência de realimentação $R_{R E}=100 \Omega$, utilizado no circuito de malha fechada de realimentação, descrito em [13].

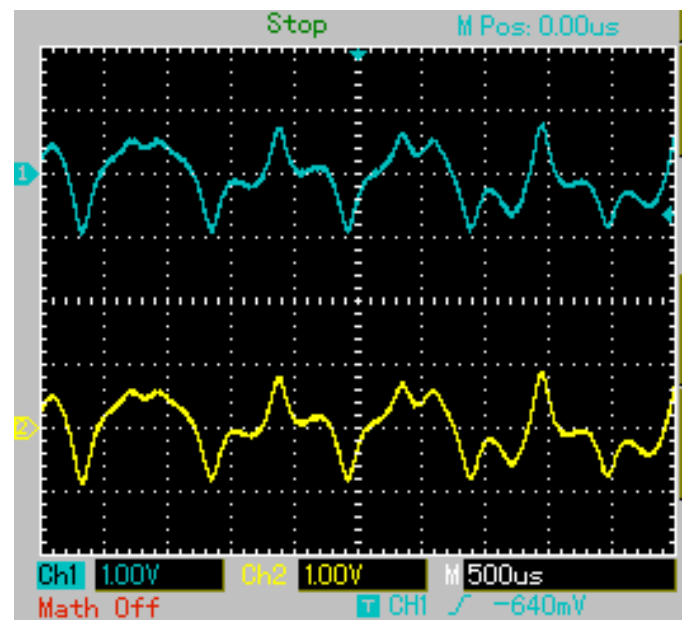

(a)

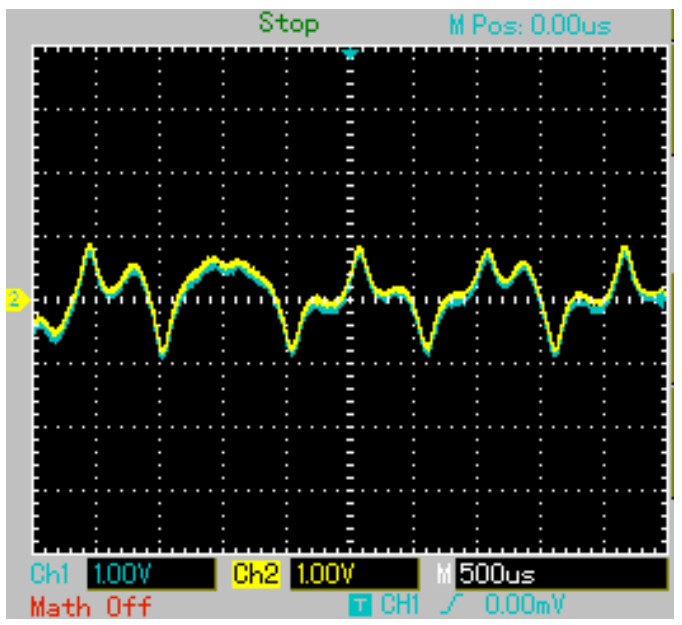

(b)

Figura 20 - (a) Formas de onda de saída dos circuitos mestre (CH1) e escravo (CH2). Pode-se observar que os circuitos exibem um rico comportamento caótico, ocorrendo o regime de sincronismo completo entre suas saídas. Em (b), são vistas as formas de onda dos circuitos sobrepostas, para resistência de realimentação $R_{R E}=100 \Omega$. 
Na Figura 21 é apresentado o diagrama de fase das saídas dos circuitos mestre (CH1) e escravo (CH2) para esta configuração proposta. Pode-se observar que o diagrama de fase exibe uma reta, cuja equação aproxima-se à função identidade, tal qual descrito na seção 3.6, podendo-se constatar a ocorrência do regime de sincronismo completo.

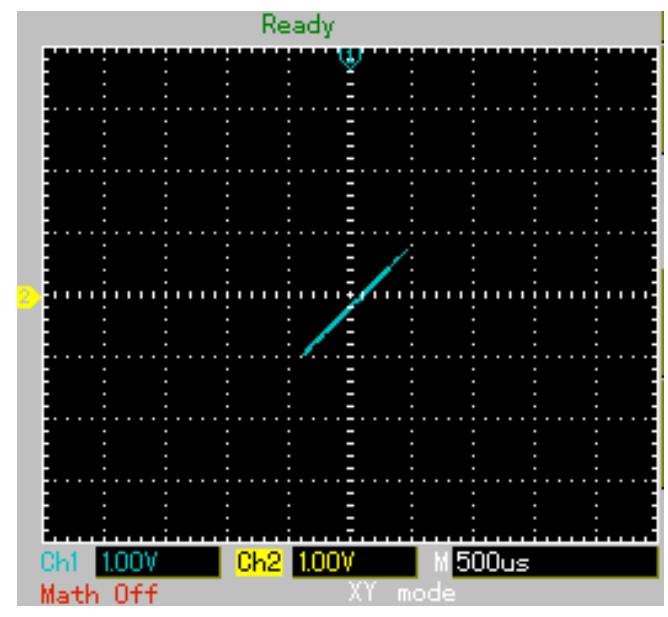

Figura 21 - Diagrama de fase das saídas dos circuitos mestre e escravo. Pode-se notar que o mesmo exibe o padrão da função identidade, tal que $x_{e}(t)=x_{m}(t)$. Este comportamento é uma evidência do regime de sincronismo completo descrito na teoria da seção 3.6.

A equação foi implementada numericamente utilizando o método preditor-corretor descrito no Apêndice A. Os resultados das simulações numéricas realizadas com o auxílio do software Matlab ® versão 7.0 para uma configuração mestre-escravo composta de circuitos partícula numa caixa idênticos, num regime de sincronismo completo, nas mesmas condições experimentais $\left(\mathrm{R}_{\mathrm{RE}}=100 \Omega\right)$ são apresentados na Figura 22.

Na Figura 22 são apresentados os resultados da simulação das saídas dos circuitos mestre $\left(\mathrm{V}_{2 \mathrm{~m}}\right)$ e escravo $\left(\mathrm{V}_{2 \mathrm{e}}\right)$, para resistência de realimentação $R_{R E}=100 \Omega$. 


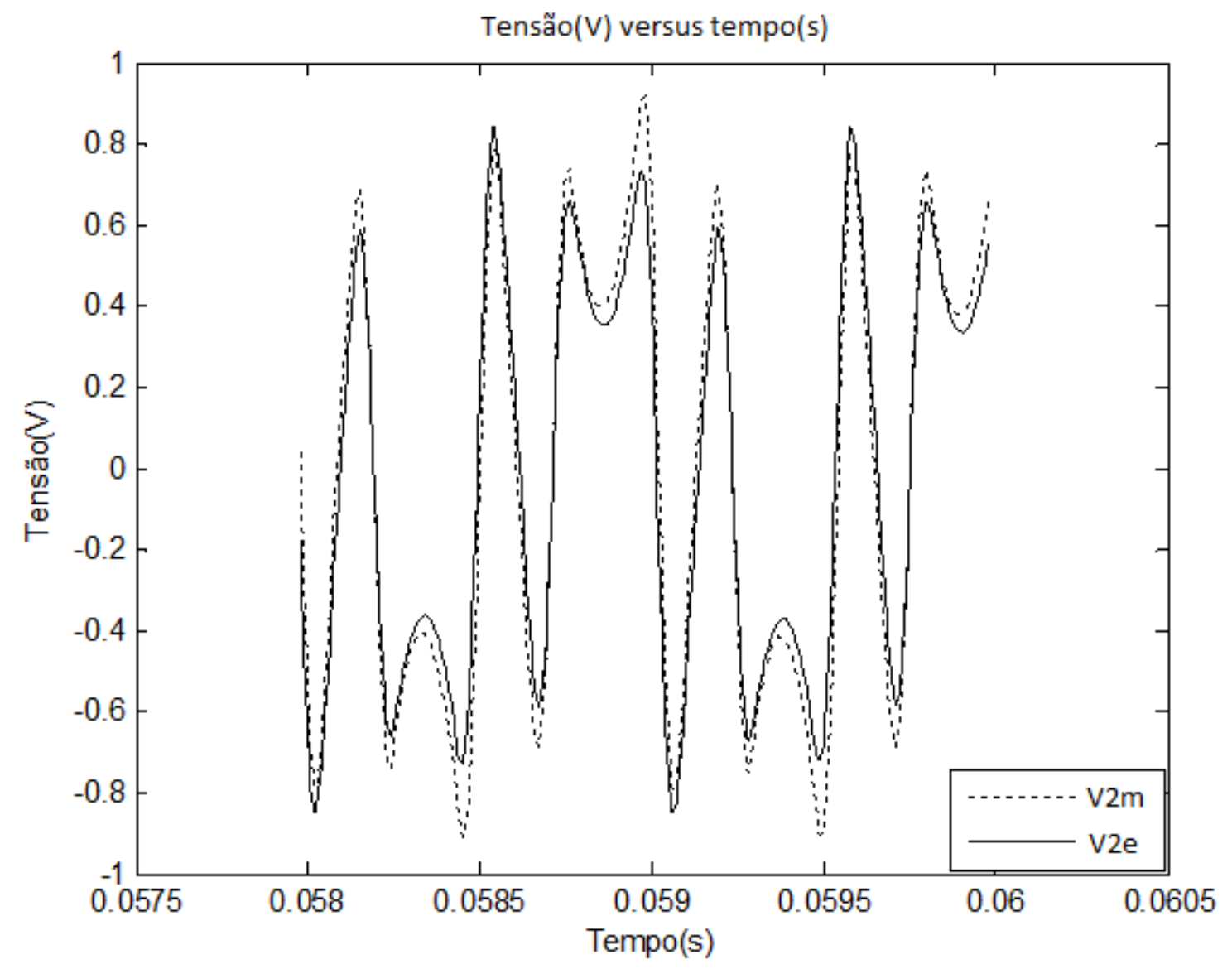

Figura 22- Resultados da simulação numérica das saídas dos circuitos mestre $\left(\mathrm{V}_{2 \mathrm{~m}}\right)$ e escravo $\left(\mathrm{V}_{2 \mathrm{e}}\right)$, para resistência de realimentação $R_{R E}=100 \Omega$. As formas de onda das saídas dos circuitos mestre e escravo apresentam regime de sincronismo completo.

Pode-se verificar, através da análise da simulação numérica das formas de onda das saídas dos circuitos mestre e escravo, que os mesmos apresentam regime de sincronismo completo.

Na Figura 23 é apresentada a simulação numérica do diagrama de fase das saídas dos circuitos mestre $(\mathrm{CH} 1)$ e escravo $(\mathrm{CH} 2)$ para esta configuração proposta. Pode-se observar que o diagrama de fase exibe uma reta, cuja equação aproxima-se à função identidade, tal qual descrito na seção 3.6, podendo-se constatar a ocorrência do regime de sincronismo completo. 


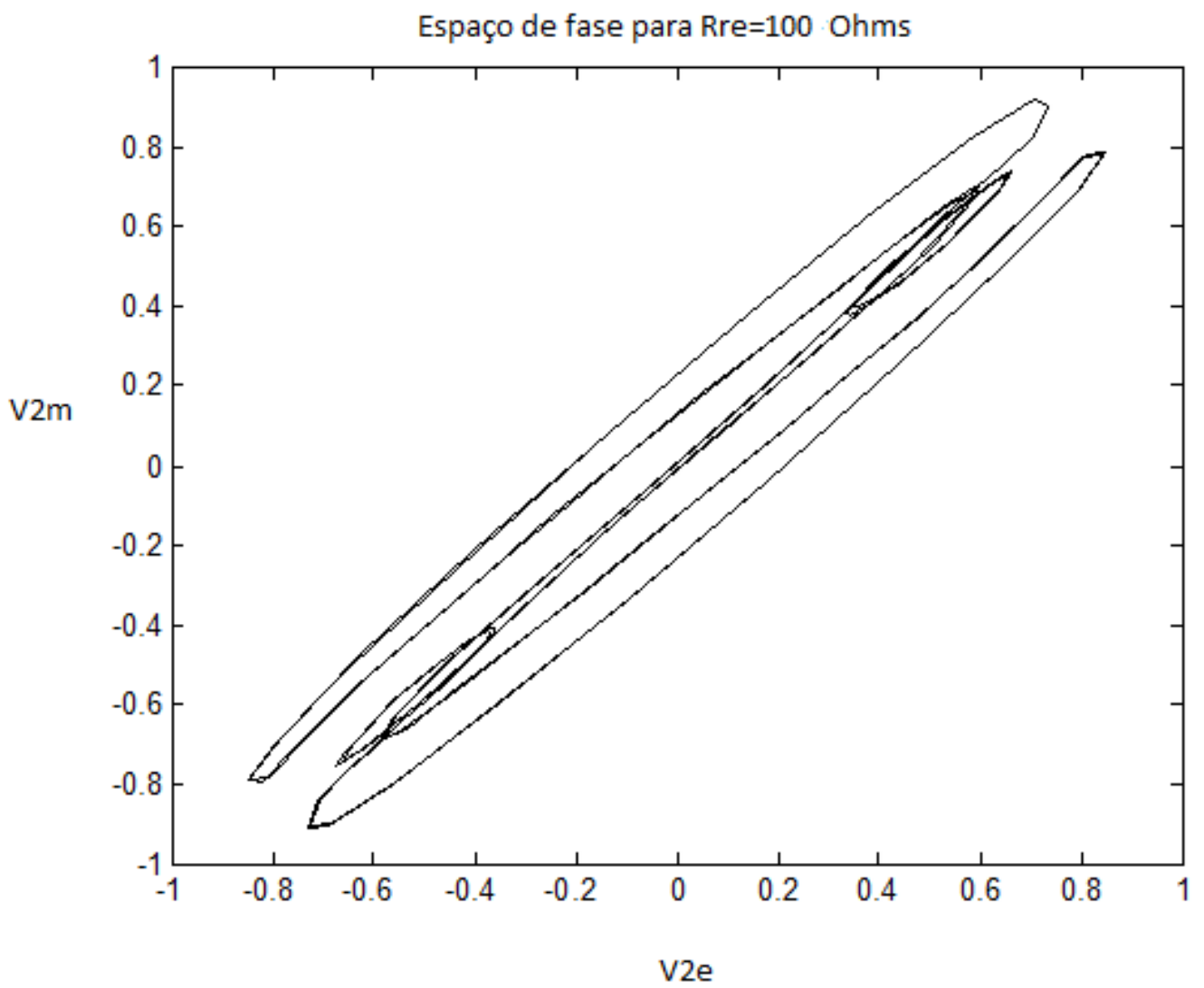

Figura 23 - Simulação numérica do diagrama de fase das saídas dos circuitos mestre (CH1) e escravo (CH2) para esta configuração proposta

\subsubsection{Sincronismo lag}

Nesta seção são apresentados os resultados experimentais e simulações numéricas para circuitos partícula numa caixa idênticos, numa configuração mestre-escravo, no regime de sincronismo lag.

Na Figura 24, são apresentadas as formas de onda de saída dos circuitos mestre (CH1) e escravo (CH2) para resistência de realimentação $R_{R E}=100 \mathrm{k} \Omega$. Nota-se que as formas de onda apresentam comportamento caótico, e que as mesmas exibem um sincronismo de atraso ou lag, como visto na sobreposição das formas de onda de saída dos circuitos. 


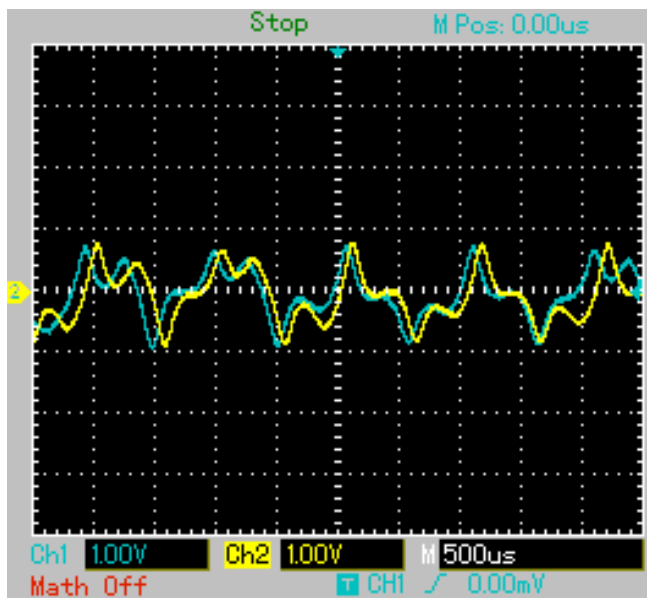

Figura 24 - Formas de onda das saídas dos circuitos mestre $(\mathrm{CH} 1)$ e escravo $(\mathrm{CH} 2)$ para resistência de realimentação $R_{R E}=100 \mathrm{k} \Omega$. As saídas dos circuitos encontram-se em atraso uma em relação à outra, ocorrendo o sincronismo de atraso, tal que $x_{e}\left(t+\tau_{0}\right) \approx x_{m}(t)$.

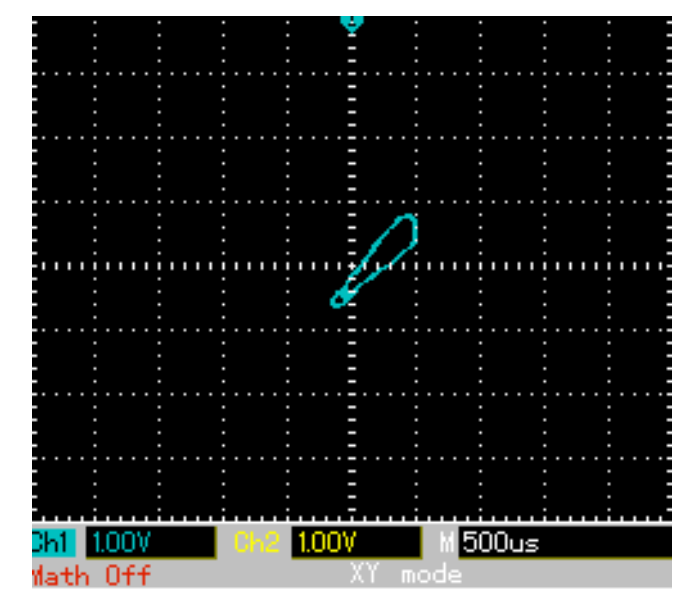

Figura 25 - Diagrama de fase dos circuitos mestre $(\mathrm{CH} 1)$ e escravo $(\mathrm{CH} 2)$ para resistência de realimentação $R_{R E}=100 \mathrm{k} \Omega$. 
Pode-se verificar, através do diagrama do espaço de fase mostrado na Figura 25, que as formas de onda dos sinais de saída dos circuitos encontram-se em atraso, uma em relação à outra, ocorrendo o sincronismo de atraso, tal que $x_{e}\left(t+\tau_{0}\right) \approx x_{m}(t)$.

Para analisar a ocorrência do regime de sincronismo de defasagem ou lag, de acordo com o modelo proposto, foi realizada a simulação numérica dos sinais de saída dos circuitos mestre $\left(V_{2 m}\right)$ e escravo $\left(V_{2 e}\right)$, utilizando-se as mesmas condições experimentais anteriormente observadas, $\mathrm{R}_{\mathrm{RE}}=100 \mathrm{k} \Omega$, e amplitude de $2 \mathrm{~V}_{\mathrm{pp}}$. Os resultados desta simulação numérica são apresentados na Figura 26.

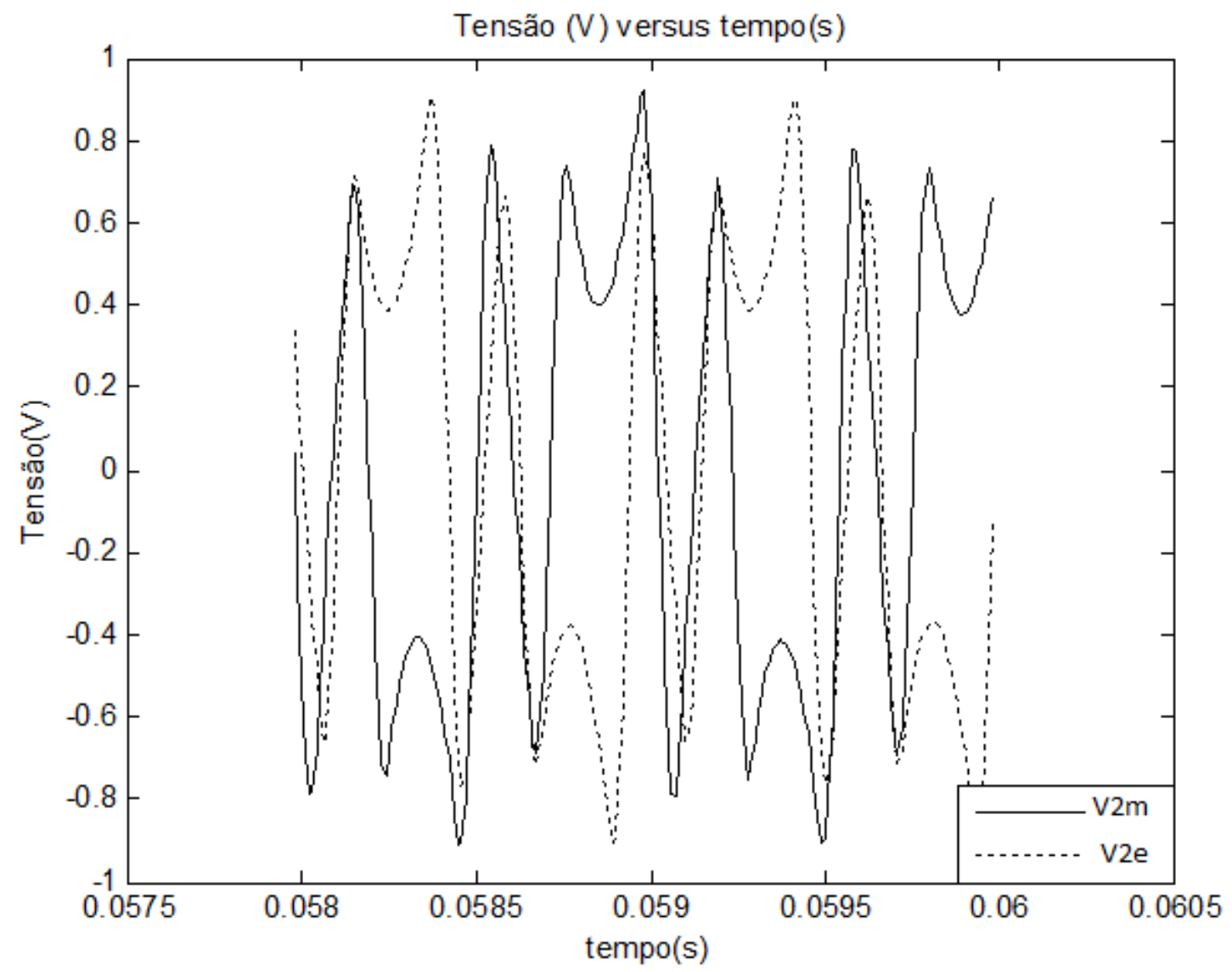

Figura 26 - Resultados da simulação numérica das formas de onda das saídas dos circuitos mestre $\left(\mathrm{V}_{2 \mathrm{~m}}\right)$ e escravo $\left(\mathrm{V}_{2 \mathrm{e}}\right)$, para resistência de realimentação $R_{R E}=100 \mathrm{k} \Omega$. 
Analisando o gráfico da Figura 26, pode-se concluir que as formas de onda dos sinais de saída dos circuitos mestre e escravo apresentam regime de sincronismo lag ou de defasagem.

Na Figura 27, são apresentados os resultados da simulação numérica do espaço de fase dos circuitos mestre $\left(\mathrm{V}_{2 \mathrm{~m}}\right)$ e escravo $\left(\mathrm{V}_{2 \mathrm{e}}\right)$, para resistência de realimentação $R_{R E}=100 \mathrm{k} \Omega$.

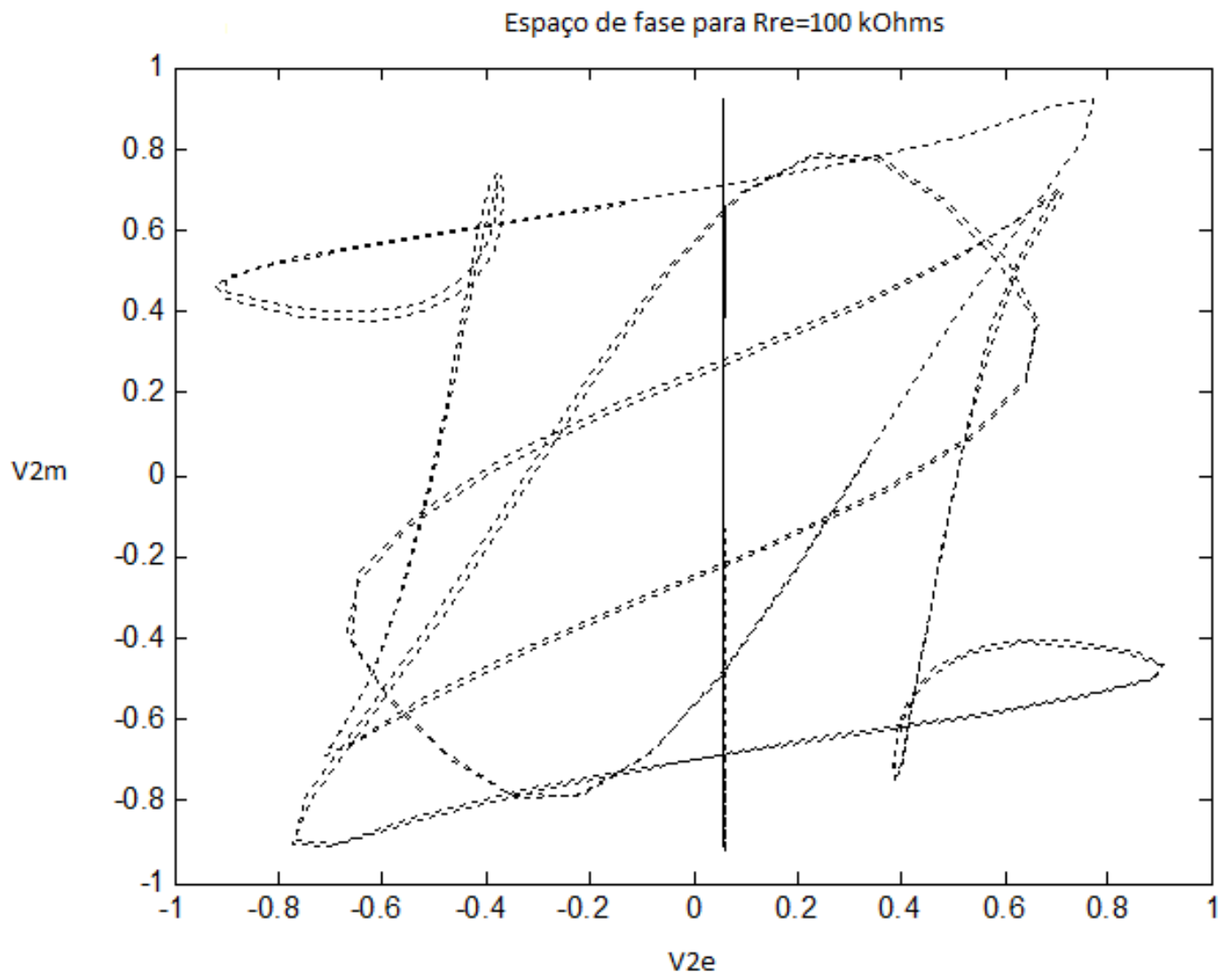

Figura 27 - Resultados da simulação numérica do espaço de fase dos circuitos mestre $\left(\mathrm{V}_{2 \mathrm{~m}}\right)$ e escravo $\left(\mathrm{V}_{2 \mathrm{e}}\right)$, para resistência de realimentação $R_{R E}=100 \mathrm{k} \Omega$. As saídas dos circuitos mestre e escravo apresentam regime de sincronismo de defasagem ou lag.

Analisando o gráfico apresentado na Figura 27, pode-se concluir que as saídas dos circuitos mestre e escravo apresentam regime de sincronismo de defasagem ou lag. 


\subsubsection{Sincronismo de fase}

Nesta seção são apresentados os resultados experimentais e simulações numéricas para circuitos partícula numa caixa idênticos, numa configuração mestre-escravo, no regime de sincronismo de fase.

Na Figura 28 são apresentadas as formas de onda de saída dos circuitos mestre (CH1) e escravo $(\mathrm{CH} 2)$ para resistência de realimentação $R_{R E}=500 \mathrm{k} \Omega$.

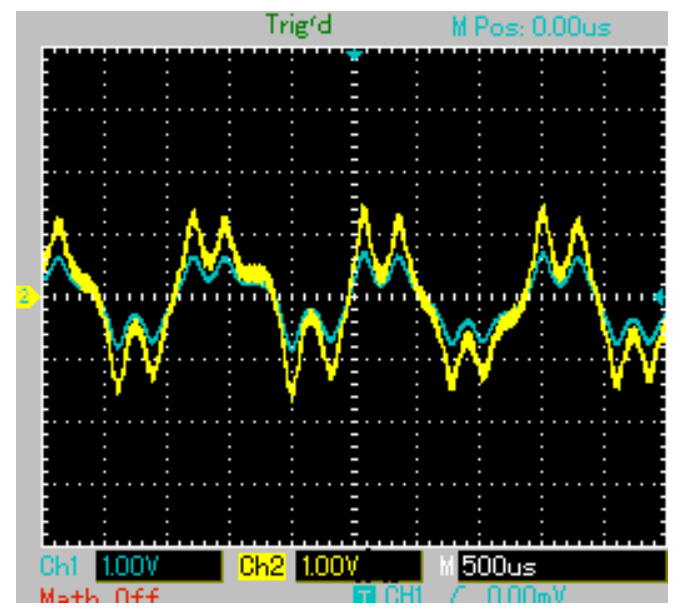

Figura 28 - Formas de onda das saídas dos circuitos mestre $(\mathrm{CH} 1)$ e escravo $(\mathrm{CH} 2)$ para resistência de realimentação $\mathrm{R}_{\mathrm{RE}}=500 \mathrm{k} \Omega$.

Analisando o gráfico apresentado na Figura 28, observa-se que as formas de onda referentes aos sinais de saída dos circuitos encontram-se em fase uma em relação à outra, porém suas amplitudes diferem. 
$\mathrm{Na}$ Figura 29 é apresentado o diagrama de fase para os circuitos mestre (CH1) e escravo $(\mathrm{CH} 2)$ para resistência de realimentação $R_{R E}=500 \mathrm{k} \Omega$, num regime de sincronismo de fase.

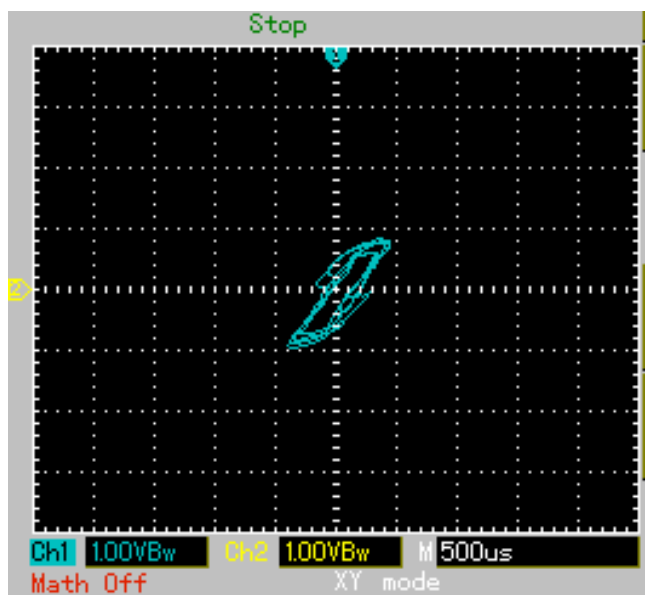

Figura 29 - Diagrama de fase para os circuitos mestre $(\mathrm{CH} 1)$ e escravo $(\mathrm{CH} 2)$ para resistência de realimentação $R_{R E}=500 \mathrm{k} \Omega$, num regime de sincronismo de fase.

Analisando o gráfico apresentado na Figura 29, observa-se que as formas de onda referentes aos sinais de saída dos circuitos encontram-se em fase uma em relação à outra, porém suas amplitudes diferem.

Na Figura 30 é apresentada a simulação numérica para as formas de onda de saída dos circuitos mestre $(\mathrm{CH} 1)$ e escravo $(\mathrm{CH} 2)$ para resistência de realimentação $R_{R E}=500 \mathrm{k} \Omega$, num regime de sincronismo de fase. 


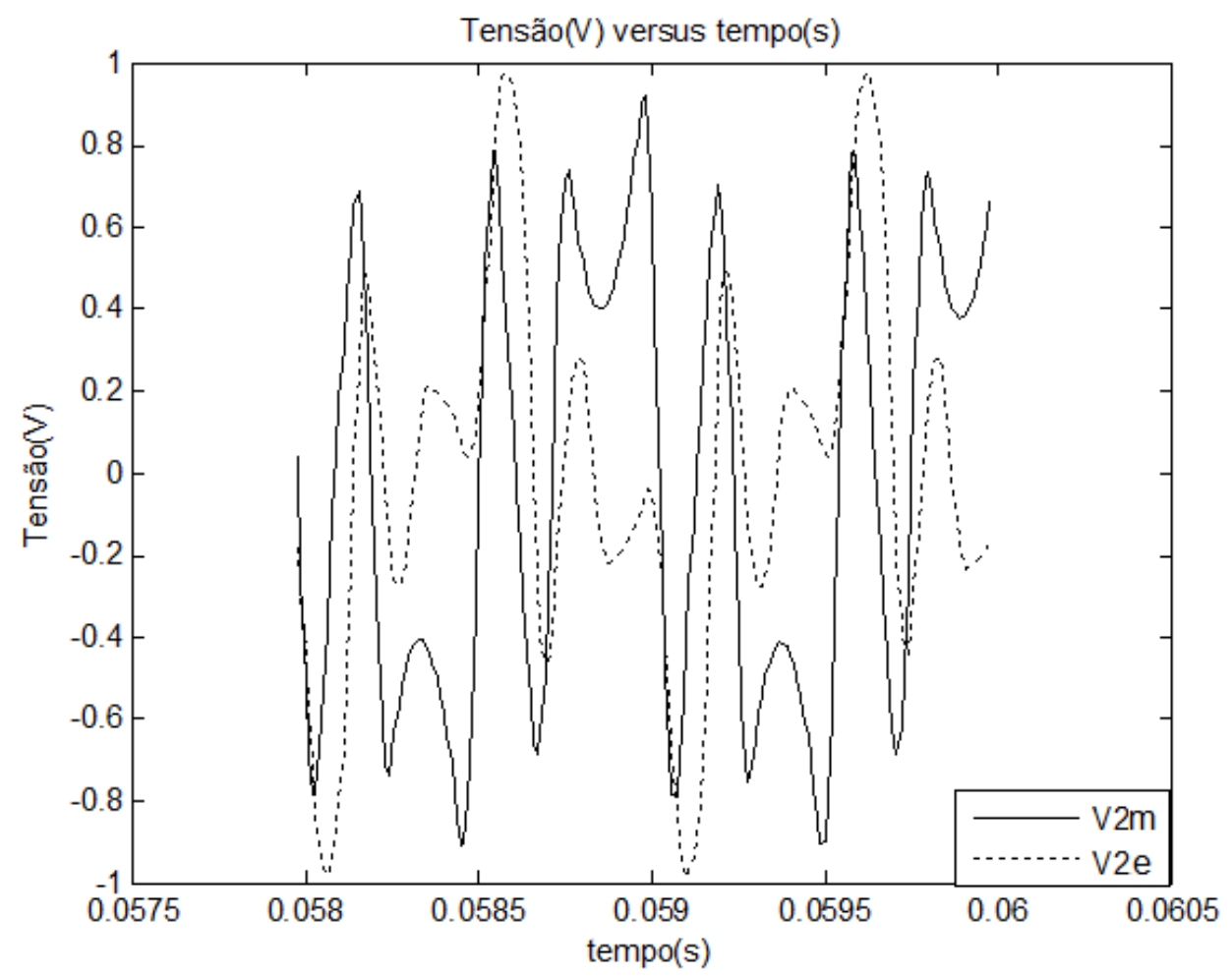

Figura 30- Simulação numérica para as formas de onda de saída dos circuitos mestre $(\mathrm{CH} 1)$ e escravo $(\mathrm{CH} 2)$ para resistência de realimentação $R_{R E}=500 \mathrm{k} \Omega$, num regime de sincronismo de fase.

Na Figura 31 é apresentada a simulação numérica para as formas de onda de saída dos circuitos mestre $(\mathrm{CH} 1)$ e escravo $(\mathrm{CH} 2)$ para resistência de realimentação $R_{R E}=500 \mathrm{k} \Omega$, num regime de sincronismo de fase. 


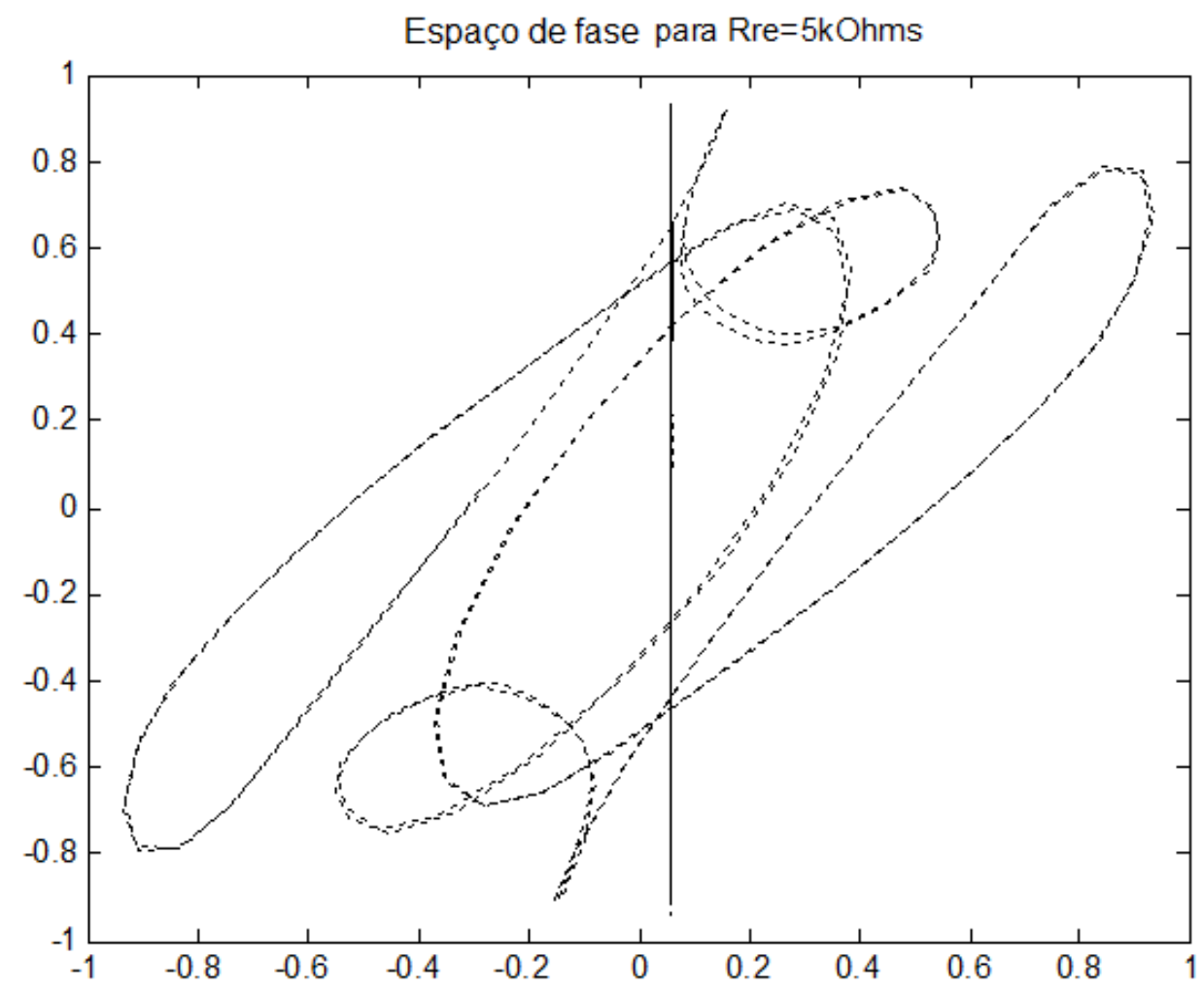

Figura 31 - Simulação numérica do diagrama de fase para os circuitos mestre (CH1) e escravo $(\mathrm{CH} 2)$ para resistência de realimentação $R_{R E}=500 \mathrm{k} \Omega$, num regime de sincronismo de fase.

\subsubsection{Resultados em diversas configurações mestre escravo com linhas de transmissão}

A fim de simular o comportamento do circuito na transmissão de infomação em um canal, foram construídas diversas configurações de linhas de transmissão entre os circuitos transmissor e receptor. Foram estabelecidas configurações de linhas de transmissão segundo o modelo T, simulando distâncias de $100 \mathrm{~m}, 1 \mathrm{~km}$ e $10 \mathrm{~km}$, conforme o diagrama de blocos anteriormente apresentado na Figura 16. 
A Figura 32 apresenta os resultados da comparação do sinal de saída do circuito mestre com o sinal de saída do circuito escravo para uma linha de transmissão modelo T, distância equivalente de $100 \mathrm{~m}$ cada.

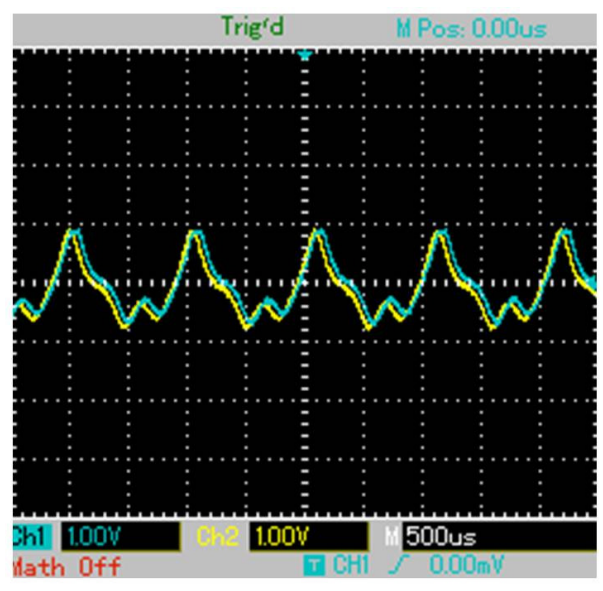

(a)

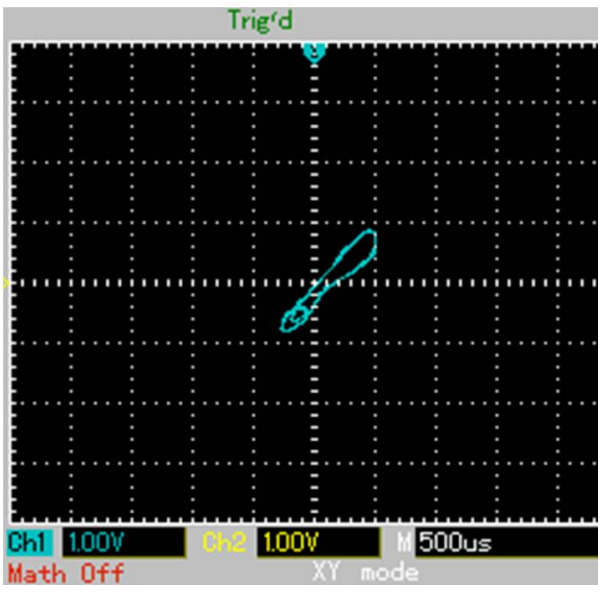

(b)

Figura 32 - (a) Sinais de saída do circuito mestre $(\mathrm{CH} 1)$ e do circuito escravo $(\mathrm{CH} 2)$ passando pela linha de transmissão T equivalente a $100 \mathrm{~m}$. (b) Diagrama de fase dos circuitos mestre e escravo, utilizando a linha de transmissão equivalente a $100 \mathrm{~m}$.

A Figura 33 apresenta os resultados comparando o sinal de saída do circuito mestre e o sinal de saída do circuito escravo para uma linha de transmissão modelo T, distância de $1 \mathrm{~km}$. 


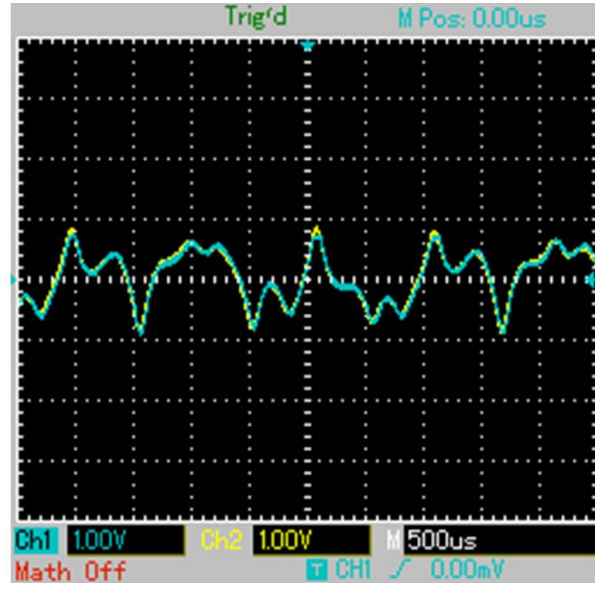

(a)

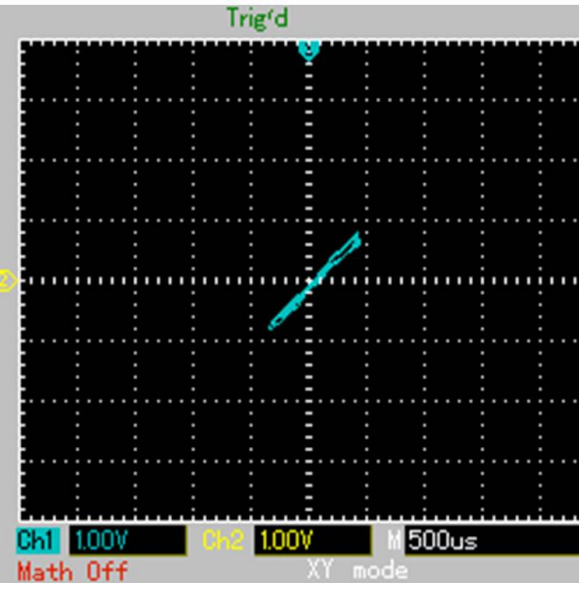

(b)

Figura 33 - (a) Sinais de saída do circuito mestre $(\mathrm{CH} 1)$ e do circuito escravo $(\mathrm{CH} 2)$ passando pela linha de transmissão T equivalente a $1 \mathrm{~km}$. (b) Diagrama de fase dos circuitos mestre e escravo, utilizando a linha de transmissão equivalente a $1 \mathrm{~km}$.

A Figura 34 apresenta os resultados da comparação do sinal de saída do circuito mestre com o sinal de saída do circuito escravo para uma linha de transmissão modelo T, distância de $10 \mathrm{~km}$.

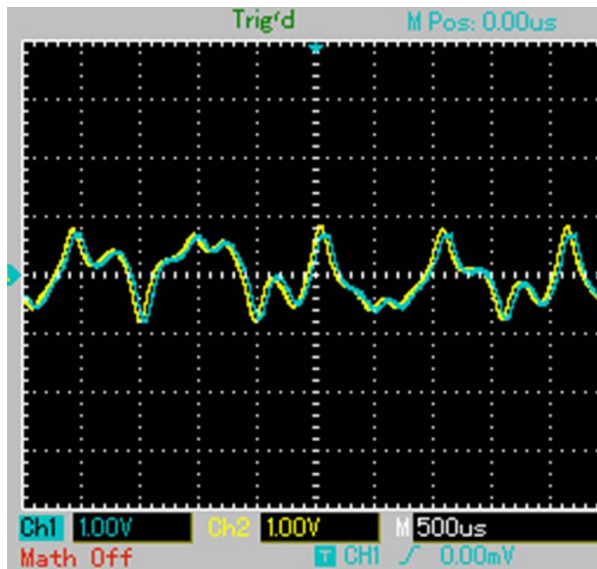

(a)

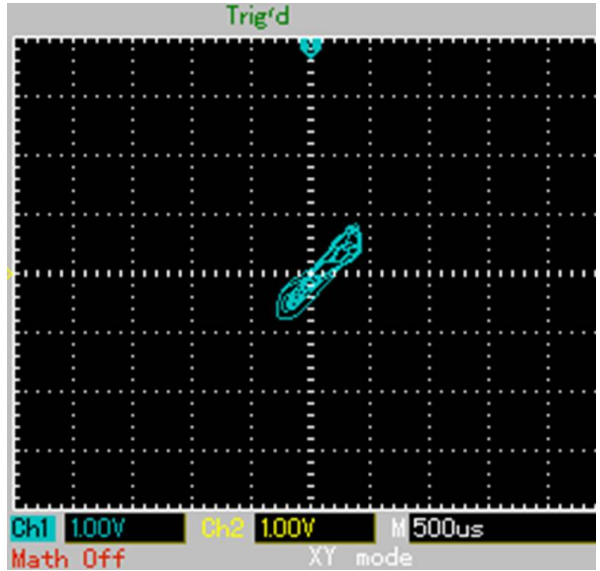

(b)

Figura 34 - (a)Sinais de saída do circuito mestre $(\mathrm{CH} 1)$ e do circuito escravo $(\mathrm{CH} 2)$ passando pela linha de transmissão T equivalente a $10 \mathrm{~km}$. (b) Diagrama de fase dos circuitos mestre e escravo, utilizando a linha de transmissão equivalente a $10 \mathrm{~km}$. 


\subsubsection{Resultados para dois pares de circuitos partícula numa caixa em configurações mestre-escravo, casados dois a dois.}

A fim de verificar a robustez do sincronismo dos circuitos mestre e escravo e aumentar a topologia do sistema, em uma possível analogia com um canal de comunicação multiusuário, foi proposta uma configuração do sistema composta de dois circuitos mestres e dois escravos, onde a saída destes era somada e utilizada na realimentação dos circuitos [13].

Foi utilizado um gerador de função para cada um dos circuitos mestre e escravo, com o objetivo de garantir que cada um deles tivesse um sinal de entrada senoidal de fase diversa. Os circuitos 1 e 2 diferem apenas no valor da resistência $R_{1}$, mostrada no diagrama da Figura 8, sendo que o valor de $\mathrm{R}_{1}$ para o primeiro circuito é $44 \mathrm{k} \Omega$, e para o segundo circuito, o valor de $\mathrm{R}_{2}$ é $47 \mathrm{k} \Omega$. Cada circuito mestre é idêntico ao seu respectivo circuito escravo. Os resultados são apresentados a seguir.

$\mathrm{Na}$ Figura 35 é vista a saída dos circuitos mestre 1e escravo $1\left(\mathrm{R}_{1}=44 \mathrm{k} \Omega\right)$, e o diagrama de fase.

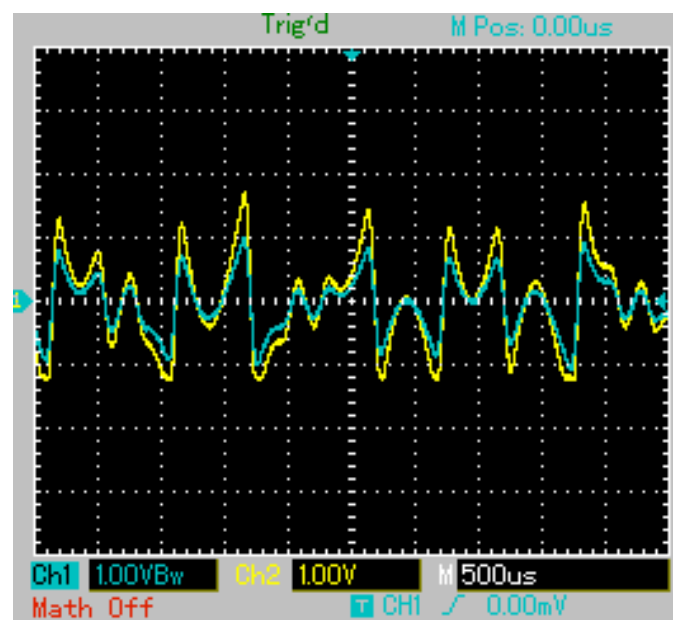

(a)

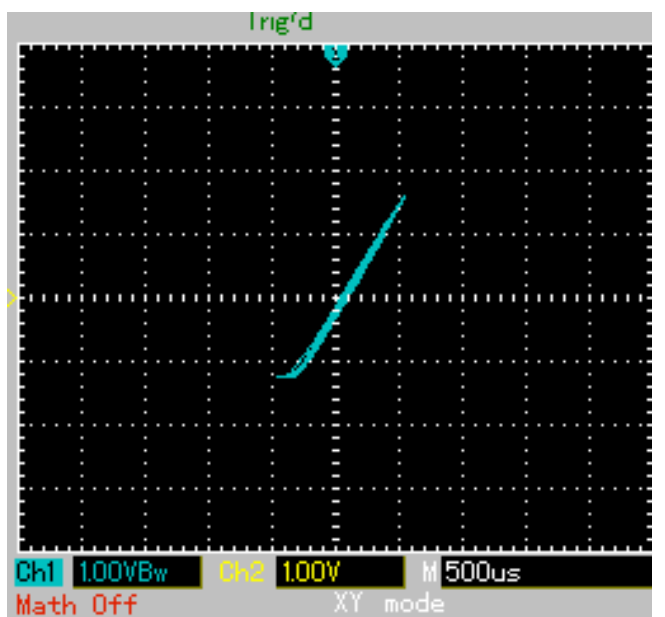

(b)

Figura 35 - (a) Sinal de saída dos circuitos mestre 1 (CH1) e escravo 1(CH2) $\left(\mathrm{R}_{1}=44 \mathrm{k} \Omega\right)$, e (b) diagrama de fase referente às saídas dos mesmos.

Nesta medição, observa-se que os circuitos mestre 1 e escravo 1 sincronizaram-se quando a soma dos sinais de saída dos circuitos escravos 1 e 2 são reaplicadas ao circuito mestre 1, através da malha de realimentação, pois os mesmos possuem parâmetros idênticos. 
Na Figura 36, é vista a saída dos circuitos mestre $1(\mathrm{CH} 1)\left(\mathrm{R}_{1}=44 \mathrm{k} \Omega\right)$ e escravo 2 $(\mathrm{CH} 2)\left(\mathrm{R}_{1}=47 \mathrm{k} \Omega\right)$, e o respectivo diagrama de fase.

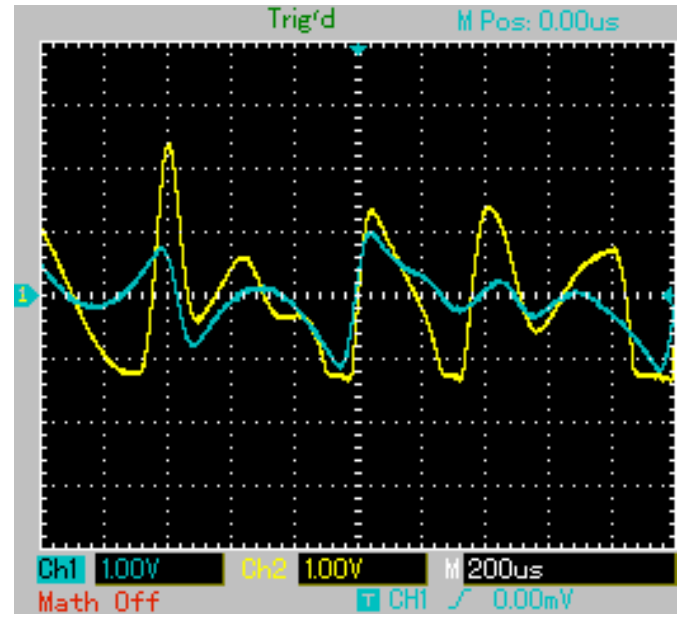

(a)

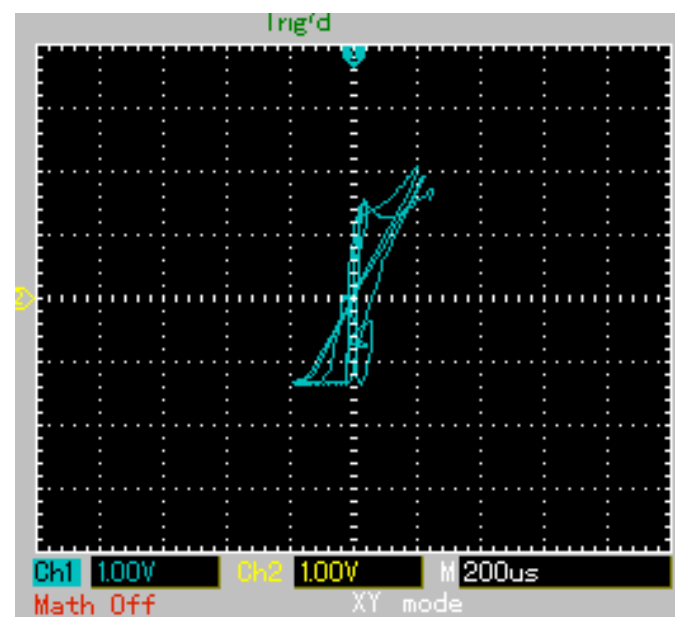

(b)

Figura 36 - (a) Sinal de saída dos circuitos mestre $1(\mathrm{CH} 1)\left(\mathrm{R}_{1}=44 \mathrm{k} \Omega\right.$ ) e escravo 2 (CH2) $\left(\mathrm{R}_{1}=47 \mathrm{k} \Omega\right)$, e (b) o respectivo diagrama de fase. Como se pode verificar, os circuitos mestre 1 e escravo 2 não se sincronizaram quando a soma dos sinais de saída dos circuitos escravos 1 e 2 são reaplicadas aos mesmos, através da malha de realimentação.

\subsubsection{Resultados para três pares de circuitos partícula numa caixa em configurações mestre-escravo, casados dois a dois.}

Com o objetivo de realizar outro teste de robustez do sincronismo dos circuitos mestre e escravo e aumentar a topologia do sistema, em analogia com um canal de comunicação multiusuário, foi proposta uma configuração do sistema composta de três pares de circuitos mestre-escravo, casados dois a dois, de forma que seus sinais de saída eram somados, e o sinal resultante era então utilizado na realimentação dos circuitos.

Os circuitos 1,2 e 3 diferem apenas no valor da resistência $R_{1}$, mostrada no diagrama da Figura 8 , sendo que o valor da resistência $\mathrm{R}_{1}$ para o primeiro par de circuitos é $44 \mathrm{k} \Omega$, para o segundo par de circuitos, o valor de $\mathrm{R}_{1}$ é $47 \mathrm{k} \Omega$, e o valor de $\mathrm{R}_{1}$ para o terceiro par de circuitos 
é $50 \mathrm{k} \Omega$. Cada circuito mestre é idêntico ao seu respectivo circuito escravo. Os resultados são apresentados a seguir.

Na Figura 37 é apresentado o gráfico dos sinais de saída dos circuitos mestre 1 e escravo $1\left(\mathrm{R}_{1}=44 \mathrm{k} \Omega\right)$, e o respectivo diagrama de fase.

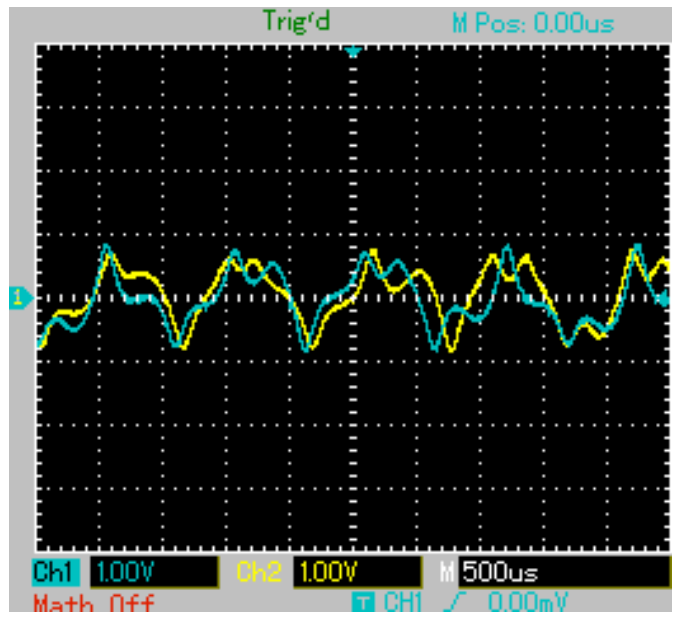

(a)

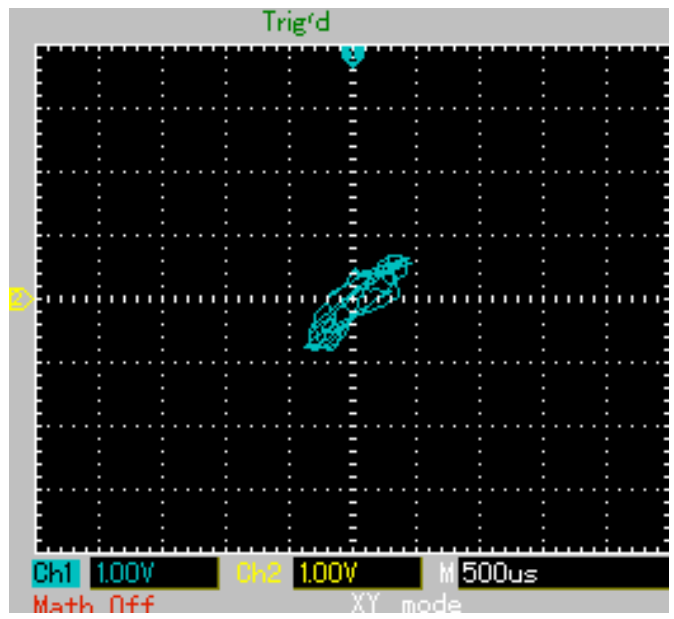

(b)

Figura 37 - (a) Sinal de saída dos circuitos mestre $1(\mathrm{CH} 1)$ e escravo $1(\mathrm{CH} 2)\left(\mathrm{R}_{1}=44\right.$ $\mathrm{k} \Omega$ ), e (b) diagrama de fase referente às saídas dos mesmos.

Verificou-se que os circuitos mestre 1 e escravo 1 sincronizaram-se quando a soma dos sinais de saída dos circuitos escravo 1, escravo 2 e escravo 3 são reaplicadas ao circuito mestre 1 através da malha de realimentação, pois os mesmos possuem parâmetros casados. Note que os resultados são semelhantes aos obtidos com o sistema composto de dois circuitos mestres e dois circuitos escravos, conforme visto na Figura 35. Entretanto quando introduzido um terceiro par de circuitos mestre/escravo, a razão sinal/ruído diminui.

Na Figura 38 é apresentado o gráfico dos sinais de saída dos circuitos mestre 2 e escravo $2\left(\mathrm{R}_{1}=47 \mathrm{k} \Omega\right)$, e o respectivo diagrama de fase. 


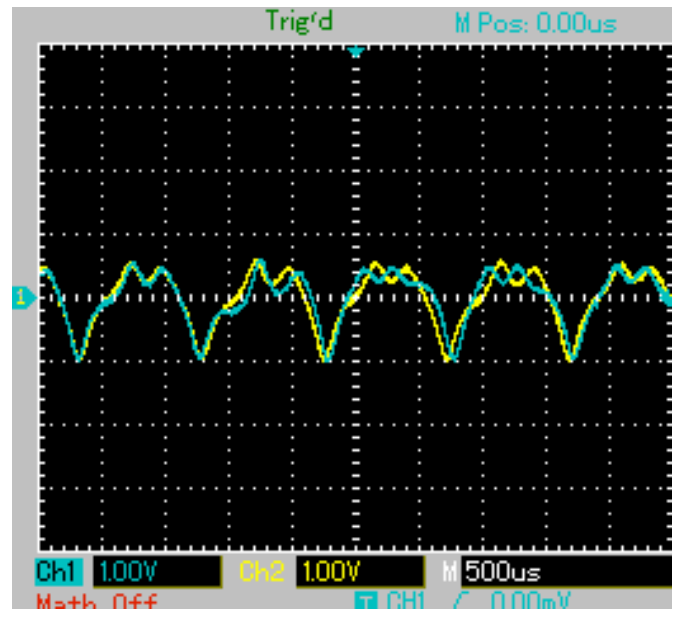

(a)

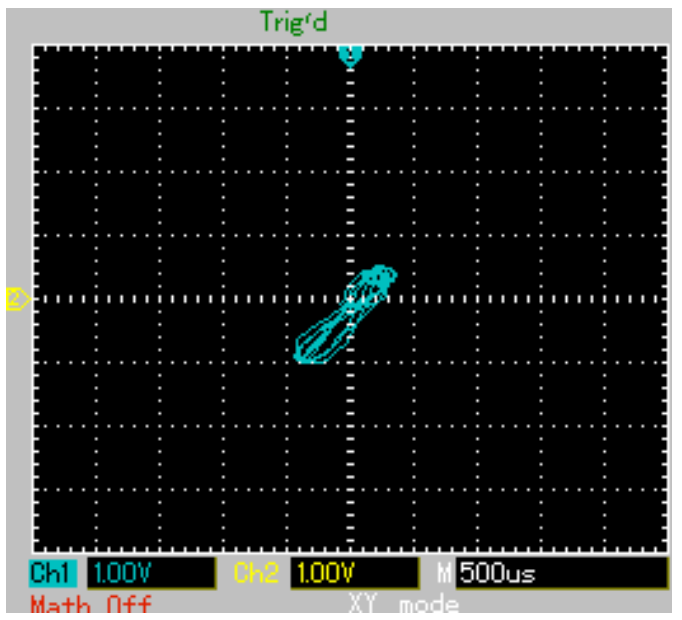

(b)

Figura 38 - (a) Sinal de saída dos circuitos mestre $2(\mathrm{CH} 1)$ e escravo 2 (CH2) $\left(\mathrm{R}_{1}=47 \mathrm{k} \Omega\right)$, e (b) diagrama de fase referente às saídas dos mesmos.

Nesta medição, observa-se que os circuitos mestre 2 e escravo 2 sincronizaram-se quando a soma dos sinais de saída dos circuitos escravos 1, 2 e 3 são reaplicadas ao circuito mestre 2, através da malha de realimentação, pois os mesmos possuem parâmetros casados. Note que os resultados são semelhantes aos obtidos com o sistema composto de dois circuitos mestre e dois circuitos escravos, conforme visto na Figura 35.

Na Figura 39 é vista a saída dos circuitos mestre 3 e escravo $3\left(R_{1}=50 \mathrm{k} \Omega\right)$, e o respectivo diagrama de fase. 


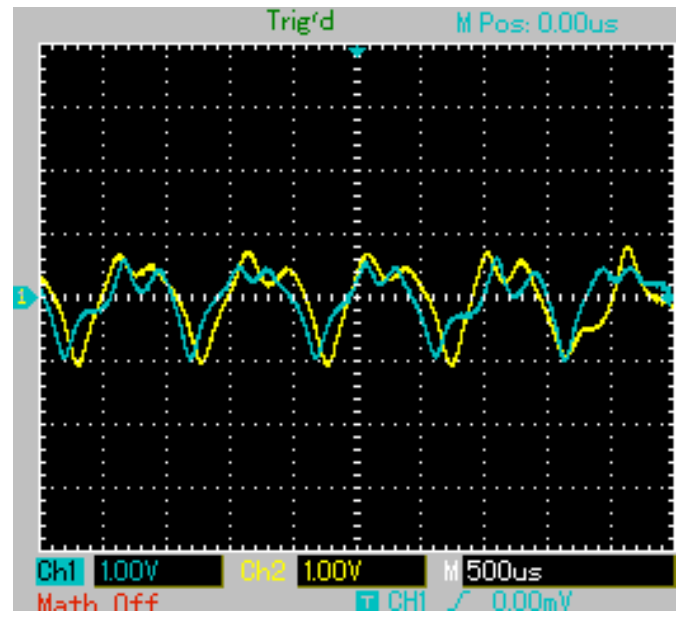

(a)

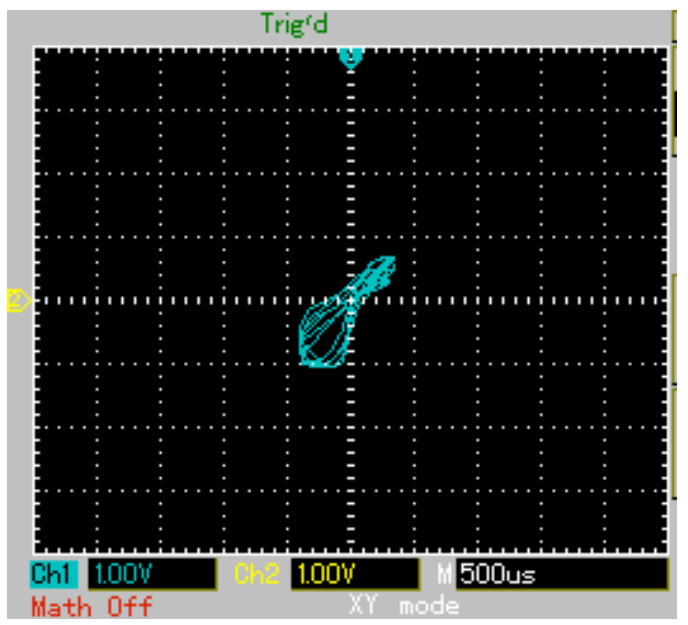

(b)

Figura 39 - (a) Sinal de saída dos circuitos mestre 3 (CH1) e escravo 3 (CH2) $\left(\mathrm{R}_{1}=50 \mathrm{k} \Omega\right)$, e (b) diagrama de fase referente às saídas dos mesmos.

Nesta medição, se observa que os circuitos mestre 3 e escravo 3 sincronizaram-se quando a soma dos sinais de saída dos circuitos escravos 1, 2 e 3 são reaplicadas ao circuito mestre 3, através da malha de realimentação, pois os mesmos possuem parâmetros casados. Observa-se que os resultados são semelhantes aos obtidos com o sistema composto de dois circuitos mestre e dois circuitos escravo, conforme visto na Figura 35.

Na Figura 40 são apresentados os sinais de saída dos circuitos mestre $1\left(R_{1}=44 \mathrm{k} \Omega\right)$, e escravo $2\left(\mathrm{R}_{1}=47 \mathrm{k} \Omega\right)$, e o respectivo diagrama de fase, quando reaplicado o sinal referente à soma dos sinais de saída dos circuitos escravo 1, escravo 2 e escravo 3. 


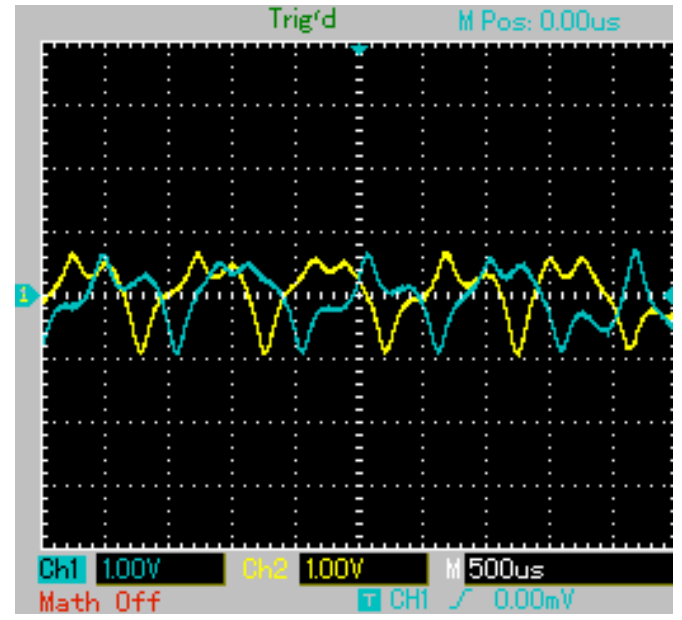

(a)

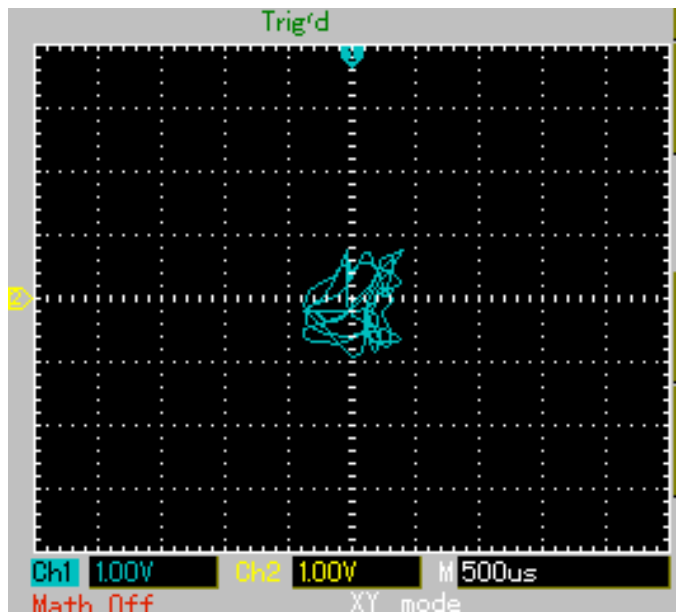

(b)

Figura 40 - (a) Sinal de saída dos circuitos mestre $1(\mathrm{CH} 1)\left(\mathrm{R}_{1}=44 \mathrm{k} \Omega\right)$ e escravo 2 $(\mathrm{CH} 2)\left(\mathrm{R}_{1}=47 \mathrm{k} \Omega\right)$, e (b) o respectivo diagrama de fase. Como se pode verificar, os circuitos mestre 1 e escravo 2 não sincronizaram-se quando a soma dos sinais de saída dos circuitos escravos 1,2 e 3 são reaplicadas aos mesmos, através da malha de realimentação.

Na Figura 41, são apresentados os sinais de saída dos circuitos mestre $1\left(R_{1}=44 \mathrm{k} \Omega\right)$ e escravo $3\left(\mathrm{R}_{1}=50 \mathrm{k} \Omega\right)$, e o respectivo diagrama de fase, quando reaplicado o sinal referente à soma dos sinais de saída dos circuitos escravos 1,2 e 3.

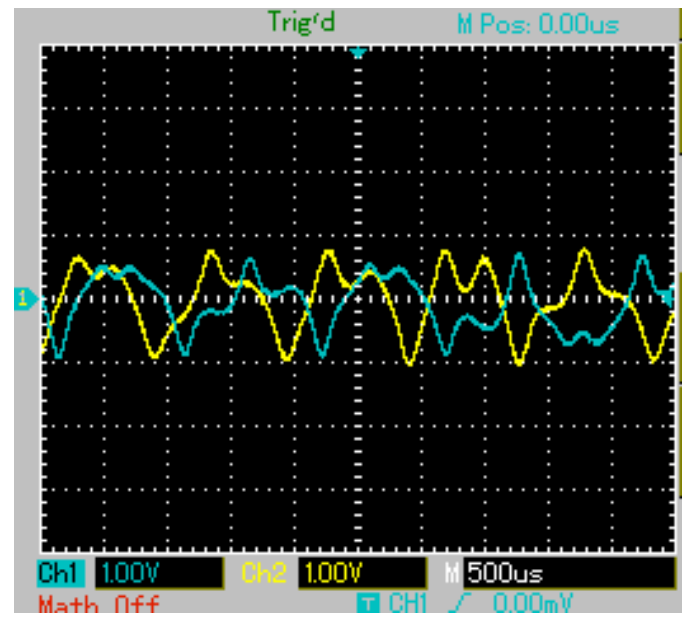

(a)

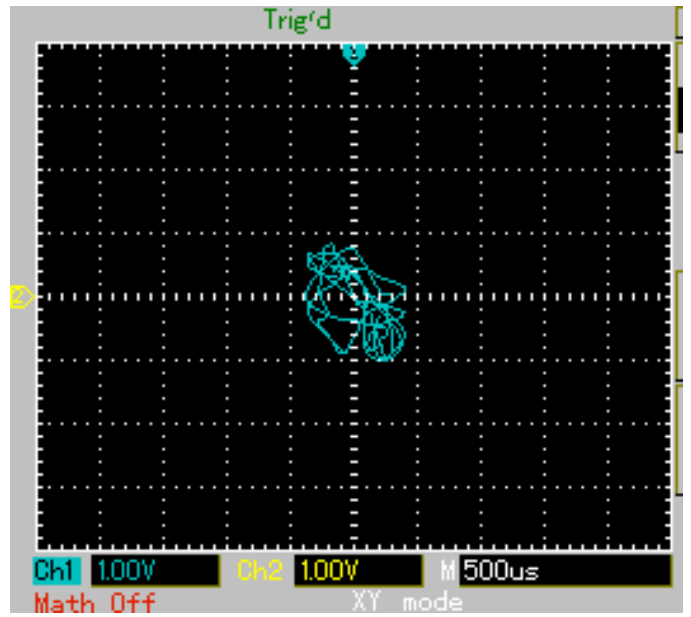

(b)

Figura 41 - (a) Sinal de saída dos circuitos mestre $1(\mathrm{CH} 1)\left(\mathrm{R}_{1}=44 \mathrm{k} \Omega\right)$ e escravo 3 $(\mathrm{CH} 2)\left(\mathrm{R}_{1}=50 \mathrm{k} \Omega\right)$, e (b) o respectivo diagrama de fase. 
Como se pode verificar, os circuitos mestre 1 e escravo 3 não se sincronizaram quando a soma dos sinais de saída dos circuitos escravos 1,2 e 3 são reaplicadas aos mesmos, através da malha de realimentação.

Na Figura 42 é apresentado o sinal de saída dos circuitos mestre $2\left(\mathrm{R}_{1}=47 \mathrm{k} \Omega\right)$ e escravo $1\left(\mathrm{R}_{1}=44 \mathrm{k} \Omega\right)$, e o respectivo diagrama de fase, quando reaplicado o sinal referente à soma dos sinais de saída dos circuitos escravos 1,2 e 3 .

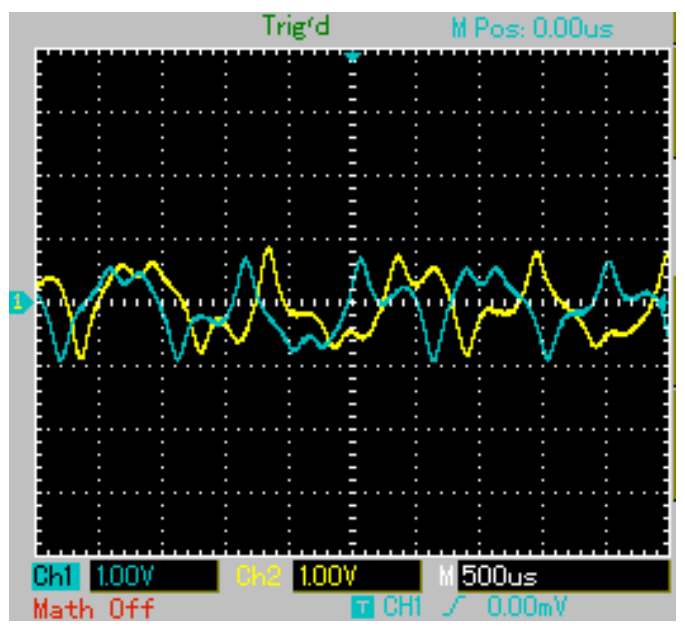

(a)

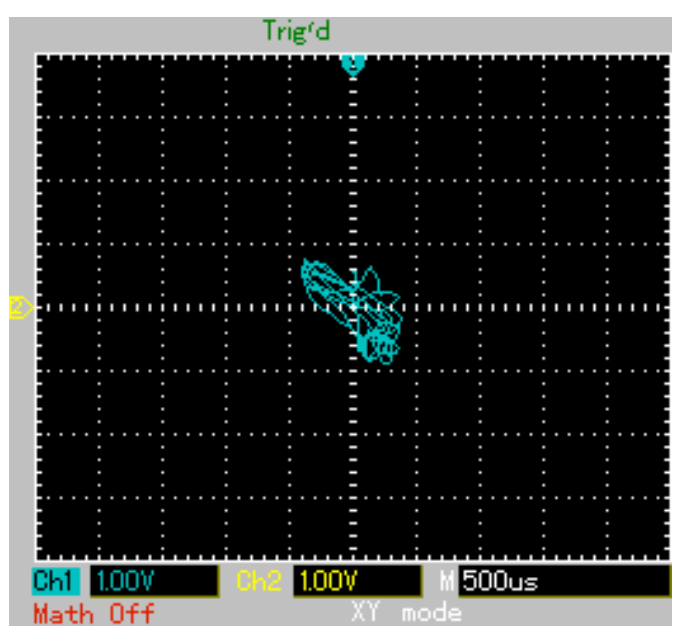

(b)

Figura 42 - Sinal de saída dos circuitos mestre $2(\mathrm{CH} 1)\left(\mathrm{R}_{1}=47 \mathrm{k} \Omega\right.$ ), e escravo $1(\mathrm{CH} 2)$ $\left(\mathrm{R}_{1}=44 \mathrm{k} \Omega\right)$, e (b) o respectivo diagrama de fase. Como se pode verificar, os circuitos mestre 2 e escravo 1 não sincronizaram-se quando a soma dos sinais de saída dos circuitos escravos 1 , 2 e 3 são reaplicadas aos mesmos, através da malha de realimentação.

Na Figura 43, é apresentado o grafico dos sinais de saída dos circuitos mestre $2\left(R_{1}=47\right.$ $\mathrm{k} \Omega$ ), e escravo $3\left(\mathrm{R}_{1}=50 \mathrm{k} \Omega\right.$ ), e o respectivo diagrama de fase, quando reaplicado o sinal referente à soma dos sinais de saída dos circuitos escravos 1,2 e 3. 


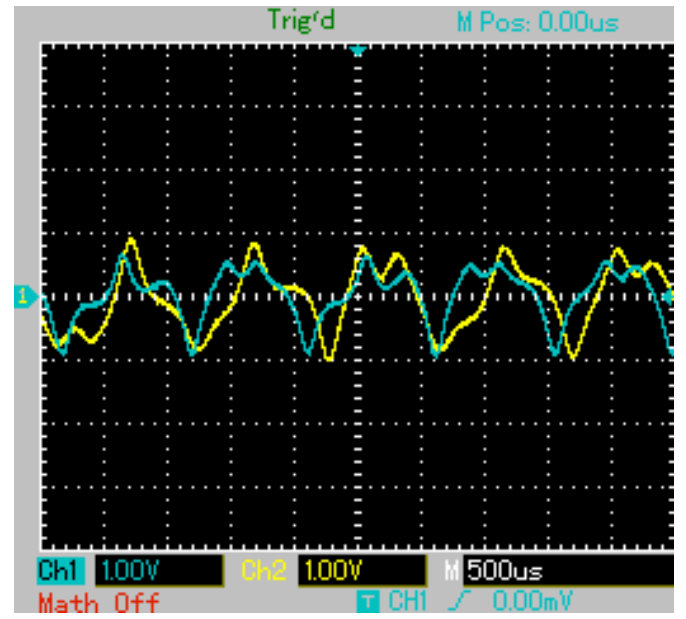

(a)

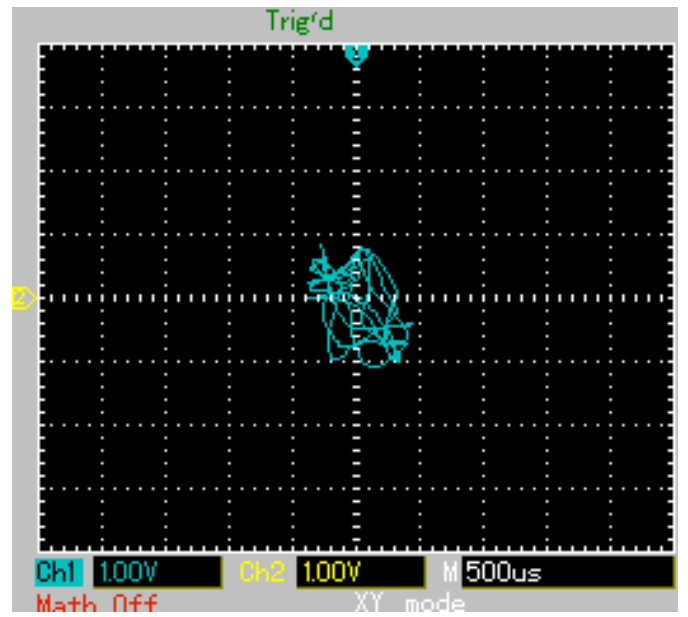

(b)

Figura 43 - Sinal de saída dos circuitos mestre $2(\mathrm{CH} 1)\left(\mathrm{R}_{1}=47 \mathrm{k} \Omega\right)$ e escravo $3(\mathrm{CH} 2)$ $\left(\mathrm{R}_{1}=50 \mathrm{k} \Omega\right.$ ), e (b) o respectivo diagrama de fase. Como se pode verificar, os circuitos mestre 2 e escravo 3 não sincronizaram-se quando a soma dos sinais de saída dos circuitos escravos 1 , 2 e 3 são reaplicadas aos mesmos, através da malha de realimentação.

A Figura 44 apresenta os sinais de saída dos circuitos mestre $3\left(R_{1}=50 \mathrm{k} \Omega\right.$ ) e escravo 1 $\left(\mathrm{R}_{1}=44 \mathrm{k} \Omega\right)$, e o respectivo diagrama de fase, quando reaplicado o sinal referente à soma dos sinais de saída dos circuitos escravos 1,2 e 3 .

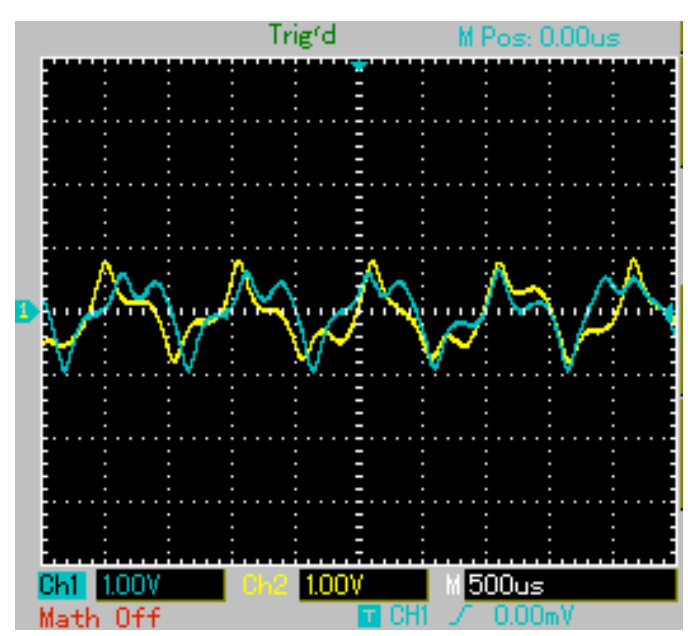

(a)

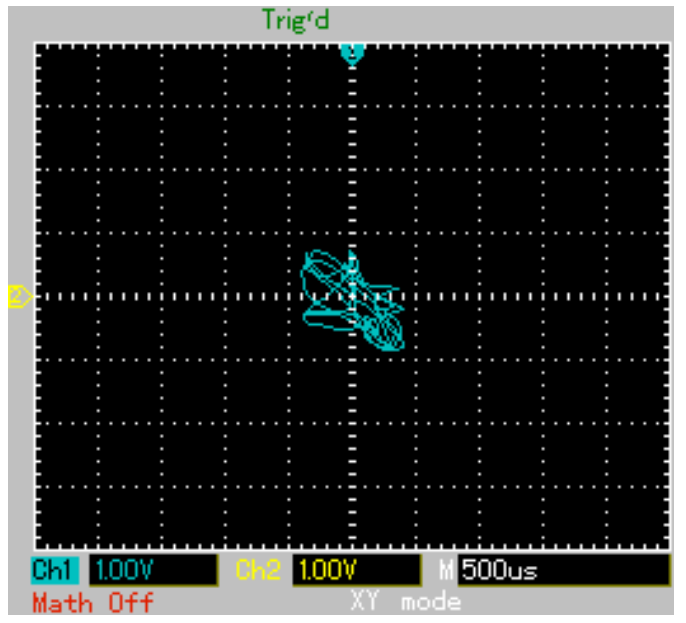

(b)

Figura 44 - Sinal de saída dos circuitos mestre $3(\mathrm{CH} 1)\left(\mathrm{R}_{1}=50 \mathrm{k} \Omega\right.$ ) e escravo $1(\mathrm{CH} 2)$ $\left(\mathrm{R}_{1}=44 \mathrm{k} \Omega\right)$, e (b) o respectivo diagrama de fase. 
Como se pode verificar, os circuitos mestre 3 e escravo 1 não sincronizaram-se quando a soma dos sinais de saída dos circuitos escravos 1,2 e 3 são reaplicadas aos mesmos, através da malha de realimentação.

A Figura 45 mostra os sinais de saída dos circuitos mestre $3\left(R_{1}=50 \mathrm{k} \Omega\right)$, e escravo 2 $\left(\mathrm{R}_{1}=47 \mathrm{k} \Omega\right)$, e o respectivo diagrama de fase, quando reaplicado o sinal referente à soma dos sinais de saída dos circuitos escravos 1,2 e 3 .

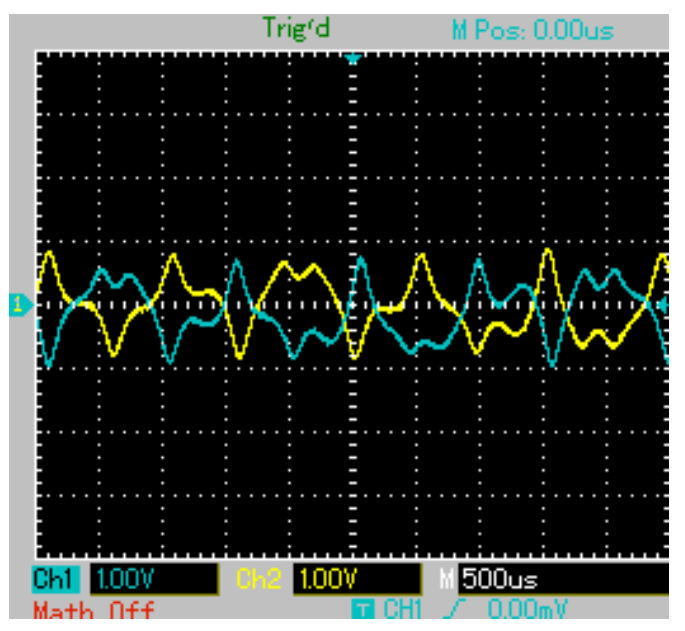

(a)

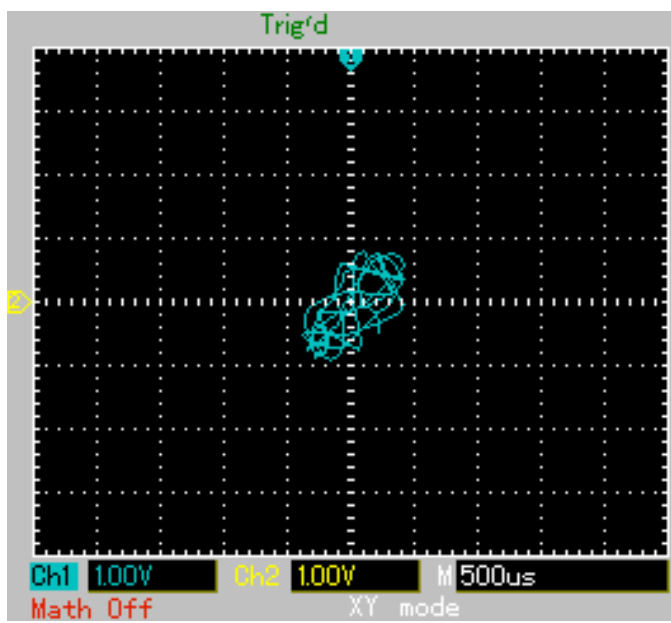

(b)

Figura 45 - Sinal de saída dos circuitos mestre $3(\mathrm{CH} 1)\left(\mathrm{R}_{1}=50 \mathrm{k} \Omega\right)$ e escravo $2(\mathrm{CH} 2)$ $\left(\mathrm{R}_{1}=47 \mathrm{k} \Omega\right)$, e (b) o respectivo diagrama de fase.

Como se pode verificar, os circuitos mestre 3 e escravo 1 não sincronizaram-se quando a soma dos sinais de saída dos circuitos escravos 1, 2 e 3 são reaplicadas aos mesmos, através da malha de realimentação. 


\section{Capítulo 6}

\section{Introdução}

Neste capítulo são apresentadas as discussões referentes a este trabalho de doutorado.

\subsection{Discussões}

Neste trabalho foi realizada originalmente a implementação elétrica do circuito eletrônico que emula o comportamento de um sistema partícula numa caixa. Foi estudado o comportamento caótico tanto experimentalmente, bem como através de simulações numéricas, utilizando-se o método preditor-corretor. A fim de se estudar o sincronismo entre circuitos partícula numa caixa idênticos, foram propostas configurações utilizando-se montagens com esquemas de malha fechada de realimentação, com as finalidades de se aumentar a precisão do sistema, rejeitar o efeito de perturbações externas; melhorar a dinâmica do sistema e, eventualmente, estabilizar um sistema naturalmente instável em malha aberta; diminuir a sensibilidade do sistema a variações dos parâmetros do processo, ou seja, tornar o sistema robusto, e por fim, eliminar divergência exponencial do sistema, ou seja, na condição onde os coeficientes de Lyapunov são positivos.

Primeiramente, foi analisado o comportamento caótico de um único circuito partícula numa caixa, o qual foi obtido pela variação do parâmetro de bifurcação que controla o circuito. A variação do parâmetro frequência do sinal de entrada senoidal $V_{E}=V_{\max } \sin (\omega t)$ foi utilizada como parâmetro de bifurcação. Observou-se a quebra de simetria do atrator do sistema, apresentada na Figura 17, e também comportamentos típicos de sistemas dinâmicos: a bifurcação e dobramento do período, observando-se a ocorrência de bifurcações de Hopf de período T, 2T, 4T, e finalmente, a transição para o regime caótico, conforme apresentado na Figura 18. Foi implementada uma simulação numérica do atrator caótico do sistema, obedecendo-se as mesmas condições experimentais utilizadas previamente, conforme Figura 19. Verificaram-se resultados semelhantes aos obtidos nos experimentos, como visto na 
Figura 18(d), o que mostra a adequação do modelo partícula numa caixa proposto com a implementação elétrica do circuito eletrônico partícula numa caixa.

Posteriormente, foram propostas configurações compostas de dois circuitos idênticos partícula numa caixa, do tipo mestre-escravo. Foram observados os diferentes regimes de sincronismo que pode ser exibidos pares de circuitos idênticos partícula numa caixa, em uma configuração mestre e escravo, e então foram analisados os diversos tipos de sincronismo previstos na literatura que o sistema poderia exibir. A fim de visualizar essas transições de regimes de sincronismo, passando pelos regimes de sincronismo completo, lag e de fase, foi alterada a resistência de realimentação entre os circuitos mestre e escravo, de forma a modificar o acoplamento entre os circuitos.

Primeiramente, analisou-se uma configuração de circuitos partícula numa caixa, como mestre-escravo, num esquema de malha fechada de realimentação, exibindo um regime de sincronismo completo. Por meio da análise das formas de onda de saída dos circuitos mestre e escravo apresentados na Figura 20, pôde-se observar que os circuitos exibem um rico comportamento caótico, ocorrendo o regime de sincronismo completo entre seus sinais de saídas, para uma resistência de realimentação $R_{R E}=100 \Omega$. O diagrama de fase das saídas dos circuitos mestre e escravo exibe uma reta, vista na Figura 21, cuja forma aproxima-se à função identidade, tal qual descrito na seção 3.6, podendo-se constatar a ocorrência do regime de sincronismo completo. Foram realizadas as simulações numéricas das formas de onda de saída dos circuitos mestre e escravo (Figura 22), bem como a simulação numérica do diagrama de fase do circuito sob as mesmas condições utilizadas nas medidas experimentais (Figura 23).

Aumentando-se o valor da resistência de realimentação $R_{R E}=100 \mathrm{k} \Omega$, e consequentemente diminuindo o acoplamento entre os circuitos mestre e escravo, observou-se que as formas de onda de saída dos circuitos mestre e escravo apresentam comportamento caótico, e que as mesmas exibem um sincronismo de atraso ou lag, como visto na sobreposição das formas de onda de saída dos circuitos, na Figura 24. As saídas dos circuitos se encontram em atraso uma em relação à outra, ocorrendo o sincronismo de atraso, tal que $x_{e}\left(t+\tau_{0}\right) \approx x_{m}(t)$. Na Figura 25 é apresentado do diagrama de fase dos circuitos mestre $\mathrm{e}$ escravo obtido experimentalmente, onde pôde ser corroborado o atraso de fase verificado anteriormente, típico do regime de sincronismo lag. Na Figura 26 são apresentados os resultados da simulação numérica das formas de onda de saída dos circuitos mestre e escravo, 
e na Figura 27 são mostrados os resultados da simulação numérica do espaço de fase dos circuitos mestre e escravo no regime de sincronismo lag. Estes resultados corroboram os resultados experimentais obtidos anteriormente, e a adequação do modelo proposto.

Aumentando-se ainda mais o valor da resistência de realimentação $R_{R E}=500 \mathrm{k} \Omega$, e consequentemente diminuindo o acoplamento entre os circuitos mestre e escravo, observou-se que as formas de onda de saída dos circuitos mestre e escravo apresentam comportamento caótico, e que as mesmas exibem um sincronismo de fase, ou seja, as fases dos sinais de saída do circuito mestre e do circuito escravo estão sincronizadas, porém suas amplitudes divergem, como visto na sobreposição das formas de onda de saída dos circuitos, na Figura 28. Na Figura 29 é visto o diagrama de fase das saídas dos circuitos mestre e escravo, para o regime de sincronismo de fase. Este resultado ajuda a elucidar a ocorrência da existência de uma fase entre os sinais de saída dos circuitos mestre e escravo. Para verificar a adequação do modelo ao regime de sincronismo observado, foram simulados numericamente os sinais de saída dos circuitos mestre e escravo para esse regime de sincronismo, como visto na Figura 30 e o diagrama de fase para esse mesmo regime, conforme apresentado na Figura 31. Ambos os resultados corroboram a adequação do modelo proposto ao seu análogo eletrônico ora implementado, e a ocorrência do regime de sincronismo de fase, previsto na literatura

A fim de simular o comportamento do circuito na transmissão de informação em um canal, foram construídas diversas configurações de linhas de transmissão entre a malha de realimentação e os circuitos mestre e escravo, que originalmente exibiriam o sincronismo completo, uma vez que foi utilizada uma resistência de realimentação $R_{R E}=100 \Omega$. Foram estabelecidas configurações de linhas de transmissão segundo o modelo $\mathrm{T}$, simulando distâncias de 100 m, 1 km e 10 km, e a montagem experimental realizada de acordo com o esquema visualizado no diagrama de blocos da Figura 16.

A Figura 32 apresenta os resultados comparando o sinal de saída do mestre e o sinal de saída do escravo acoplado à uma linha de transmissão modelo T, distância de $100 \mathrm{~m}$. Na Figura 33 são apresentados os resultados comparando o sinal de saída do mestre e o sinal de saída do escravo acoplado à uma linha de transmissão modelo T, distância de $1 \mathrm{~km}$. Na Figura 34 são apresentados os resultados comparando o sinal de saída do mestre e o sinal de saída do escravo para uma linha de transmissão modelo T, distância de $10 \mathrm{~km}$. Com estes ensaios empregando linhas de transmissão acopladas à malha de realimentação nos circuitos mestre e 
escravo, foi observada a ocorrência de sincronismo entre os sinais dos circuitos mestre e escravo, o que também demonstra a robustez do acoplamento elétrico entre circuitos mestreescravo casados.

A fim de verificar a robustez do sincronismo dos circuitos mestre e escravo, e aumentar a topologia do sistema, em analogia com um canal de comunicação multiusuário, foi proposta uma configuração de sistema composta de pares de circuitos mestres e escravos idênticos, casados dois a dois. Os sinais de saída dos circuitos mestre e escravo eram somados, e então utilizados na realimentação dos circuitos [4]. Inicialmente foram utilizados dois pares de circuitos mestre-escravo, casados dois a dois. Os circuitos 1 e 2 diferem apenas no valor da resistência $R_{1}$, mostrada no diagrama da Figura 8 , sendo que o valor de $R_{1}$ para o circuito denominado circuito 1 é $44 \mathrm{k} \Omega$, e para o circuito denominado circuito 2 , o valor de $R_{2}$ é 47 $\mathrm{k} \Omega$. É importante ressaltar que o sinal de saída advindo circuito mestre 1 é interpretado como um ruído para o circuito escravo 2, e vice-versa. A intenção deste experimento é verificar a robustez do acoplamento entre circuitos partícula numa caixa, em uma configuração mestre escravo, que inicialmente apresentaria um regime de sincronismo completo. Na Figura 35, é exibido o gráfico do experimento analisando o sincronismo entre circuitos mestre 1 e escravo 1, que apresentam parâmetros casados. Verificou-se a ocorrência de sincronismo entre os sinais de saída dos circuitos mestre e escravo, fato que pode ser corroborado através da análise do diagrama de fase das saídas dos circuitos mestre e escravo casados. Na Figura 36 é exibido o gráfico do experimento analisando o sincronismo entre circuitos mestre 1 e escravo 2, que apresentam parâmetros não casados. Verificou-se que não ocorre sincronismo entre os sinais de saída dos circuitos mestre e escravo, fato que pode ser corroborado através da análise do diagrama de fase das saídas dos circuitos mestre e escravo não casados.

Com o objetivo de realizar outro teste de robustez do sincronismo dos circuitos transmissor e receptor, bem como aumentar a topologia do sistema, em uma possível analogia com um canal de comunicação multiusuário, foi proposta uma configuração do sistema composta de três pares de circuitos mestre-escravo, casados dois a dois, de forma que os sinais de saída destes eram somados, e sua soma então utilizada na realimentação dos circuitos. Os circuitos 1,2 e 3 diferiam apenas no valor da resistência $R_{1}$, ilustrada no diagrama da Figura 8 , sendo que o valor de $R_{1}$ para o primeiro par de circuitos é $44 \mathrm{k} \Omega$ e para o segundo par de circuitos, o valor de $\mathrm{R}_{1}$ é $47 \mathrm{k} \Omega$, e para o terceiro par de circuitos, o valor de $\mathrm{R}_{1}$ é $50 \mathrm{k} \Omega$. 
Na Figura 37 é apresentado o gráfico dos sinais de saída dos circuitos mestre 1 e escravo $1\left(\mathrm{R}_{1}=44 \mathrm{k} \Omega\right)$, e seu respectivo diagrama de fase. Verificou-se que os circuitos mestre $1 \mathrm{e}$ escravo 1 sincronizaram-se quando a soma dos sinais de saída dos circuitos escravos 1,2 e 3 são reaplicadas ao circuito mestre 1 por meio da malha de realimentação, uma vez que os mesmos possuem parâmetros casados. Os resultados estão em concordância com os resultados obtidos utilizando-se o sistema composto de dois circuitos mestre e dois circuitos escravo, conforme visto na Figura 35, entretanto quando introduzido um terceiro par de circuitos mestre/escravo, a razão sinal/ruído diminui. Na Figura 38 é apresentado o gráfico dos sinais de saída dos circuitos mestre 2 e escravo $2\left(\mathrm{R}_{1}=47 \mathrm{k} \Omega\right)$, e o respectivo diagrama de fase. Nesta medição, observa-se que os circuitos mestre 2 e escravo 2 sincronizaram-se quando a soma dos sinais de saída dos circuitos escravos 1, 2 e 3 são reaplicadas ao circuito mestre 2, por meio da malha de realimentação. Na Figura 39 é apresentado o gráfico analisando os sinais de saída dos circuitos mestre 3 e escravo $3\left(R_{1}=50 \mathrm{k} \Omega\right.$ ), e seu respectivo diagrama de fase. Analisando os resultados obtidos neste experimento, observa-se que os circuitos mestre 3 e escravo 3 sincronizaram-se quando a soma dos sinais de saída dos circuitos escravos 1,2 e 3 é reaplicada ao circuito mestre 3 , através da malha de realimentação, como esperado, uma vez que os mesmos possuem parâmetros casados. Observa-se que os resultados são semelhantes aos obtidos com o sistema composto de dois circuitos mestre e dois circuitos escravo, conforme visto na Figura 35.

Na Figura 40 é apresentado o gráfico das formas de onda de saída dos circuitos mestre 1 $\left(\mathrm{R}_{1}=44 \mathrm{k} \Omega\right)$ e escravo $2\left(\mathrm{R}_{1}=47 \mathrm{k} \Omega\right)$, e o respectivo diagrama de fase, quando reaplicado o sinal referente à soma dos sinais de saída dos circuitos escravos 1, 2 e 3. Na Figura 41, são apresentadas as formas de onda de saída dos circuitos mestre $1\left(\mathrm{R}_{1}=44 \mathrm{k} \Omega\right)$, e escravo 3 $\left(\mathrm{R}_{1}=50 \mathrm{k} \Omega\right)$, e o respectivo diagrama de fase, quando reaplicado o sinal referente à soma dos sinais de saída dos circuitos escravos 1, 2 e 3. Na Figura 42 são analisadas as formas de onda de saída dos circuitos mestre $2\left(\mathrm{R}_{1}=47 \mathrm{k} \Omega\right)$, e escravo $1\left(\mathrm{R}_{1}=44 \mathrm{k} \Omega\right)$, e o respectivo diagrama de fase, quando reaplicado o sinal referente à soma dos sinais de saída dos circuitos escravos 1, 2 e 3. Na Figura 43, é analisada a forma de onda de saída dos circuitos mestre $2\left(R_{1}=47 \mathrm{k} \Omega\right)$, e escravo $3\left(R_{1}=50 \mathrm{k} \Omega\right)$, e o respectivo diagrama de fase, quando reaplicado o sinal referente à soma dos sinais de saída dos circuitos escravos 1, 2 e 3. A Figura 44 apresenta as formas de onda de saída dos circuitos mestre $3\left(R_{1}=50 \mathrm{k} \Omega\right)$, e escravo $1\left(\mathrm{R}_{1}=44 \mathrm{k} \Omega\right)$, e o respectivo 
diagrama de fase, quando reaplicado o sinal referente à soma dos sinais de saída dos circuitos escravos 1, 2 e 3. A Figura 45 apresenta as formas de onda de saída dos circuitos mestre 3 $\left(\mathrm{R}_{1}=50 \mathrm{k} \Omega\right)$, e escravo $2\left(\mathrm{R}_{1}=47 \mathrm{k} \Omega\right)$, e o respectivo diagrama de fase, quando reaplicado o sinal referente à soma dos sinais de saída dos circuitos escravos 1,2 e 3.

A partir dos resultados da análise das formas de onda de saída dos circuitos partícula numa caixa com parâmetros não casados, depreende-se que os mesmos não apresentaram sincronismo, uma vez que seus parâmetros divergem, como previsto na literatura. Por outro lado, analisando os resultados das formas de onda de saída dos circuitos mestre-escravo com parâmetros casados, verificou-se que existe robustez no seu acoplamento. Tais resultados obtidos poderiam sugerir o uso deste circuito em telecomunicações, em sistemas de comunicação multiusuário, análogos à tecnologia CDMA. 


\section{Capítulo 7}

\section{Introdução}

Neste capítulo serão apresentadas as conclusões deste trabalho de doutorado, bem como as contribuições da pesquisa e as considerações finais.

\subsection{Conclusões}

Neste trabalho foram realizados a implementação elétrica do circuito partícula numa caixa, bem como implementação elétrica de um sistema composto por dois circuitos idênticos, em um esquema de malha fechada de realimentação, observando seu rico comportamento caótico.

Foi investigada experimentalmente e através de simulações numéricas a robustez do acoplamento entre circuitos eletrônicos partícula na caixa em diferentes configurações, observando-se diversos tipos de sincronismo descritos na literatura.

Primeiramente, foi realizada a implementação elétrica de um único circuito eletrônico partícula numa caixa. Foi analisado o comportamento caótico do circuito partícula numa caixa proposto obtido através da variação do parâmetro de bifurcação, que controla o circuito. A variação do parâmetro frequência do sinal de entrada senoidal $V_{E}=V_{\max } \sin (\omega t)$ foi utilizada como parâmetro de bifurcação, observando-se comportamentos típico de sistemas dinâmicos: quebra de simetria, bifurcação e dobramento do período, período T, 2T, 4T e finalmente, o comportamento do regime caótico.

Posteriormente, o mesmo circuito foi estudado em diferentes configurações por meio da compostas de circuitos partícula numa caixa idênticos, em um esquema de malha fechada de realimentação, observando seu rico comportamento caótico. Foram observados os diferentes regimes de sincronismo entre os circuitos mestre e escravo, transições de regimes de sincronismo, passando pelos sincronismos completo, lag, e de fase, e suas mudanças devido à alteração de parâmetros como a resistência de realimentação, relacionada com o 
acoplamento entre os circuitos partícula numa caixa. Foram também comparados os resultados obtidos através dos experimentos e simulações numéricas. Os resultados experimentais e as simulações numéricas estão em concordância, o que demonstra adequação do modelo proposto à implementação elétrica dos circuitos.

A fim de emular o comportamento do circuito na transmissão de informação em um canal, foram construídas diversas configurações de linhas de transmissão entre os circuitos mestre e escravo. Foram estabelecidas configurações de linhas de transmissão segundo o modelo T, simulando distâncias de $100 \mathrm{~m}, 1 \mathrm{~km}$ e $10 \mathrm{~km}$. Com estes ensaios empregando linhas de transmissão acopladas à malha de realimentação nos circuitos mestre e escravo, foi observado o sincronismo completo entre os sinais dos circuitos transmissor e receptor, uma vez que os diagramas do espaço de fase sugerem o sincronismo de fase entre os estados do sistema mestre e do sistema escravo, e se aproximam da relação $x_{m}(t)=x_{e}(t)$, conforme descrito na teoria da seção 3.6.

Através do estudo do sistema composto de dois pares de circuitos partícula numa caixa mestre-escravo, casados dois, foi verificado que os circuitos mestre e escravo casados sincronizaram-se quando a soma dos sinais de saída dos circuitos escravos 1 e 2 são reaplicadas ao circuito mestre 1 , por meio da malha de realimentação.

Em analogia com um canal de comunicação multiusuário, foi proposta uma configuração do sistema composta de três pares de circuitos mestre-escravo, casados dois a dois, onde a saída destes era somada e então utilizada na realimentação dos circuitos. Analisando os resultados deste experimento, foi observado que os circuitos mestre e escravo casados sincronizaram-se quando a soma dos sinais de saída dos circuitos escravos 1,2 e 3 é reaplicada ao respectivo circuito mestre, através da malha de realimentação. Observa-se que os resultados são semelhantes aos obtidos com o sistema composto de dois pares de circuitos mestre e dois circuitos escravo, entretanto a razão sinal/ruído quando empregados três pares de circuitos mestre-escravo casados dois a dois diminui.

Foram então analisados os sinais de saída e diagramas de fase dos circuitos mestre e escravo com parâmetros não casados. Observou-se nestes experimentos que os circuitos escravos não se sincronizaram com os circuitos mestres não casados, uma vez que os parâmetros dos mesmos diferem, de acordo com a teoria do sincronismo de circuitos caóticos descrita anteriormente. 
Por meio da variação do parâmetro de acoplamento $\varepsilon$, relacionado à resistência de realimentação, é possível observar a transição dos regimes de sincronismo dos circuitos, passando pelos regimes de sincronismo de fase, lag e completo. Foi possível medir e analisar esse comportamento, bem como emular este comportamento, uma vez que o modelo proposto adequou-se às condições experimentais observadas na implementação elétrica do circuito eletrônico partícula numa caixa.

O circuito proposto apresenta vantagens em relação a outros descritos na literatura, devido à simplicidade da sua configuração, e consequentemente, facilidade em propor outras configurações a partir do mesmo. Os resultados obtidos poderiam sugerir o uso deste circuito em telecomunicações, em sistemas de comunicação multiusuário, análogos à tecnologia CDMA. 


\section{Capítulo 8}

\subsection{Bibliografia}

[1] HRAMOV, A. E.; KORONOVSKII, A. A . (2005). Generalized Synchronization: A modified system approach. Physical Review E, v.71, n.67201, pp. 1-4.

[2] KORONOVSKII, A. A, O. I. MOSKALENKO, HRAMOV, A. E. (2009). On the use of chaotic synchronization for secure communication. Physics-Uspeki, v. 52 (12), pp. $1213-1238$.

[3] TSIMRING; L. S.; SUSHCHIK, M. M. (1996). Multiplexing chaotic signals using synchronization. Physical Letters A, v. 213, pp. 155.

[4] BLAKELY, J .N; CORRON, N. J. (2005). Multiplexing symbolic dynamicsbased chaos communications using synchronization. Journal of Physics: Conference Series, v.23, pp. 259-266.

[5] LORENZ, E. N. In: The Essence of Chaos, $1{ }^{\text {a }}$ Edição, University of Washington Press, 1993.

[6] CHUA, L. O., KOMURO, M., MATSumoto, T. (1986). The double scroll family. IEE Transactions Circuits and Systems, CAS-33, pp. 1073, 1118.

[7] CHUA, L. O., KOCAREV, L., ECKERT, K.(1992). Experimental chaos synchronization in Chua's circuit. International Journal of Bifurcation and Chaos, v.2, n.3, pp.705-708.

[8] BARBOZA, R., CHUA, L. O. (2008). The four-element Chua's circuit. International Journal of Bifurcation and Chaos, v.18, n.4, pp. 943-955.

[9] MUTShUSAWAMY, B., CHUA, L. O. (2010). Simplest Chua's Circuit. International Journal of Bifurcation and Chaos, v. 20, n.5, pp. 1567-1580.

[10] PECORA, L. M., CARROLL, T. L. (1990). Synchronization in chaotic systems. Physical Review Letters, v. 64, n. 8, pp. 821-825.

[11] CARROL, T. L.; PECORA, L. M. (1991). Synchronizing chaotic circuits. IEEE Transactions on Circuits and Systems, v.18, n.4, pp. 453-356.

[12] ZIMMERMAN, R., CELASCHI, S., NETO, L. G. (1991). The electronic bouncing ball. American Journal of Physics, v.60, n.4, pp. 370-375. 
[13] PIZOLATO, J. P. Jr.; ROMERO, M. A.; NETO, L .G. (2008). Chaotic Communication Based on the Particle-in-a-Box Electronic Circuit. IEEE Transactions on Circuits and Systems -I Regular Papers, v.55, n. 4, pp. 1108-1115.

[14] DIXON, R. C . In: Spread spectrum systems with commercial applications. $3^{\text {a }}$ ed. New York: John Wiley \&Sons, 1994.

[15] GOODMAN, J. W. In: Introduction to Fourier Optics, $3^{\text {a }}$. ed. Roberts \& Company Publishers, 2004.

[16] LORENZ, E. N. In: The Essence of Chaos, $1{ }^{\text {a }}$ Edição, University of Washington Press, 1993.

[17] YORKE, T. Y. L. (1975). Period Three Implies Chaos. American Mathematical Monthly, v. 82, n. 10, pp. 985-992.

[18] MAY, R. M. (1976). Simple mathematical models with very complicated dynamics. Nature, v. 261, pp. 459-467.

[19] FEIGENBAUM, M. J. (1978). Quantitative universality for a class of nonlinear transformations. Journal of Statistical Physics, v. 19, n. 1, pp. 25-52.

[20] MANDELBROT, B. et al. (1980). Critical Phenomena on Fractal Lattices. Physical Review Letters, v. 45, pp. 855-858.

[21] WOLF, A. et. al. (1985). Determining Lyapunov exponents from a time series. Physica 16D, pp.285-317.

[22] ALLIGOOD, K.T, SAUER, T.D., YORKE, J.A. In: Chaos: An Introduction to Dynamical Systems, 1ํㅡㄹ Edição, Springer Verlag, 1996.

[23] GROS, C. In: Complex and Adaptative Dynamical Systems, Springer, 2008.

[24] OTT, E. In: Chaos in Dynamical Systems, $1{ }^{\text {a }}$ Edição, Cambridge University Press, 1993.

[25] HUYGENS, C. In: Horologium Oscillatorium (1673), Tradução para o inglês: (1986) The Pendulum Clock, Iowa State University Press.

[26] CENCINI, M..;CECCONI, F.;VULPIANI, A. In: Chaos: From Simple Models to Complex Systems, v.17, World Scientific, 2010.

[27] ROSEnBlum, M. G, PIKOVSKY, A. S., KURTHS, J. (1997). From Phase to Lag Synchronization in Coupled Chaotic Oscillators. Physical Review Letters, v. 78, n. 22, pp. 4193-4196. 
[28] BROWN, R. (2000). A unifying definition of synchronization for dynamical systems. Chaos, v. 10, n. 2, pp. 344-349.

[29] ROSENBLUM, M. G. et al. (1996). Phase Synchronization of Chaotic Oscillators. Physical Review Letters, v.76, n.11, pp. 1804-1807.

[30] PYRAGAS, K. (1996). Weak and strong synchronization of chaos. Physical Review E, v. 54, pp. 4508-4511.

[31] KOLUMBÁN, G.; KENNEDY, M. P.; CHUA, L. O. (1998). The role of synchronization in digital communications using chaos-part II: chaotic modulation and chaotic synchronization. IEE Transactions on circuits and systems I: fundamental theory and applications, v. 45, n. 11, pp. 1129-1140.

[32] HAYES, S. et al (1993). Communicating with chaos. Physical Review Letters, v. 70, pp. 32-36.

[33] NEFF, J., CARROLL,T. (1993). Circuits that get chaos in sync. Scientific American, v. 269, pp. 120-122.

[34] KORONOVSKII, A. A., MOSKALENKO, O. I, HRAMOV, A. E. (2009). On the use of chaotic synchronization for secure communication. Physics Uspekhi, v. 52, n. 12, pp. 1213-1238.

[35] SADIKU, M. N. O. In: Elementos de Eletromagnetismo, $3^{\text {a }}$ Edição, Editora Bookman, 2004.

[36] GROSU, I. et al. (2008). Designing Coupling for Synchronization and Amplification of Chaos. Physical Review Letters, v. 100; pp. 234102-1 -234102-4.

[37] GONÇALVES, L. N. (1990). Modelos eletrônicos do atrito seco, sistemas biestáveis e colisões inelásticas. Dissertação (Mestrado)-Instituto de Física e Química de São Carlos- Departamento de Física e Ciência dos Materiais, Universidade de São Paulo, 1990.

[38] GONÇALVES, C.; GONÇALVES, L. N. (2011). Electrical implementation of a complete synchronization dynamic system. 2011 Journal of Physics: Conference Series, Dynamic Days South America 2010, v. 285, pp. 01-10. Disponível em: http://iopscience.iop.org/1742-6596/285/1/012013. Acesso em 13/10/2011.

[39] GONÇALVES, C.; GONÇALVES, L. N. (2011). Electrical implementation of a complete synchronization dynamic system. 2011. In: Dynamic Days South America, 
2010, São José dos Campos. Proceedings, extended abstracts. Disponível em : http://mtcm19.sid.inpe.br/rep/sid.inpe.br/mtcm19@80/2010/07.30.01.03?languagebutt on=en\&searchsite=bibdigital.sid.inpe.br:80. Acesso em 13/10/2011. 


\section{Apêndice A}

\section{Algoritmo para simulação do circuito partícula na caixa}

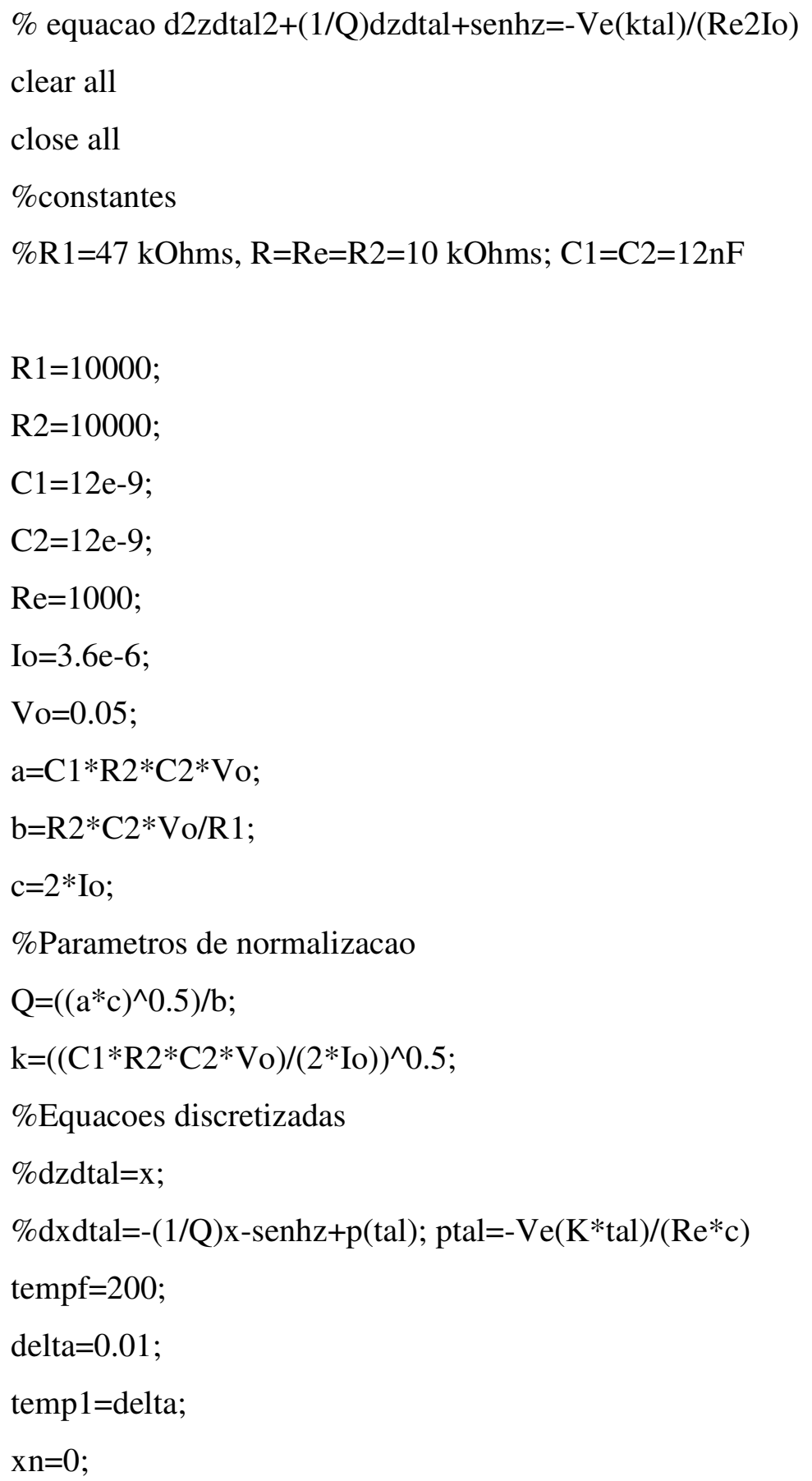


$\mathrm{zn}=0$;

temp $=0$;

cont $=1$;

Amp $=2.0$;

$\mathrm{f}=1096$;

$\mathrm{w}=2 * \mathrm{pi} * \mathrm{f}$

while (temp $1<=$ tempf)

$\mathrm{pn}=-(\mathrm{Amp} * \sin (\mathrm{w} * \mathrm{k} * \mathrm{temp})) /\left(\operatorname{Re}^{*} \mathrm{c}\right)$;

z0n1=zn+delta*xn;

$\mathrm{x} 0 \mathrm{n} 1=\mathrm{zn}+\operatorname{delta}^{*}(-(1 / \mathrm{Q}) * \mathrm{xn}-\sinh (\mathrm{zn})+\mathrm{pn})$;

pn1 $=-\left(A m p * \sin \left(w^{*} k * \operatorname{temp} 1\right)\right) /\left(\operatorname{Re}^{*} \mathrm{c}\right)$;

$\mathrm{zn} 1=\mathrm{zn}+(\operatorname{delta} / 2) *(\mathrm{xn}+\mathrm{x} 0 \mathrm{n} 1) ;$

$\mathrm{xn} 1=\mathrm{xn}+(\mathrm{delta} / 2) *(-(1 / \mathrm{Q}) *(\mathrm{xn}+\mathrm{x} 0 \mathrm{n} 1)-\sinh (\mathrm{zn})-\sinh (\mathrm{z} 0 \mathrm{n} 1)+\mathrm{pn}+\mathrm{pn} 1) ;$

$\mathrm{xn}=\mathrm{xn} 1$;

$\mathrm{zn}=\mathrm{zn} 1$;

temp=temp1;

temp1=temp1+delta;

$\%$ armazenado os valores para plotar o diagrama de fase

$\mathrm{X}($ cont $)=\mathrm{xn}$;

$\mathrm{Z}($ cont $)=\mathrm{zn}$;

cont $=$ cont +1 ;

end

$\%$ plotando os diagramas de fase

figure

$\operatorname{plot}(\mathrm{Z}($ cont-1-10000:cont-1),X(cont-1-10000:cont-1),'k');

title('Espaço de fase'); 


\section{Artigo}

Durante este trabalho de doutorado foi publicado o artigo Electrical implementation of a complete synchronization dynamic system [38]. 


\section{Congresso}

Durante este trabalho de doutorado foi publicado o resumo estendido [39] do trabalho Electrical implementation of a complete synchronization dynamic system. 


\section{Anexo A}

\section{Método trapezoidal}

Para equações diferenciais que não podem ser solucionadas analiticamente, deve-se recorrer a métodos numéricos, sendo o método trapezoidal um dos mais utilizados para este tipo de solução.

Sejam duas coordenadas x e y no plano de fase, o sistema pode ser descrito por duas equações:

$$
\begin{gathered}
\frac{d x}{d t}=y \\
\frac{d y}{d t}=f(x, y, t)
\end{gathered}
$$

Pode-se aproximar a integral de uma função $\frac{d y}{d t}=f(t)$ em um intervalo de tempo $\Delta$, onde $\Delta=t_{n+1}-t_{n}$, pela área de um trapézio, tal que:

$$
\begin{gathered}
\int_{t_{n}}^{t_{n+1}} f(t) d t \cong A \\
A=\left(t_{n+1}-t_{n}\right) \frac{f\left(t_{n+1}\right)+f\left(t_{n}\right)}{2}
\end{gathered}
$$

Mas como $\int f(t) d t=F(t)+\alpha$

$$
\int_{t_{n}}^{t_{n+1}} f(t) d t=F\left(t_{n+1}\right)-F\left(t_{n}\right) \cong \frac{\Delta}{2}\left(f\left(t_{n+1}\right)+f\left(t_{n}\right)\right)
$$

Quanto menor o intervalo de integração, maior a precisão do resultado obtido. Pode-se determinar a função $x_{t_{n+1}}$ e $y_{t_{n+1}}$ do sistema:

$$
\begin{gathered}
\int_{t_{n}}^{t_{n+1}} \frac{d x}{d t} d t=x_{t_{n+1}}-x_{t_{n}} \cong \frac{\Delta}{2}\left(y_{t_{n+1}}+y_{t_{n}}\right) \\
\int_{t_{n}}^{t_{n+1}} \frac{d y}{d t} d t=y_{t_{n+1}}-y_{t_{n}} \cong \frac{\Delta}{2}\left(f\left(x_{t_{n+1}}, y_{t_{n+1}}, t_{n+1}\right)+f\left(x_{t_{n}}, y_{t_{n}}, t_{n}\right)\right)
\end{gathered}
$$


Então:

$$
\begin{gathered}
x_{t_{n+1}}=x_{t_{n}}+\frac{\Delta}{2}\left(y_{t_{n+1}}+y_{t_{n}}\right) \\
y_{t_{n+1}}=y_{t_{n}}+\frac{\Delta}{2}\left(f\left(x_{t_{n+1}}, y_{t_{n+1}}, t_{n+1}\right)+f\left(x_{t_{n}}, y_{t_{n}}, t_{n}\right)\right)
\end{gathered}
$$

Para sistemas dinâmicos, se utiliza o artificio de agrupar os termos que possuem variáveis $x_{t_{n+1}}$ e $y_{t_{n+1}}$, utilizando o artifício de prever os valores dessas variáveis, a saber:

$$
\begin{gathered}
x_{t_{n+1}}^{0}=x_{t_{n}}+\Delta \frac{d x\left(t_{n}\right)}{d t}=x_{t_{n}}+\Delta y_{t_{n}} \\
y_{t_{n+1}}^{0}=y_{t_{n}}+\Delta \frac{d y\left(t_{n}\right)}{d t}=y_{t_{n}}+\Delta f\left(x_{t_{n}}, y_{t_{n}}, t_{n}\right)
\end{gathered}
$$

Assim,

$$
\begin{gathered}
x_{t_{n+1}}=x_{t_{n}}+\frac{\Delta}{2}\left(y_{t_{n+1}}^{0}+y_{t_{n}}\right) \\
y_{t_{n+1}}=y_{t_{n}}+\frac{\Delta}{2}\left(f\left(x_{t_{n+1}}^{0}, y_{t_{n+1}}^{0} t_{n+1}\right)+f\left(x_{t_{n}}, y_{t_{n}}, t_{n}\right)\right)
\end{gathered}
$$

Quanto menor o valor de $\Delta$, maior será a precisão do método.

Foi efetuada a normalização da equação para o sistema de acordo com a referência [12] conforme as equações:

$$
\begin{aligned}
& a \frac{d^{2} z}{d t^{2}}+b \frac{d z}{d t}+f(z)=p(t) \\
& z=c y \\
& a c \frac{d^{2} y}{d t^{2}}+b c \frac{d y}{d t}+f(y)=p(t) \\
& t=k \tau \\
& \frac{a c}{k^{2}} \frac{d^{2} y}{d t^{2}}+b c \frac{d y}{d t}+f(y)=p(k \tau) \\
& k=\frac{a}{b} \\
& \frac{d^{2} y}{d \tau^{2}}+\frac{d y}{d \tau}+f(y)=p(\tau) \\
& p(\tau)=\frac{a}{b^{2} c} p(t)
\end{aligned}
$$


Electrical implementation of a complete synchronization dynamic system

This article has been downloaded from IOPscience. Please scroll down to see the full text article.

2011 J. Phys.: Conf. Ser. 285012013

(http://iopscience.iop.org/1742-6596/285/1/012013)

View the table of contents for this issue, or go to the journal homepage for more

Download details:

IP Address: 189.35.25.235

The article was downloaded on 13/10/2011 at 01:28

Please note that terms and conditions apply. 


\title{
Electrical implementation of a complete synchronization dynamic system
}

\author{
C Gonçalves ${ }^{1}$ and L G Neto ${ }^{1}$ \\ ${ }^{1}$ Universidade de São Paulo \\ Avenida Trabalhador São-Carlense, 400 CEP 13566-590 São Carlos-SP \\ E-mail: cristhiane.goncalves@usp.br
}

\begin{abstract}
This work presents an electrical implementation of complete synchronization systems, proposing a master/slave synchronization of two identical particle-in-a-box electronic circuits, exhibiting a rich chaotic behaviour. This behaviour was measured, and also emulated, and the results were compared. Just a few works in literature describe experimental measurements of chaotic systems. The master/slave electronic circuits employed have a very simple electronic implementation and results show a complete synchronization of the system.
\end{abstract}

\section{Introduction}

Synchronization of chaotic systems is a phenomenon that occurs when chaotic oscillators are coupled, or when a chaotic oscillator drives another one. In several situations, these systems can exhibit exponential divergence of the trajectories of two identical chaotic systems started with nearly the same initial conditions. However, synchronization of coupled or driven chaotic oscillators is a phenomenon well established experimentally, and well understood theoretically. It has been found that chaos synchronization is a rich phenomenon wich presents a variety of forms.

Synchronization between dynamical systems is being extensively explored in electronic circuits [1, 2]. There are many types of circuits with potential applications to generate chaotic signals, like Chua's circuit [3] and Lorenz-based chaotic circuit [4]. Pecora and Carroll proposed the drive-response scheme and determined conditions of synchronization by means of conditional Lyapunov exponents[5].

Dynamical systems can exhibit several types of synchronization, among them: complete synchronization; generalized synchronization, phase synchronization and lag synchronization.

Complete synchronization occurs when there is coincidence of states of two interacting subsystems, as described by equation (1):

$$
x_{d}(t)=x_{r}(t)
$$

This regime appears only if the both interacting systems are identical [6].

Generalized synchronization has also been described in the literature [7], and introduced for driveresponse systems, as the presence of a relation between the states of response and drive, thus:

$$
x_{r}(t)=\mathfrak{S}\left[x_{d}(t)\right]
$$


Considering the behavior of two unidirectionally coupled chaotic systems:

$$
\begin{aligned}
& \dot{x}_{d}=H\left(x_{d}, g_{d}\right) \\
& \dot{x}_{r}=G\left(x_{r}, g_{r}\right)+\varepsilon P\left(x_{d}, x_{r}\right)
\end{aligned}
$$

Where $x_{d, r}$ are the state vectors of the drive and response systems, respectively, and $H$ and $G$ define the vector fields of these systems, $g_{d}$ and $g_{r}$ are the controlling parameters, $P$ represents the coupling term, and $\varepsilon$ is the scalar coupling parameter.

The generalized synchronization (GS) regime can be observed for two identical systems, with equal or mismatched parameters, and unidirectional coupling. In this particular case, the systems are identical, so the dimensions of drive and response oscillators are equal. The system is described as follows:

$$
\begin{aligned}
& \dot{x}_{d}=H\left(x_{d}, g_{d}\right) \\
& \dot{x}_{r}=G\left(x_{r}, g_{r}\right)+\varepsilon A\left(x_{d}-x_{r}\right)
\end{aligned}
$$

Where $A=\left\{\delta_{i j}\right\}$ is the coupling matrix, and $\delta_{\mathrm{ii}} \neq 0$ or 1 , and $\delta_{i j}=0$, if $i \neq j$. The dynamics of the response system may be considered as the no autonomous dynamics of a modified system [7]:

$$
\dot{x}_{m}=H^{\prime}\left(x_{m}, g_{r}, \mathcal{E}\right)
$$

Under the external force $\varepsilon A x_{d}$ :

$$
\dot{x}_{m}=H^{\prime}\left(x_{m}, g_{r}, \varepsilon\right)+\varepsilon A x_{d}
$$

Where $H^{\prime}(x, g)=H(x, g)-\varepsilon A x_{d}$. The term $-\varepsilon A x_{d}$ brings the dissipation into the modified system.

The regime of complete synchronization is a particular case of generalized synchronization [7].

In this paper, it was investigated synchronization between two identical particle-in-a-box circuits, exhibiting a rich chaotic behavior. Although the great interest in chaotic systems, just a few works in the literature show also experimental realization of these systems [1]. The great advantage of this work is to obtain synchronism with robust coupling by using simple electronic circuits $[8,9]$, in a closed loop scheme. In Section 2 we present the purpose of this work. In Section 3, the particle-in-a box mechanical system is described, as well as the master-slave configuration proposed by using two particle-in-a-box identical circuits, and experimental methods employed. In Section 4, and experimental results are shown. Section 5 discusses results, and conclusions are given on Section 6.

\section{Methods}

The electronic circuit proposed emulates a particle-in-a-box mechanical system, described as follows, on figure 1 .

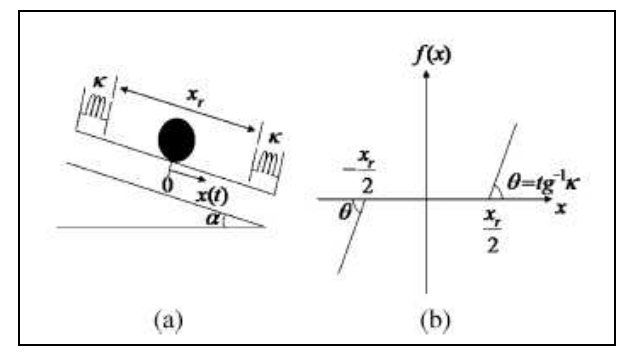

Figure 1-(a) Particle inside an oscilate box. (b)Force applied by the springs. In this system, a particle with mass $m$ can collide with the box walls in $x$-direction. The walls are supported by linear springs with coefficient $k$.

In this system, a particle with mass $m$ can collide the box walls in the $x$-direction. The term $x_{r}$ is the distance between the walls. The walls are supported by linear springs with coefficient $k$, and the collisions between the particle and the walls are totally inelastic. The walls and springs have no mass and dimension. The contribution of the forces acting in the particle of Fig. 1(a) results in the equation: 


$$
m \frac{d^{2} x}{d t^{2}}+\mu \frac{d x}{d t}+f(x)=m g \sin \alpha
$$

Where $\mu$ represents the viscous coefficient and $f(x)$ is the force applied by the springs. The angle $\theta$ represents the term $t^{-1} k$ and the term $m g \sin \alpha$ describes the external force acting on the particle due the gravitational acceleration $g$.

The particle-in-a-box circuit is described on figure 2. This circuit simulates the mechanical behavior of the system of the figure 1(a).

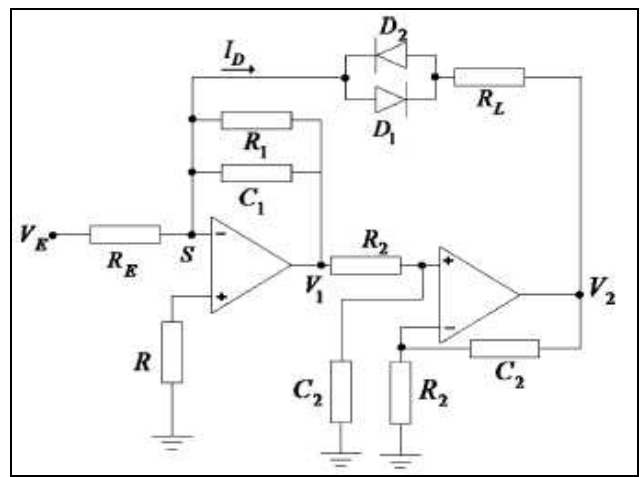

Figure 2 - Particle-in-a-box circuit. The component values are: resistors $\left(k \Omega ; R_{1}=47 ; R=R_{E}=R_{2}=10 ; R_{L}=0.51\right)$, capacitors $\left(n F ; C_{1}=C_{2}=12\right)$, diodes $D_{1}=D_{2}: 2 N 4148$, operational amplifiers 741 or equivalents.

The particle-in-a-box electronic circuit has a sinusoidal input $V_{E}=V_{\max } \sin (\omega t)$, and the contribution of the currents in the point $S$, shown in figure 2 , results in the differential equation:

$$
R_{2} C_{1} C_{2} \frac{d^{2} V_{2}}{d t^{2}}+\frac{R_{2} C_{2}}{C_{1}} \frac{d V_{2}}{d t}+I_{D}\left(V_{2}\right)=-\frac{V_{E}}{R_{E}}
$$

In equation (10), the sign $V_{2}$ is the position $x$, and the signal is the velocity $\frac{d x}{d t}$.

The key devices of this circuit are the anti-parallel diodes $D_{1}$ e $D_{2}$ in association with the resistor $R_{L}$. They emulate the nonlinearity of this circuit, as shown on figure 3.

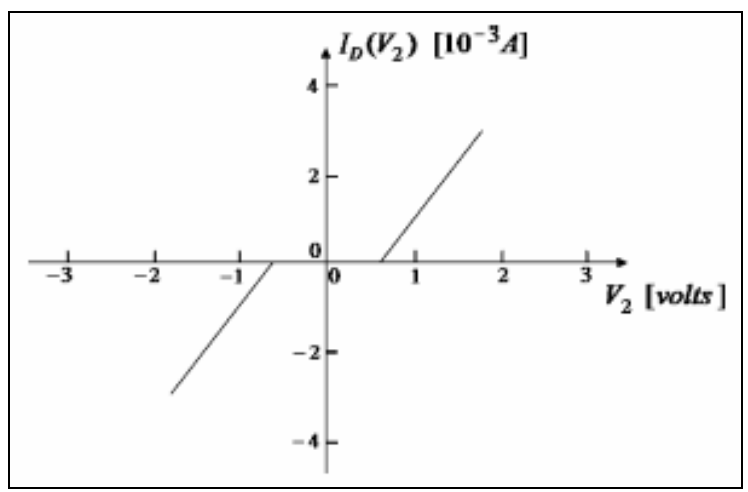

Figure 3- Current versus voltage for anti-parallel diodes $\mathrm{D}_{1}$ and $\mathrm{D}_{2}$. They emulate the collisions of the particle with the walls.

A master-slave configuration was proposed by using two identical systems as shown on figure 4, in a closed-loop scheme, by using $R_{R E}=470 \Omega$. 


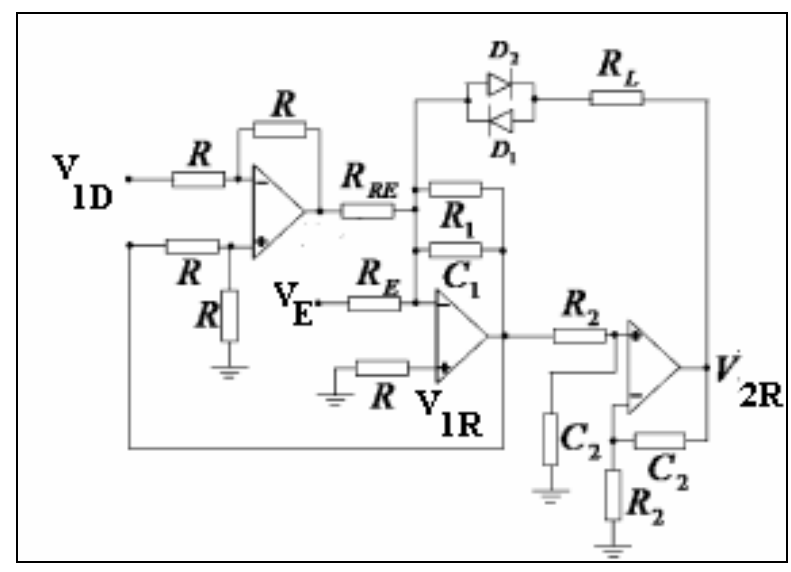

Figure 4-The circuits were applied to closed-loop scheme. The chaotic output signals $V_{2}$ obtained from the drive and response systems were taken from a digital oscilloscope and then analyzed.

A master-slave configuration was implemented by using two identical systems as shown on figure 5 , in which a closed-loop scheme was applied, as described on figure 4. Measurements were taken by using a digital oscilloscope Minipa MO 2061, two function generators Minipa MGF 4201A 2MHz, a digital electronic font Minipa MPL 3303, and data were transferred to a personal computer, as shown on figure 6.

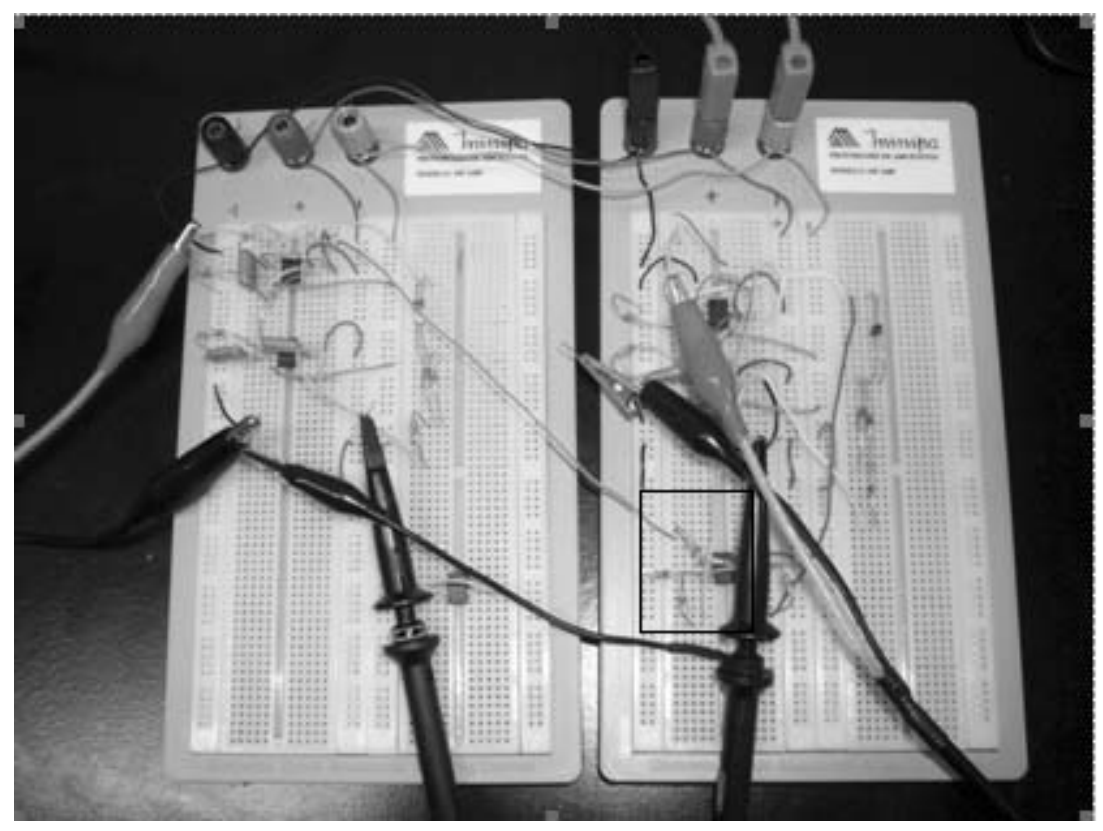

Figure 5 - Experimental realization of the proposed dynamical system. Master (left) and slave (right) particle-in-a-box electronic circuits. Detail shows the closed-loop scheme, $R_{R E}=470 \Omega$. 


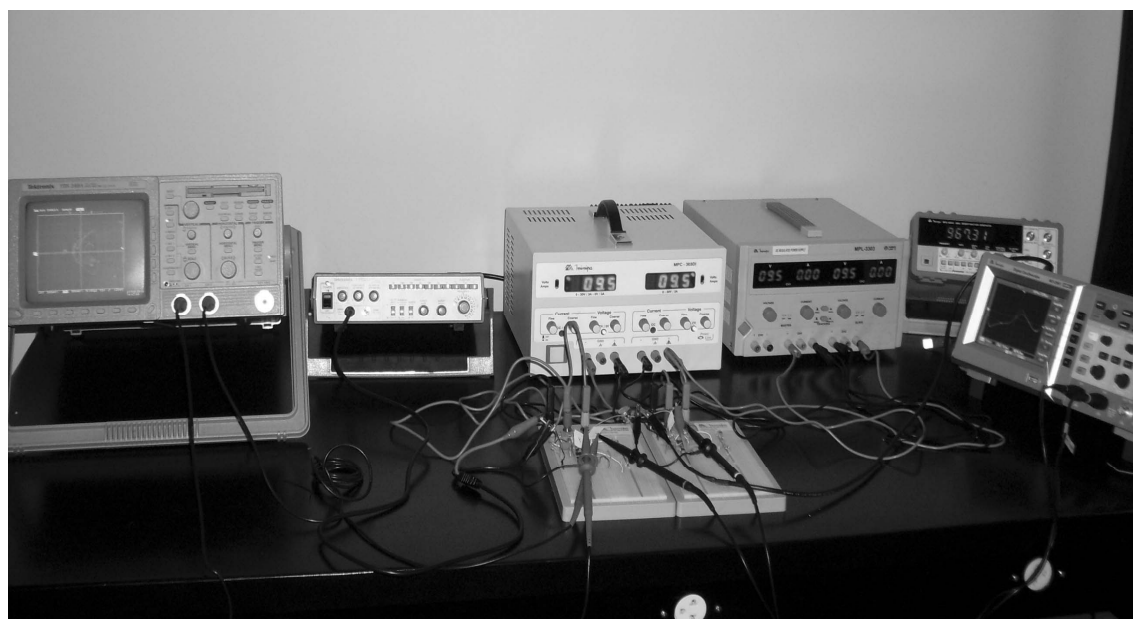

Figure 6 - Measurement of dynamical system.

\section{Results}

\subsection{Numerical simulations results}

Simulated results of synchronization between chaotic drive and response subsystems using the same parameters of experimental conditions are shown in this section.

Figure 7 exhibits the phase diagram of the particle-in-a-box circuit ( $V_{1 d}$ and $V_{2 d}$ ), in a frequency of $f=1096 \mathrm{~Hz}$.

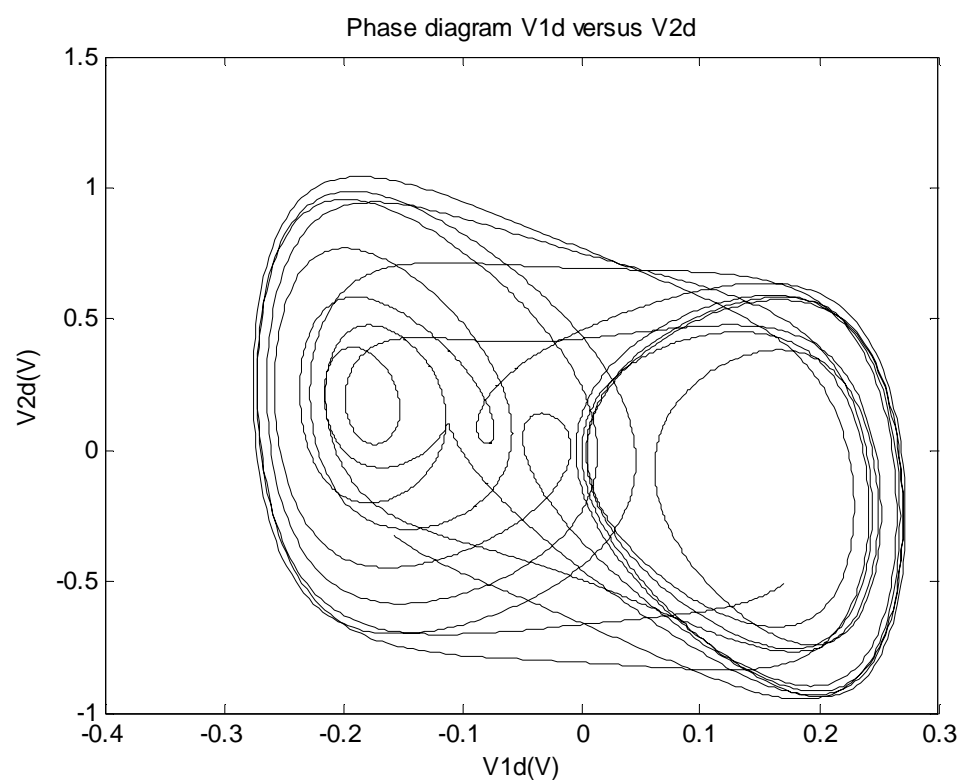

Figure 7- Numerical simulation of phase diagram of the particle-in-abox circuit $\left(V_{l d}\right.$ and $V_{2 d}$ ), by using a frequency $f=1096 \mathrm{~Hz}$. As shown, chaotic behaviour s is exhibited.

Figure 8 exhibits the results obtained from the numerical simulation of the complete synchronization regime between output signals of drive and response subsystems. 


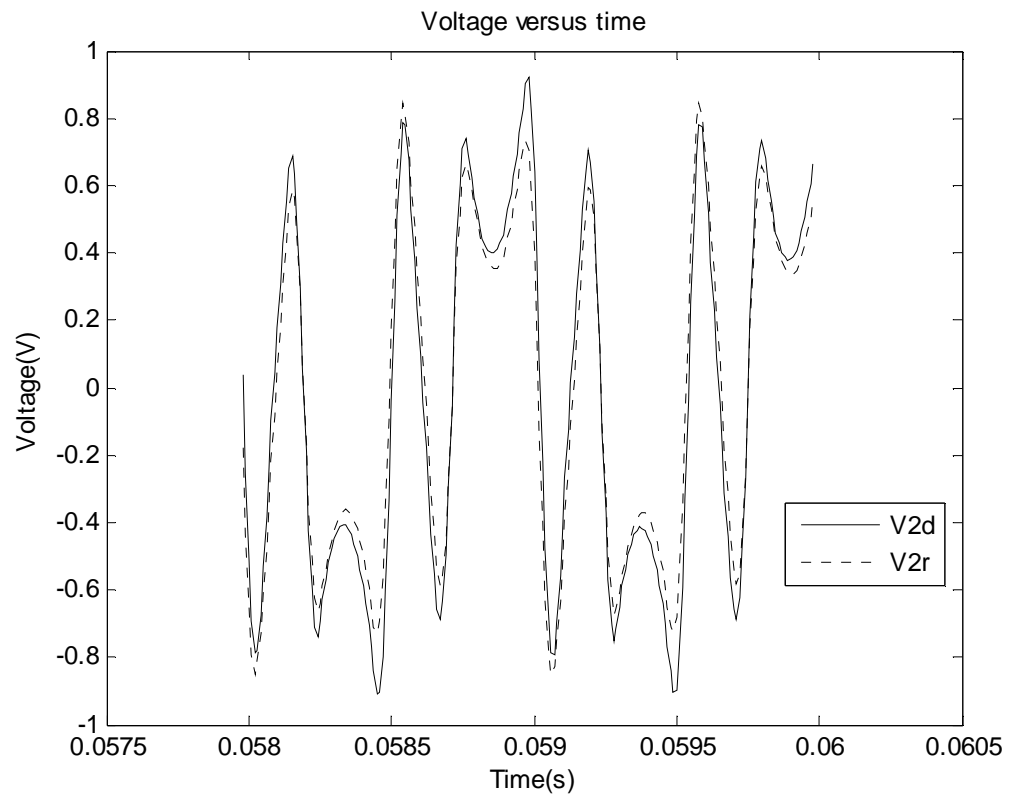

Figure 8- Numerical simulation of synchronism between output signals of drive $\left(V_{2 d}\right)$ and response $\left(V_{2 r}\right)$ subsystems. As shown, complete synchronization is exhibited.

\subsection{Experimental results}

Experimental results of measurements taken from a particle-in-a-box circuit are shown on this section. The periodic chaotic behavior can be obtained by the variation of the parameter of bifurcation of the circuit shown on figure 2, which controls the circuit. The variation of the parameter frequency of the input sinusoidal signal $V_{E}=V_{\max } \sin (\omega t)$ can be used as the bifurcation parameter. Phase diagrams are shown on figure 9.

At first, the master-slave configuration of the proposed system was obtained by using two identical particle-in-a-box circuits. The circuits were applied to closed-loop scheme, by using $R_{R E}=470 \Omega$. The output signals $V_{2}$ obtained from master and slave circuits were taken from a digital oscilloscope and then analyzed. It was observed complete synchronism between drive and response signals, as shown on figure 10. 


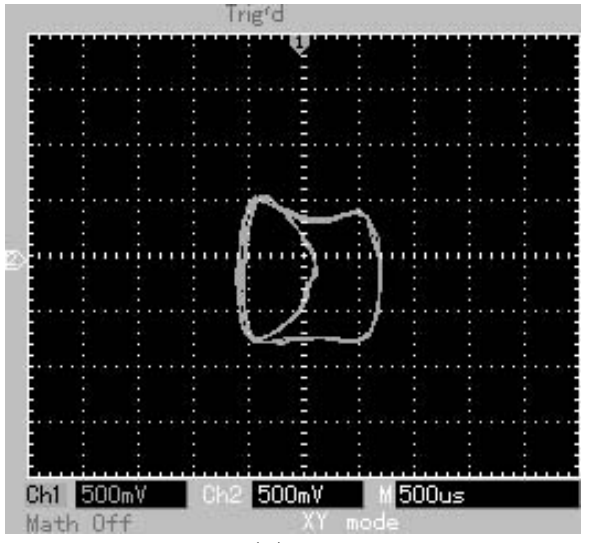

(a)

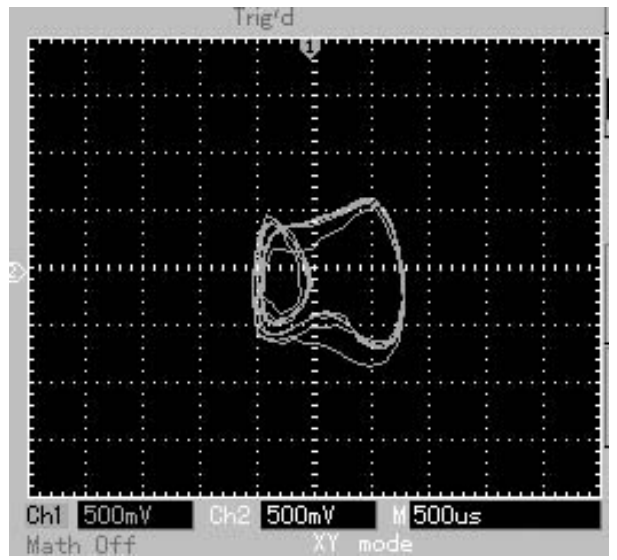

(c)

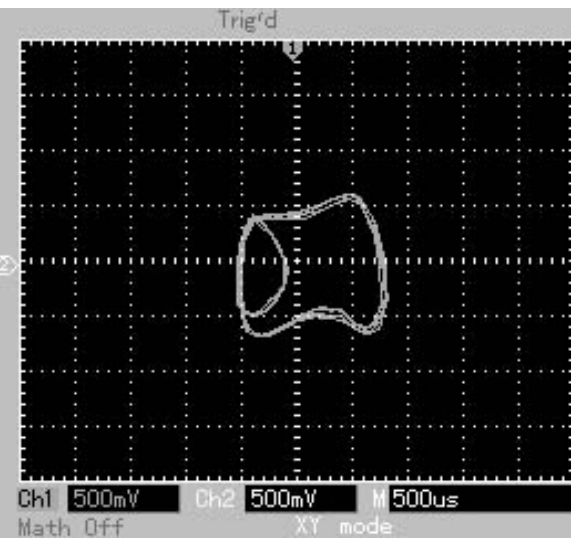

(b)

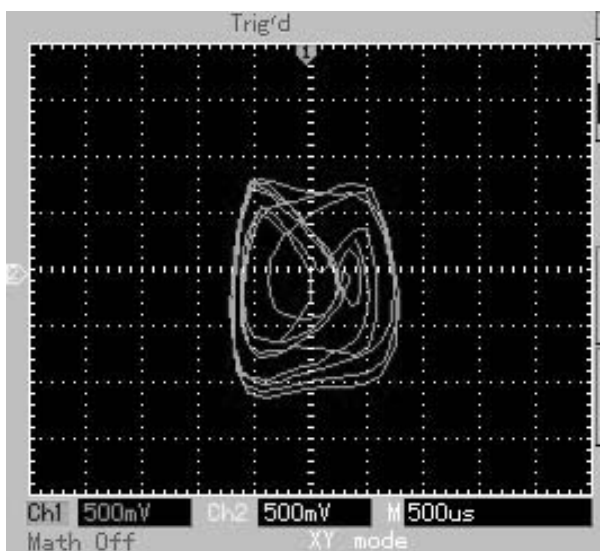

(d)

Figure 9- Phase diagrams of the particle-in-a-box circuit for the fixed amplitude $2 \mathrm{~V}$, and variable frequency as bifurcation parameter: (a) Period 1-f $=958 \mathrm{~Hz} ;(\mathrm{b})$ Period $2-f=963 \mathrm{~Hz}$;(c) $f=965 \mathrm{~Hz}$;(d) Chaos $f=1096 \mathrm{~Hz}$.

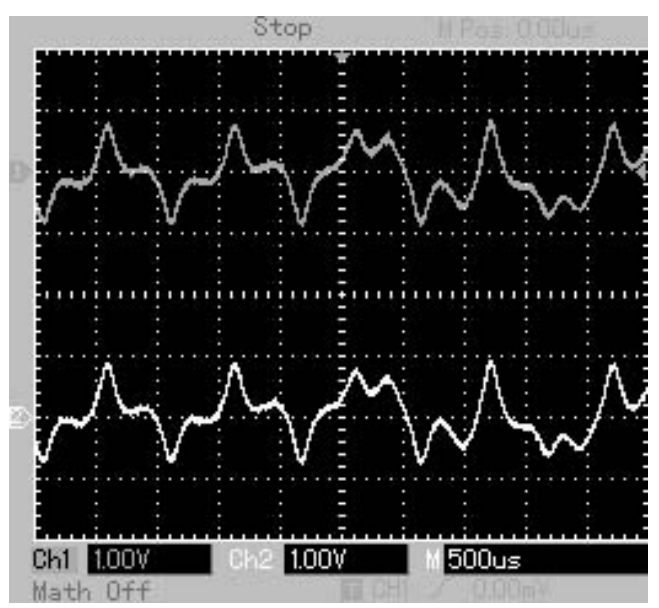

(a)

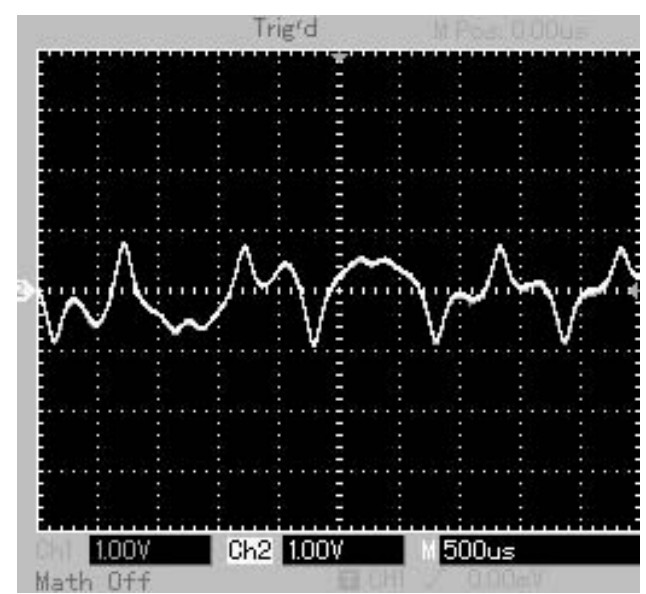

(b)

Figure 10- (a) Output signals of drive and response subsystems. (b)Complete synchronism exhibited between output signals of drive and response subsystems. 
Complete synchronism can be also observed analyzing the phase diagram obtained from output signals of drive and response subsystems in a closed-loop scheme, by using $R_{R E}=470 \Omega$. Results are shown on figure 11. Phase diagram exhibits the relation $x_{d}=x_{r}$, which means that complete synchronism was achieved.

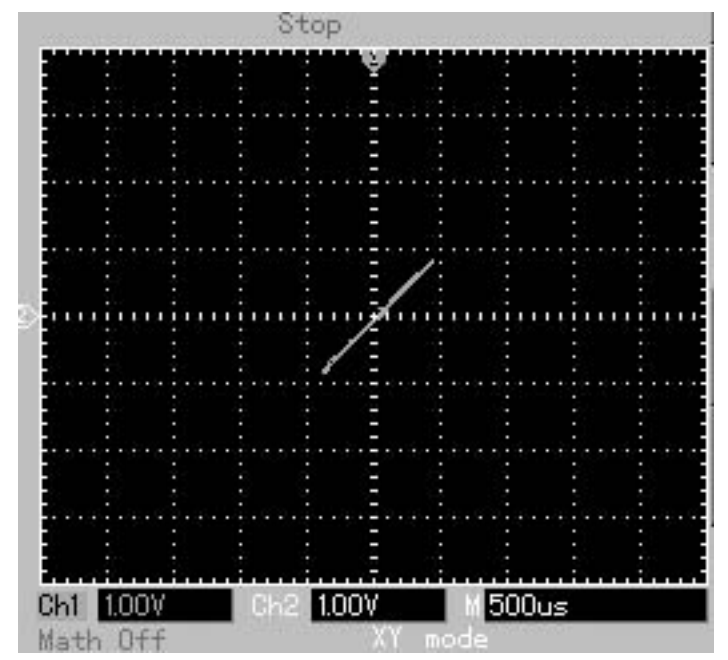

Figure 11- Phase diagram synchronism obtained from output signals of drive and response subsystems, $R_{R E}=470 \Omega$. Complete synchronism was observed, according to relation $x_{d}=x_{r}$.

Finally, a configuration with a master and two slave particle-in-a-box circuits was proposed to verify robustness of the coupling. The circuits were applied to closed-loop scheme, by using $R_{R E}=470 \Omega$. The output signals $V_{2}$ obtained from master and slaves circuits were taken from a digital oscilloscope and then analyzed. It was observed complete synchronism between drive and response signals, as shown on figure 12.

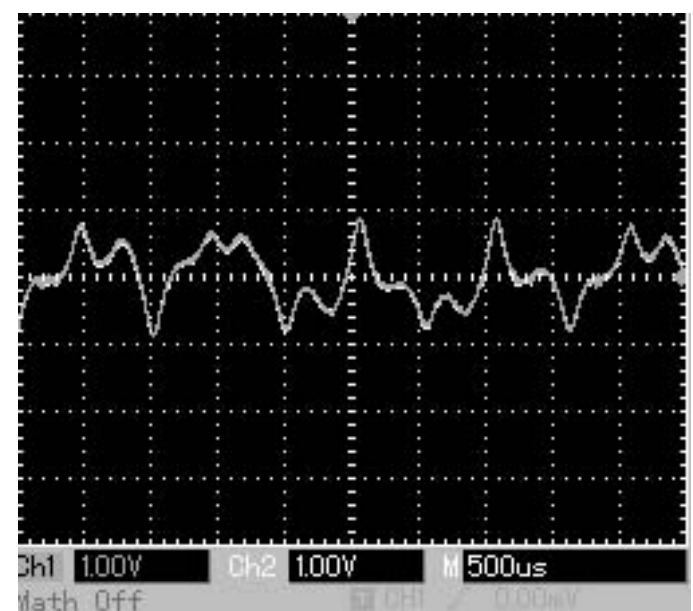

(a)

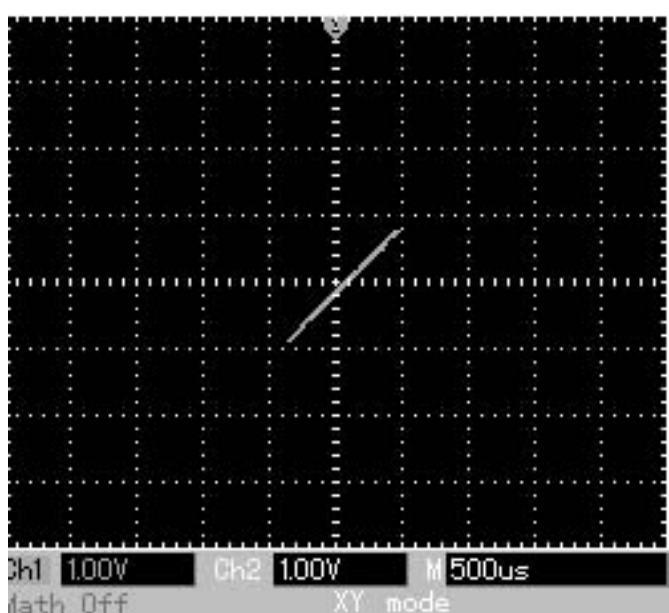

(b)

Figure 12-(a) Output signals of slaves subsystems (b) Phase diagram synchronism obtained from output signals of slaves subsystems. As shown, complete synchronism between slaves subsystems was achieved. Phase diagram shows mathematical relation $x_{d}=x_{r}$. 


\section{Discussion}

Figure 7 shows the phase diagram for an only particle-in-a-box circuit emulated according to equation (10), for the fixed amplitude $2 \mathrm{~V}$, and frequency $f=1096 \mathrm{~Hz}$. Figure 8 exhibits the results obtained from the numerical simulation of the complete synchronization regime between output signals of drive and response subsystems.

Phase diagrams of the particle-in-a-box circuit for the fixed amplitude $2 \mathrm{~V}$, by using variable frequency as bifurcation parameter, are shown on figure 9: (a) Period 1- $f=958 \mathrm{~Hz}$; (b) Period 2$f=963 \mathrm{~Hz}$; (c) Period 4- $f=965 \mathrm{~Hz}$; and (d) Chaos- $f=1096 \mathrm{~Hz}$.

Two identical particle-in-a-box circuits were connected by using a closed-loop scheme, where $R_{R E}=470 \Omega$. They exhibit a complete synchronization regime. Figure 10 shows output signals of drive and response subsystems. Phase diagram obtained from output signals of drive and response subsystems is shown on figure 11. Both results are in agreement to mathematical relation $x_{d}=x_{r}$.

At last, a configuration with a master and two slave particle-in-a-box circuits, to verify robustness of the coupling. The circuits were applied to closed-loop scheme, by using $R_{R E}=470 \Omega$. The output signals $V_{2}$ obtained from master and slaves circuits were taken from a digital oscilloscope and then analyzed. As shown on figure 12, complete synchronism between both slaves subsystems was achieved. Phase diagram shows mathematical relation $x_{d}=x_{r}$. Experimental results showed good agreement with the simulation results.

\section{Conclusion}

Just a few works in literature describe experimental measurements of chaotic systems, and most employ complex electronic circuits. The master/slave electronic circuits employed in this work have a very simple electronic implementation.

Numerical results show agreement with experimental results, and show the robustness of the coupling in this system. Analyzing preliminary results, it may be concluded that the proposed system emulates the chaotic behavior of a particle-in-a-box circuit, and results show complete synchronization of the system. Due to robustness of the coupling between these systems, we intend to apply this system in chaotic secure communication. Results suggest the system could be employed in chaotic mask successfully.

\section{References}

[1] Grosu I, Padmanaban E, Roy P K and Dana S K 2008 Phys.Rev. Lett., 100, 23, 234102-1-4.

[2] Reagy J F, Carroll T L, Pecora L M 1994 Phys Rev. Lett. A , 73, 2, 3528-31

[3] Hu Z, Chen X 2006, Dyn. Cont.Disc.Impuls. Syst.-Series A-Math. Anal. 13, 489-499

[4] Cuomo K M , Oppenheim A V, Strogats S H 1993, IEEE Trans.Circ. and Syst. II, Analog. Dig. Sig. Proc., 40, 10, 626-633

[5] Pecora L M, Carroll T L 1989 Phys.Rev.Let. 64, 10, 821-824.

[6] Pikovsky A S 1983 Zeitsch. für Phys. B Cond. Mat., 55, 2, 149-154.

[7] Hramov A E , Koronovskii A A 2005. Phys.Rev.E, 71, 067201-04 


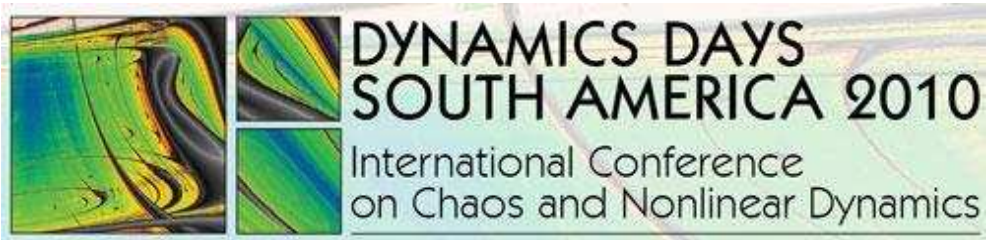

INPE - National Institute for Space Research

São José dos Campos - SP - Brazil - July 26-30, 2010

\title{
Electrical implementation of a complete synchronization dynamic system
}

\author{
Cristhiane Gonçalves 1, Luiz Gonçalves Neto 2
}

\begin{abstract}
1University of São Paulo, São Carlos, Brazil, cristhiane.goncalves@usp.br
\end{abstract}
2 University of São Paulo, São Carlos, Brazil, lgneto@sc.usp.br

\begin{abstract}
This work presents an electrical implementation of a complete synchronization system, proposing a master/slave synchronization of two identical particle-in-a-box electronic circuits, exhibiting a rich chaotic behavior. This behavior was experimentally observed, and also emulated. Just a few works in literature describe experimental measurements of chaotic systems.
\end{abstract}

keywords: Synchronization, chaotic circuit, particle-in-abox circuit, phase synchronization.

\section{INTRODUCTION}

Synchronization between dynamical systems are being extensively explored in electronic circuits $[1,2]$.

There are many types of circuits with potential applications to generate chaotic signals, like Chua's circuit [3], Lorenz-based chaotic circuit [4] and PecoraCarroll synchronization and error-feedback synchronization [5].

Complete or full synchronization occurs when there is coincidence of states of two interacting subsystems, as:

$$
x_{d}(t)=x_{r}(t)
$$

Although the great interest in chaotic systems, just a few works in the literature show also experimental realization of these systems [1]. The great advantage of this work is to employ simple chaotic and identical systems, exhibiting a rich chaotic behavior.

\section{PURPOSE}

The aim of this work is to realize a electrical implementation of a synchronization dynamic system, by using two identical dynamic subsystems, using a driveresponse scheme proposed by Pecora-Carroll [5], analyzing its behavior, and comparing the experimental results with data simulation.

\section{METHODS}

The electronic circuit proposed emulates a particlein-a-box mechanical system, described in [6].

The particle-in-a-box circuit is described on Figure 1(a). The key devices of this circuit are the anti-parallel diodes $D_{1}$ e $D_{2}$. They emulate the nonlinearity of this circuit The curve of current versus voltage of the antiparallel diodes $D_{1}$ and $D_{2}$ is shown on Figure 1(b).

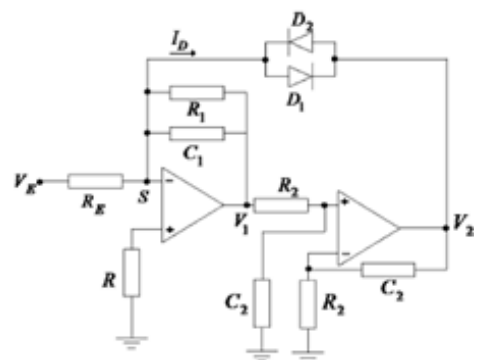

(a)

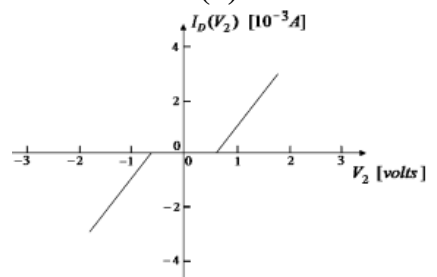

(b)

Figure 1 (a)- Particle-in-a-box circuit. The component values are: resistors $\left(k \Omega ; R_{1}=47 ; R=R_{E}=R_{2}=10\right)$,

capacitors $\left(n F ; C_{1}=C_{2}=12\right)$, diodes $D_{1}=D_{2}: 2 N 4148$, operational amplifiers 741 or equivalents; (b) current versus voltage curve of the anti-parallel diodes $D_{1}$ and $D_{2}$.

The particle-in-a-box electronic circuit has a sinusoidal input $V_{E}=V_{\max } \sin (\omega t)$, and the contribution of the currents in the point $S$, shown in Figure 1, results in the differential equation:

$$
R_{2} C_{1} C_{2} \frac{d^{2} V_{2}}{d t^{2}}+\frac{R_{2} C_{2}}{C_{1}} \frac{d V_{2}}{d t}+I_{D}\left(V_{2}\right)=-\frac{V_{E}}{R_{E}}
$$

The key devices of this circuit are the anti-parallel diodes $D_{1}$ and $D_{2}$. A master-slave configuration was proposed by using two identical systems according to the open-loop error feedback technique described in [5].

\section{RESULTS}

Experimental results of measurements taken from a particle-in-a-box circuit are shown. The periodic chaotic behavior can be obtained by the variation of the parameter frequency of the sinusoidal signal 
$V_{E}=V_{\max } \sin (\omega t)$. Phase diagrams are shown on Figure 2.

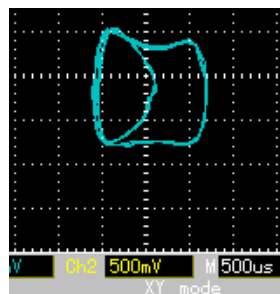

(a)

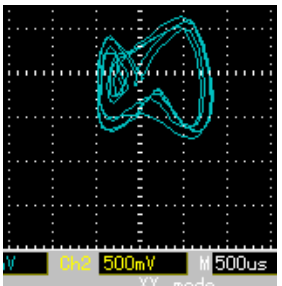

(c)

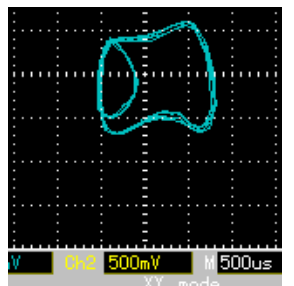

(b)

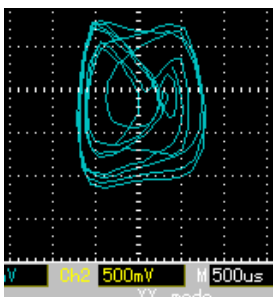

(d)
Figure 2-Phase diagrams of the particle-in-a-box circuit for the fixed amplitude $2 \mathrm{~V}$, and variable frequency as bifurcation parameter: (a)Period 1- $f=958 \mathrm{~Hz}$;

(b) Period 2- $f=963 \mathrm{~Hz}$;(c) Period 4- $f=965 \mathrm{~Hz}$;(d) Chaos- $f=1096 \mathrm{~Hz}$, scale: $500 \mathrm{mV} /$ div, time scale:500 $\mu \mathrm{s}$.

The chaotic output signals $V_{2}$ were taken from a digital oscilloscope and then analyzed. It was observed complete synchronism analyzing data between output signals of drive and response subsystems as shown on Figure 3.

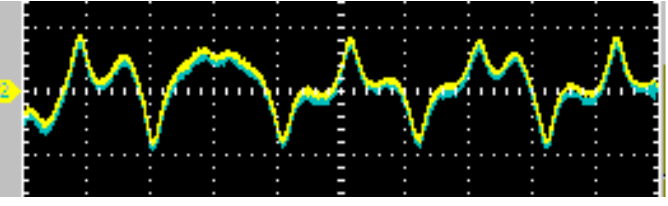

Figure 3- Complete synchronism exhibited between output signals of drive and response subsystems. scale: $1 \mathrm{~V} / \mathrm{div}$, time scale: $500 \mu \mathrm{s}$.

As shown on Figure 4, the phase diagram of output signals exhibits a identity, as described by equation (1).

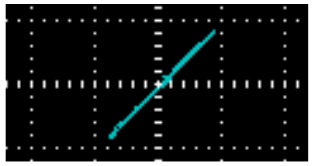

Figure 4- Phase diagram exhibited between output signals of drive and response subsystems; scale: $1 \mathrm{~V} / \mathrm{div}$, time scale:500 $\mathrm{s}$

Simulated results of synchronization between chaotic drive and response subsystems using similar parameters of experimental conditions are shown in this section. Figure 5 exhibits the results obtained from numerical simulation of the complete synchronization regime between output signals of drive and response subsystems.

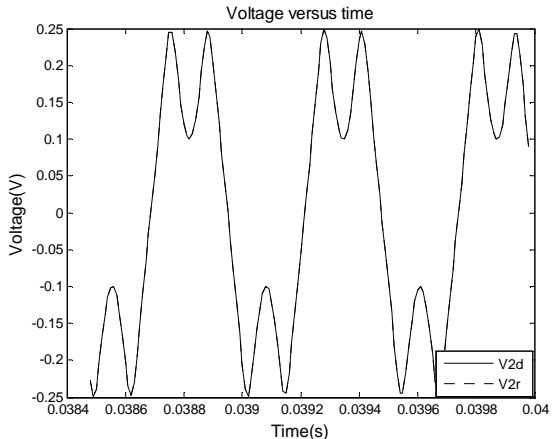

Figure 5- Numerical simulation of synchronism between output signals of drive and response subsystems.

\section{DISCUSSION}

Experimental results demonstrate the chaotic behavior of the system in complete synchronization regime. Figure 2 shows phase diagrams of the particle-ina-box circuit for the fixed amplitude $2 \mathrm{~V}$, and variable frequency as bifurcation parameter. Figures 3 and 4 show complete synchronism regime exhibited by the system. Numerical results are in agreement with experimental results, as shown on Figure 5.

\section{CONCLUSION}

It may be concluded that numerical simulation results show agreement with experimental results. As shown, complete synchronization regime is observed.

\section{ACKNOWLEDGMENTS}

The authors thank to Department of Electrical Engineering of University of São Paulo, for the support.

\section{REFERENCES}

[1] I. Grosu, E. Padmanaban, P.K. Roy, S.K. Dana, "Designin Coupling for Synchronization and Amplification of Chaos" Physical Review Letters Vol. 100, No. 23, pp. 234102-1-234102-4, June 2008.

[2] J.F. Reagy, T.L. Carroll, L.M. Pecora "Experimental and Numerical Evidence for Riddled Basins in Coupled Chaotic Systems" Physical Review Letters A, Vol. 73, No. 2,pp 3528-3531, August 1994.

[3] Z. Hu, X. Chen, "Synchronization of chaotic cryptosystems based on Chua's circuits with key functions ", Vol. 13, pp 489-499, October 2006.

[4] K.M. Cuomo, A.V. Oppenheim, S.H. Strogats, "Synchronization of Lorenz-based chaotic circuits with applications to communications", IEEE Transactions Circuits and Systems II, Analog. Digit. Signal Process. Vol. 40, No 10, pp 626-633, October 1993.

[5] L.M. Pecora, T.L. Carroll, "Synchronization in chaotic systems ", Physical Review Letters, Vol. 64, No 10, pp 821-824, December 1989.

[6] J.C.Pizolato Jr, M.A. Romero, L. G. Neto, "Chaotic Communication Based on the Particle-in-a-Box Electronic Circuit", IEE Transactions on Circuits and Systems I, Vol. 55, No 4, pp 1108-1115, May 2008. 